University of Redlands

\title{
Annual Brome (Bromus tectorum) Wildfire Fuel Breaks: Web-enabled GIS Wildfire Model Decision Support System
}

A Major Individual Project submitted in partial satisfaction of the requirements for the degree of Master of Science in Geographic Information Systems

by

Charles E. Armstrong, Jr.

Mark Kumler, Ph.D., Chair

Jennifer Vollmer, Ph.D.

August 2007 
Annual Brome (Bromus tectorum) Wildfire Fuel Breaks:

Web-enabled GIS Wildfire Model Decision Support System

Copyright (C) 2007

by

Charles E. Armstrong, Jr. 
The report of Charles E. Armstrong, Jr. is approved.

Jennifer Vollmer, Ph.D.

Mark Kumler, Ph.D., Chair

August 2007 



\section{ACKNOWLEDGEMENTS}

I would like to acknowledge and thank the faculty and staff at the University of Redlands, the staff at the Redlands Institute, and the instructors and staff at ESRI for their assistance. I would especially like to thank Mark Kumler for his valuable feedback on drafts of this document and Bryan Baker for his tireless assistance throughout the project. I would like to acknowledge and thank BASF and Jennifer Vollmer for their support and participation in the project. I would also like to acknowledge and thank Bethany Bradley, of Princeton University, for sharing cheatgrass data and Brian Bastian and Jeff Eidenshink from USDA Forest Service Landfire project for their assistance. I would especially like to thank my wife Beth and my two daughters Emma and Casey for their support and sacrifice that made this project possible. 



\begin{abstract}
Annual Brome (Bromus tectorum) Wildfire Fuel Breaks: Web-enabled GIS Wildfire Model Decision Support System
\end{abstract}

by

Charles E. Armstrong, Jr.

Annual brome (Bromus tectorum), also known as Cheatgrass, is a non-native invasive plant that has degraded rangeland, and wildlife habitat, and has increased the frequency and severity of wildfires in the Western United States. An ArcGIS Server web-enabled GIS decision support system has been developed to empower landowners and land managers to identify critical areas for placing wildfire suppression annual brome fuel break on their land in order to protect their lives and property. The model identifies the critical predictive annual brome habitat and wildfire threat parameters, and uses web services to input the relevant GIS data that represent the model parameters. The GIS analysis is geoprocessed remotely and the potential fire break locations are distributed as a map web service accessible by a web browser with a graphical user interface, on a thinclient computer, along with technical information about the installation of wildfire fuel breaks. 



\section{Table of Contents}

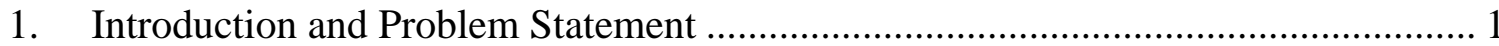

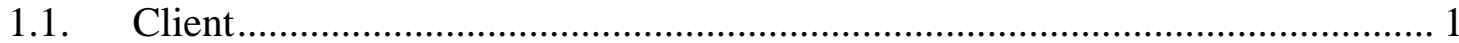

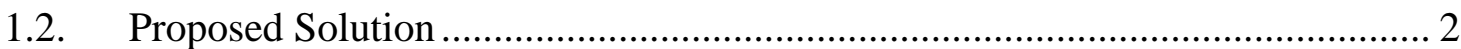

2. Background and Literature Review ................................................................ 3

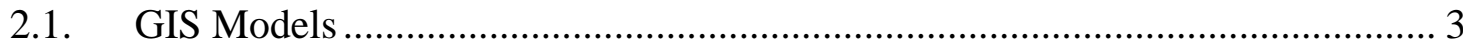

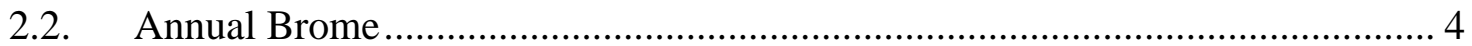

2.2.1. Annual Brome Models and Parameters ..................................................... 4

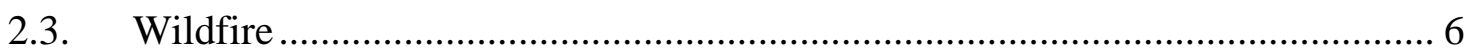

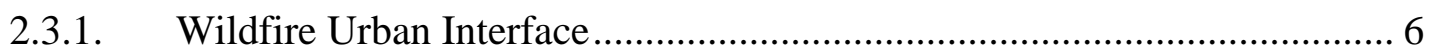

2.3.2. Wildfire Models and Parameters .............................................................. 7

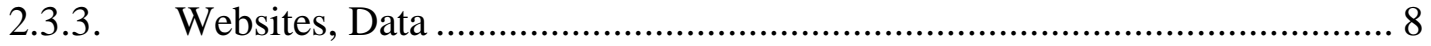

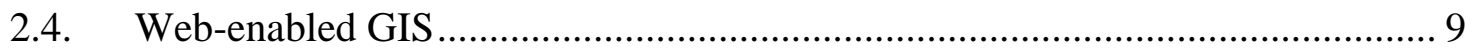

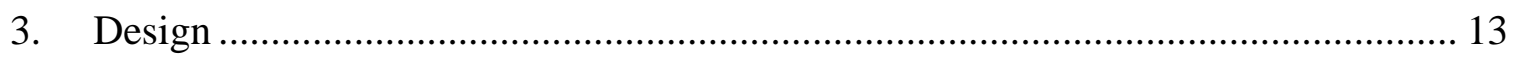

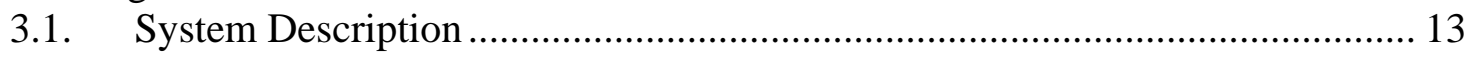

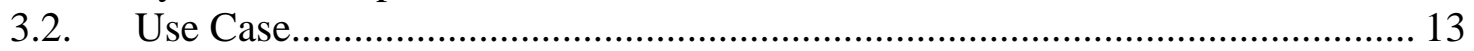

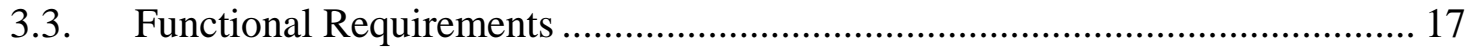

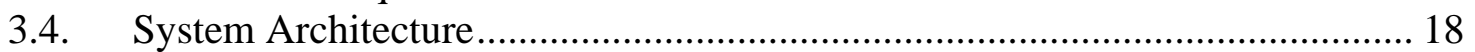

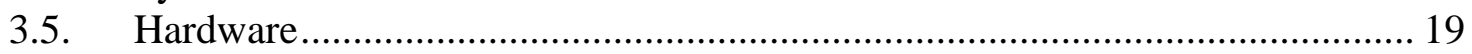

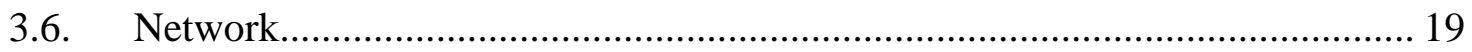

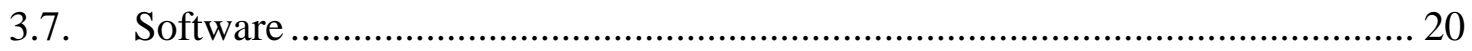

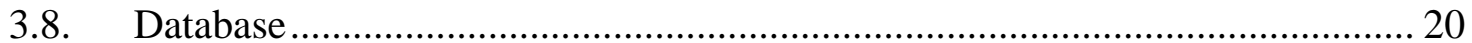

3.8.1. Annual Brome................................................................................ 21

3.8.2. Wildland Urban Interface (per University of Wisconsin SILVIS Lab).... 25

3.8.3. Wildfire (per USDA Forest Service Landfire)...................................... 26

3.8.4. Geographic Coordinate System and Map Projection................................ 28

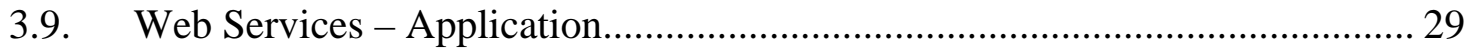

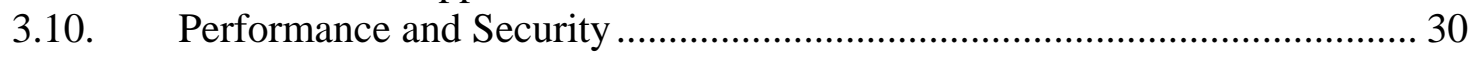

3.11. Web Map Application User Interface ............................................... 31

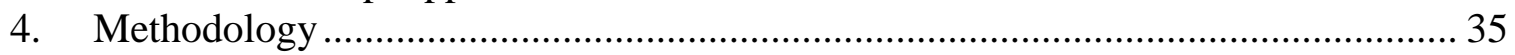

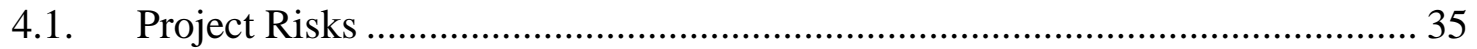

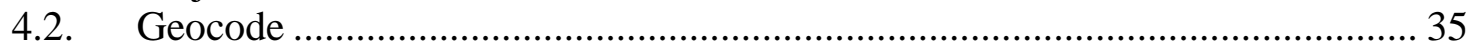

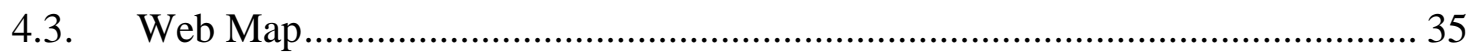

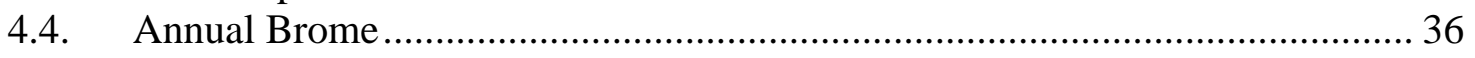

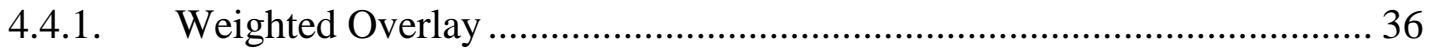

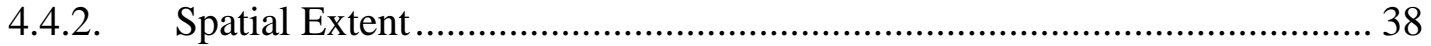

4.4.3. Euclidean Distance and Reclassify ..................................................... 38

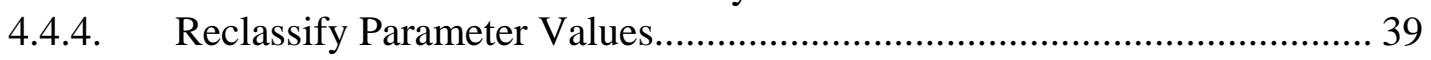

4.4.5. Annual Brome Habitat Model................................................................ 43

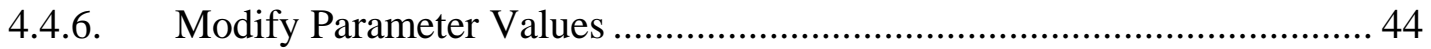

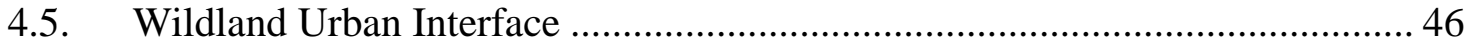

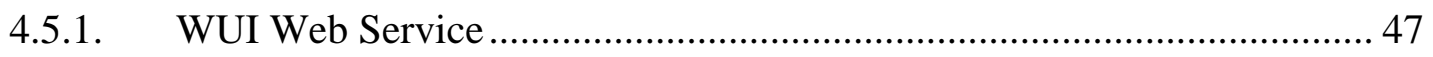

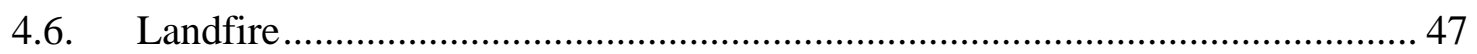

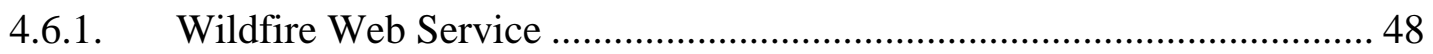

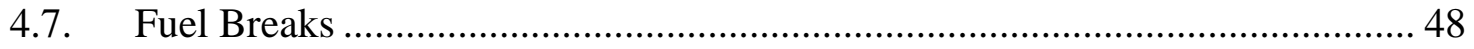




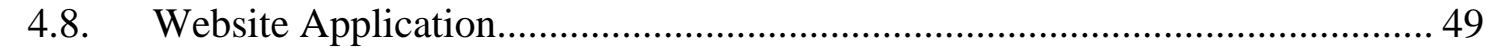

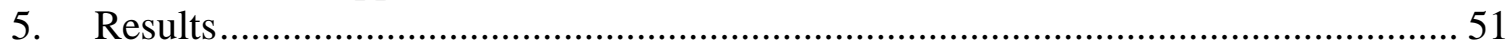

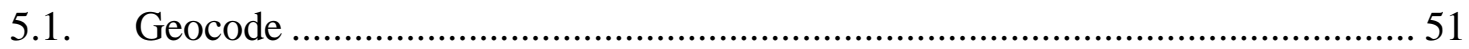

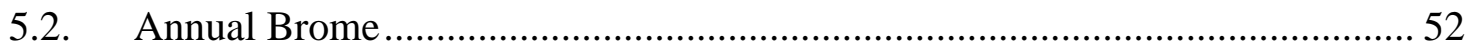

5.3. Wildland Urban Interface …………………............................................... 54

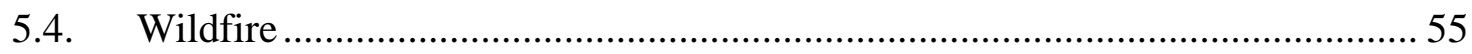

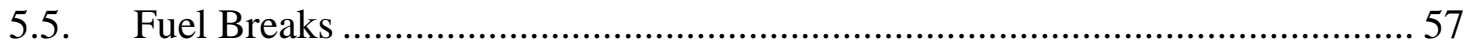

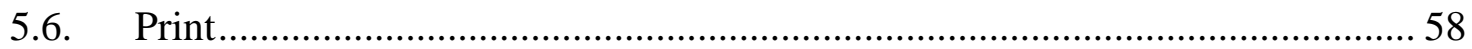

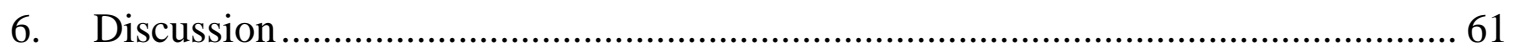

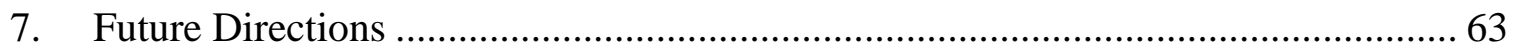

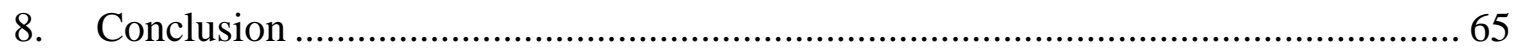

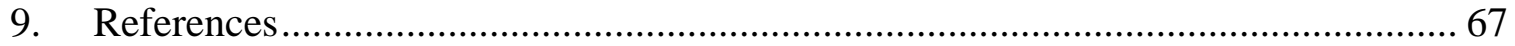

Appendix A: Application Development Framework (ADF) ............................................. 71

\section{Table of Figures}

Figure 2-1. Annual Brome Phenology and Wildfire Threat ............................................... 4

Figure 3-1. System Architecture .............................................................................. 18

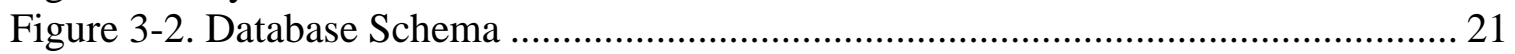

Figure 3-3. Annual Brome Input Parameter Data............................................................ 22

Figure 3-4. Locator Map for the Study Area and the Great Basin..................................... 24

Figure 3-5. The University of Wisconsin SILVIS Lab WUI Web Map............................. 25

Figure 3-6. Landfire 13 Anderson Fire Behavior Fuel Models Web Map ........................ 27

Figure 3-7. Landfire Fire Regime Groups Web Map …………....................................... 28

Figure 3-8. Add External Web Service......................................................................... 30

Figure 3-9. Website User Interface................................................................................. 31

Figure 3-10. Website User Interface Magnifier Window .................................................... 32

Figure 3-11. Website Model Input Layers, Overview ..................................................... 33

Figure 3-12. National Agriculture Imagery Program (NAIP) Map ................................... 34

Figure 4-1. Annual Brome Weighted Overlay Model .......................................................... 37

Figure 4-2. Annual Brome Model Delineate Area of Interest .......................................... 38

Figure 4-3. Euclidean Distance Reclassify Model.......................................................... 38

Figure 4-4. Raster Extract by Attributes ........................................................................ 39

Figure 4-5. Power line Reclassifications ..................................................................... 40

Figure 4-6. Annual Brome Habitat Risk Model................................................................ 43

Figure 4-7. Reclass by Table ........................................................................................ 46

Figure 4-8. Add The SILVIS Lab WUI Web Service .................................................... 47

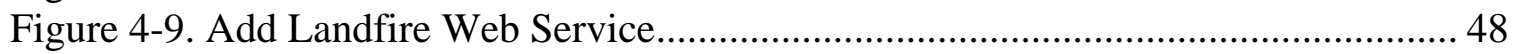

Figure 4-10 Annual Brome Wildfire Fuel Break Model ................................................... 49

Figure 5-1. Geocode Address Website User Interface....................................................... 51

Figure 5-2. Find Place Results.............................................................................. 51

Figure 5-3. Annual Brome Model - Delineate Area of Interest, Input Parameters............ 52

Figure 5-4. Annual Brome Risk Map Classified 1, 9 …………………………….......... 53

Figure 5-5. Annual Brome Risk Map Parameters Classified 1 - 9 ..................................... 53 
Figure 5-6. The University of Wisconsin SILVIS Lab WUI Web Map Results .............. 54

Figure 5-7. Landfire 13 Anderson Fire Behavior Fuel Models Web Service Map .......... 55

Figure 5-8. Landfire Fire Regime Group Web Service Map ........................................ 56

Figure 5-9. Fuel Break Decision Support Maps .......................................................... 57

Figure 5-10. Print Task Website User Interface ....................................................... 58

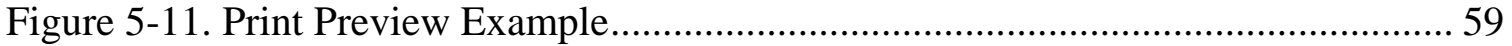

Figure Appendix A-1. Add ArcWeb Geocode Service ................................................ 72

\section{List of Tables}

Table 2-1 Annual Brome Predictive Parameters ............................................................ 5

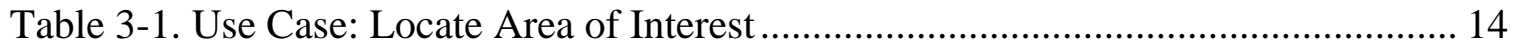

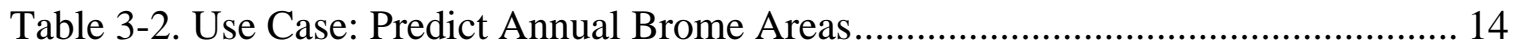

Table 3-3. Use Case: Wildfire Danger Areas ................................................................ 15



Table 3-5. Use Case: Potential Annual Brome Wildfire Fuel Break Areas...................... 16

Table 3-6. Use Case: Wildfire Fuel Break Installation Information Alternatives ............ 16

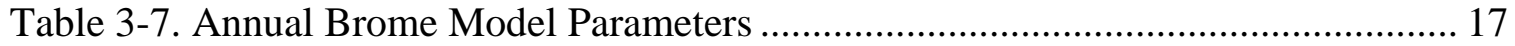

Table 3-8. Annual Brome Input Parameter Metadata...................................................... 23

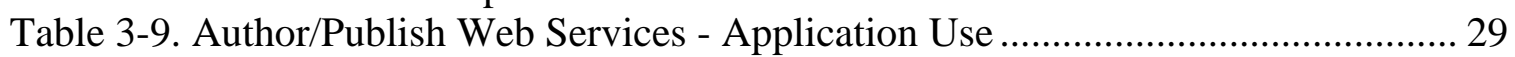

Table 3-10. External Web Service Uniform Resource Locators (URLs) ......................... 30

Table 4-1 Annual Brome Weighted Overlay ................................................................ 37

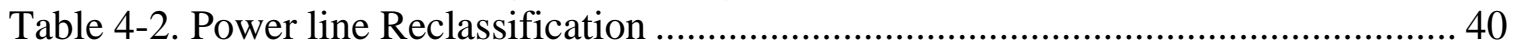

Table 4-3. Cheatgrass Distance Reclassification ....................................................... 40

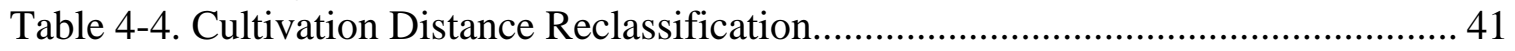

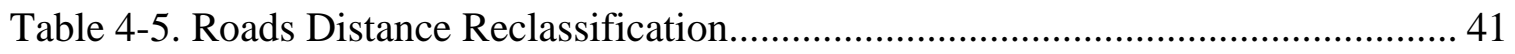

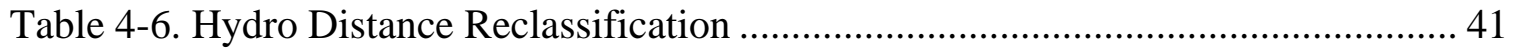

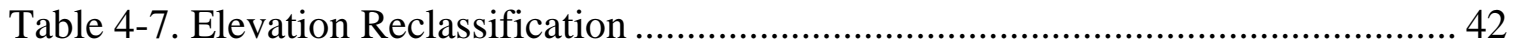

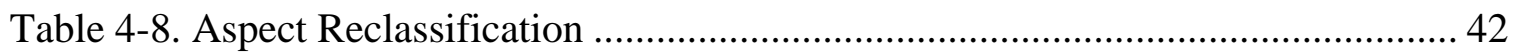

Table 4-9. ArcGIS Server Supported Parameter Data Types ........................................ 45

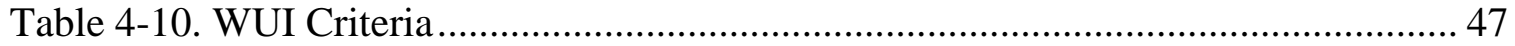

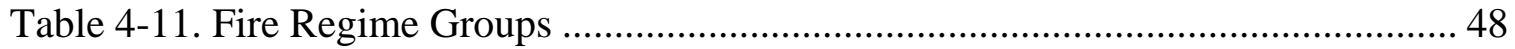

\section{List of Acronyms}

ADF Application Development Framework

AJAX Asynchronous JavaScript and XML

ANSI American National Standards Institute

COTS Commercial Off the Shelf

CPU Central Processing Unit

DEM Digital Elevation Model

EPSG European Petroleum Survey Group 


$\begin{array}{ll}\text { ESRI } & \text { Environmental Systems Research Institute } \\ \text { FARSITE } & \text { Fire Area Simulator } \\ \text { FGDC } & \text { Federal Geographic Data Committee } \\ \text { FEIS } & \text { Fire Effects Information System } \\ \text { FIREMON } & \text { Fire Effects Monitoring and Inventory Protocol } \\ \text { FOFEM } & \text { First Order Fire Effects Model } \\ \text { FRAMES } & \text { Fire Research and Management Exchange System } \\ \text { FRCC } & \text { Fire Regime Condition Class } \\ \text { FSA } & \text { Farm Service Agency } \\ \text { GIS } & \text { Geographic Information System } \\ \text { GML } & \text { Geographic Markup Language } \\ \text { HTTP } & \text { Hypertext Transfer Protocol } \\ \text { HTTPS } & \text { Hypertext Transfer Protocol Secure } \\ \text { IEEE } & \text { Institute Electrical and Electronics Engineers } \\ \text { ISO } & \text { International Standards Organization } \\ \text { NED } & \text { National Elevation Dataset } \\ \text { NDVI } & \text { Normalized Difference Vegetation Index } \\ \text { NFPA } & \text { National Fire Protection Association } \\ \text { LAN } & \text { Local Area Network } \\ \text { LANDFIRE } & \text { Landscape Fire and Resource Management Planning Tools Project } \\ \text { MHz } & \text { Megahertz } \\ \text { NAIP } & \text { National Agriculture Imagery Program } \\ \text { NBII } & \text { National Biological Information Infrastructure } \\ \text { NCLD } & \text { National Land Cover Dataset } \\ \text { NIFTT } & \text { National Interagency Fuels Technology Team } \\ \text { OGC } & \text { Open Geospatial Consortium } \\ \text { REST } & \text { Representational State Transfer } \\ \text { SOAP } & \text { Simple Object Access Protocol } \\ \text { SQL } & \text { Structured Query Language } \\ \text { TCP/IP } & \text { Transmission Control Protocol/Internet Protocol } \\ \text { TIGER } & \text { Topologically Integrated Geographic Encoding and Referencing } \\ \text { UDDI } & \text { Universal Description Discovery and Integration } \\ \text { URL } & \text { Uniform Resource Locator } \\ \text { USDA } & \text { United States Department of Agriculture } \\ \text { USGS } & \text { United States Geological Survey } \\ \text { UTM } & \text { Universal Transverse Mercator } \\ \text { WGS } & \text { World Geodetic System } \\ \text { WISP } & \text { Weed Invasion Susceptibility Prediction } \\ \text { WSDL } & \text { Web Services Description Language } \\ \text { WUI } & \text { Wildland Urban Interface } \\ \text { W3C } & \text { World Wide Web Consortium } \\ \text { XML } & \text { Extensible Markup Language } \\ & \end{array}$




\section{Introduction and Problem Statement}

There is a great need for tools and techniques to help land managers decide how, when, and where to enact fire management prescriptions. A Geographic Information Systems (GIS) is a combination of computers, software, and data that can tie together vast resource information, for example key fire threat indicators such as fuel, moisture, vegetation, disturbance, fire history, elevation, topography, aspect, soils, and weather (wind, temperature, rainfall, drought) along with other factors such as schools, hospitals, transportation, and housing parcels, to spatial locations on the land. This spatial database, or geodatabase, enables systematic data collection, retrieval, manipulation, analysis, and modeling in two, three and four dimensions (over time). The GIS analysis can transparently show where fire threats are located, the nature of the threat, and who could be impacted, and also support decisions about what mitigations to employ and when to utilize them. Many of the factors contributing to fire threats and possible remedies are constantly changing. Access to fire threat analysis information as a service over the web with recent or real time data provides land managers the resources they need to make good decisions.

While forest fires receive most of the attention and are sometimes thought to be synonymous with wildfires, that is not really the case, as shown by recent wildfire numbers. In the 2006 fire season (through September $25^{\text {th }}$ ), nine percent of wildfires were forest only, while sixty-seven percent were non-timber, and the remaining twenty-four percent were a mixture (Wilderness Society, 2006). Wildfire threats due to fine fuels such as grassland and shrub land comprise a significant portion of the total and warrant more attention.

Annual Brome is a non-native invasive plant that has degraded rangeland, and wildlife habitat, and has increased the frequency and severity of wildfires in the Western United States. The annual brome complex includes Bromus tectorum, B. seculinous, B. diandrus, and $B$. rubens which are often referred to as Cheatgrass by layman. They will be referred to collectively as annual brome throughout this project document. The fire threat due to annual brome, as with other fine fuels, has not been adequately addressed. To answer this need responsively, an annual brome web-enabled wildfire fuel break website was created to provide information supporting wildfire fuel break location decisions for fine fuels. The online annual brome suitability map surface is produced by an annual brome geoprocessing model, which incorporates annual brome geodata predictive parameter inputs derived from research. In addition to capitalizing on the new ability within ArcGIS Server 9.2 to geoprocess data in real time over the web, the annual brome model parameters are exposed to the end user for modification to allow for local variability. Wildfire data layers are accessed as external web map services which leverages previous extensive wildfire research. The website GIS application combines locally generated annual brome habitat suitability model output with external web map service wildfire susceptibility information to produce the fuel break location information solution.

\subsection{Client}

The project client is BASF, a multinational corporation headquartered in Ludwigshafen, Germany and the world's largest chemical company. The company has approximately 
94,000 employees, 150 facilities, and sells its products in 170 countries. Operations primarily include chemicals, plastics, performance products, agricultural products, and oil and gas (BASF, 2006). A weed scientist with the BASF Corporation, Jennifer Vollmer, would like a simple, web-enabled decision support tool with which landowners, land managers, land insurers, and others could locate parcels and determine where annual brome fuel breaks are required in order to protect life and property. The decision support wildfire model incorporates a predictive model for annual brome to identify areas for potential firebreaks. The website will include links to alternative prescriptions to create annual brome fuel breaks where appropriate and, as an option, includes the herbicide Plateau manufactured by BASF. To demonstrate the concept for BASF, a prototype of the web-enabled Annual brome decision support tool was built for an area in northern Nevada. In the future, after successful execution of the current project, BASF would like to expand the web-enabled annual brome fuel fire break decision support tool to a wider region.

\subsection{Proposed Solution}

Annual brome is a wildfire threat to life and property in the western United States, which wildfire predictive modeling efforts have not fully addressed. There is a need for an easily accessible, easy-to-use web-enabled GIS tool to help landowners, land managers and others identify their land, determine the threat to their life and property from wildfire due to annual brome and access to information about alternatives to establish fuel breaks. An additional goal will be to join the annual brome wildfire danger analysis with other wildfire models threats for shrub and forest fuel to produce a total threat of wildfire scenario. The project will combine the latest, most advanced GIS, information technology, weed science, and fire science to achieve the desired results.

The delivery of the proposed solution as a service to the end-user through a thin client browser will rely on a sophisticated web server with geoprocessing capacity to deliver the analysis in a timely and efficient manner. Accurate analysis will rely on a well-designed geoprocessing model which incorporates accurate predictive annual brome and fire geospatial sub-models. In turn, the model performance will rely on identifying significant predictive parameters for annual brome fire threat as well as the appropriate spatial data at the appropriate scale and accuracy in a compatible format to represent the parameters. To achieve easily scalable results, input data will be acquired as a web service so that the data can be current, easily acquired, and easily maintained over time.

The project will focus on an area of Nevada where annual brome research results are available to be web-enabled and wildfire data can be accessed as a web map service and combined in a single website. The successful implementation of a solution for this area will serve as a prototype to be expanded throughout the Intermountain West. 


\section{Background and Literature Review}

The background and literature review will include discussion of web-enabled GIS, and natural resources GIS models, including wildfire and annual arome predictive models, as well as relevant fire and weed science domain information. The significant weed and fire science domain predictive variables will supply the parameters for the natural resource GIS model to compute the output of desired fuel break locations. The web-enabled GIS will obtain the GIS data input, perform analysis, and distribute the output to the end user over the Internet through a thin client browser.

Previously for BASF, as part of a Major Individual Project submitted in partial satisfaction of the requirements for the degree of Master of Science in Geographic Information Systems, Heidi Esh created an ArcGIS Spatial Analyst desktop decision support system to locate cheatgrass fuel breaks in the Wildland/Urban Interface (Esh, 2006). BASF desired that the current project build upon the work done by Esh through creation of a web-enabled decision support model based upon a review of the essential weed and fire science. The Esh study site was Big Bear, California, a mixed forest region, while the current project study site is a portion of northern Nevada, which includes mixed forest land, shrub land, and grassland habitat.

\subsection{GIS Models}

GIS models can be thought of as the highest level of geographic representation which can describe the world as well as topological and process interactions between geographic phenomena. Encapsulating the functional logic of geographic relationships can be used to simulate reality to achieve greater analytical understanding of how the world works to solve problems. Geographic representation is by nature an abstraction, a selective generalization, a reduction of reality and a transformation of space, which in turn introduces some uncertainty. Although the advancement of GIS has been driven by the improvement of computer processing power and software innovation to store, represent and manipulate vast amounts of geographic data, it is still subject to the same geographic principles and limitations. Geospatial uncertainty considerations include limitations due geographic generalization, spatial transformation, and data spatial resolution and accuracy. In this project, suitability models for annual brome and wildfire are used to help determine possible locations for fuel breaks. Care must be taken to properly qualify the spatial resolution of the output (Longley, Goodchild, Maguire, \& Rhind, 2005).

GIS analysis is applicable to many fields including urban planning, transportation, and utilities, but it is particularly well suited to environmental modeling. On the horizon, there are many natural resources issues that await, including global warming, loss of biodiversity, invasive organisms, pollution, water quality, forest health, rangelands health, fish and wildlife habitat, the energy crisis, and wildfire management, to name a few. To better understand the complicated, interconnected, changing world we live in, GIS - particularly an extensive web GIS - can capture the voluminous geographic data that represents the world and its relationships in a logical, database information system and can produce supportive tools that can help distinguish the key factors at play and to formulate solutions. 


\subsection{Annual Brome}

Annual Brome (Bromus tectorum), also known as cheatgrass, is a non-native invasive plant that is found in many parts of the United States and is a particularly widespread problem on rangeland in the arid western states (see Figure 2-1).

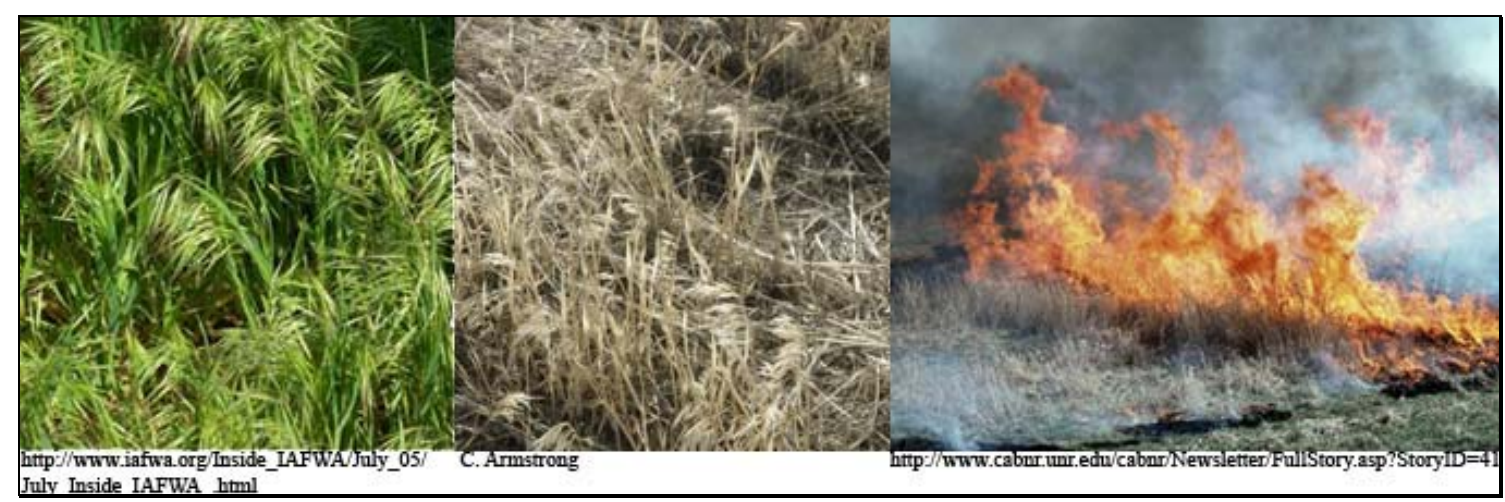

Figure 2-1. Annual Brome Phenology and Wildfire Threat

Introduced accidentally from Europe and Asia over a hundred years ago, it has opportunistically gained a foothold in physically disturbed areas (Neese, 2000). Annual brome is a significant factor in increasing the frequency and severity of wildfires in the western United States and degrading rangelands and wildlife habitat. Annual brome is itself a wildfire threat and also serves as a fuel connection between other sources such as shrub and forest fuels extending a wildfire that may otherwise burn out on its own (USDA Forest Service, 2006b).

In a wet year annual brome can produce significant fuel loads, in measurable tons per acre (Brown, 2006), that ignite very easily (Davison \& Smith, 2005) and can result in a windblown fire that can travel at speeds up to 40 miles per hour (Brown, 2006). It infiltrates open areas between native bunch grasses and creates a dense mat, replacing the native perennials. annual brome is a winter annual and its phenological characteristic to turn green early in the spring gives it a competitive advantage over native vegetation for water. This early senescence creates an earlier and longer fire season. Annual brome also produces large quantities of seed that fall to the ground early in the season where they are protected from fire, which in turn enhances Annual brome's ability to survive and proliferate. Once established, the presence of annual brome can shorten the natural fire cycle from 50 to 60 years down to 3 to 5 years (USDA Forest Service, 2006b).

\subsubsection{Annual Brome Models and Parameters}

One of the most vital aspects of the current project will be to identify the significant predictive parameters for annual brome that will drive the suitability model and to locate and incorporate relevant GIS data to represent those indicators. For cheatgrass parameters, Esh (2006) relied on experts in the field from ESRI, the United States Department of Agriculture Forest Service, and a thesis by Gillham (2001). Gillham had developed an ArcView 3.2 extension known as WISP (Weed Invasion Susceptibility Prediction) to model the presence of five invasive species in Wyoming. He used aspect, elevation, land cover, soil texture, soil $\mathrm{pH}$, slope, precipitation, seed life, and disturbance, but he did not model annual brome (Gillham, 2001). Esh used aspect and elevation, for 
inputs, and she used roads, urban areas, fuel reduction zones, and fire history to represent disturbance, which are likely entry point for invasive plants (Esh, 2006).

In a recent study, Bradley and Mustard (2006) used Landsat remotely sensed data to identify cheatgrass areas in Nevada, and then correlated their occurrence to six landscape variables to develop a risk model. Bradley and Mustard used the early green-up, early senescence growth habit revealed by the Normalized Difference Vegetation Index (NDVI) in remotely sensed data (over a range of years) to identify annual brome, and collected ground data to verify accuracy. They found that the presence of nearby historic cheatgrass, elevation, aspect, hydrographic channels, cultivation, roads, and power lines were indicators in a multi-criteria evaluation for cheatgrass suitability. Elevation range between 1400 and 1700 meters, west and northwest facing slopes, location within hydrographic channels, within 3000 meters of cultivation, within 700 meters of a road, within 1000 meters of a power line, and within 150 meters of historic cheatgrass were predictive. The predictive parameters identified by Bradley and Mustard are used in the web-enabled annual brome model for this project.

It is noteworthy that Bradley and Mustard's predictive parameters are a departure from earlier annual brome predictive model work; in particular the factors used by Esh in her model (see Table 2-1).

Table 2-1 Annual Brome Predictive Parameters

\section{Esh (Big Bear, California)}

Aspect: $\mathrm{S} \& \mathrm{~W}$

Elevation: $>762$ meters

Roads: 180 meters

Urban Areas: 180 meters

Fuel Reduction Zones

Fire History

\author{
Bradley \& Mustard (Nevada) \\ Aspect: W \& NW \\ Elevation: 1400 - 1700 meters \\ Roads: 700 meters \\ Hydrologic Channels \\ Cultivation: 3000 meters \\ Power lines: 1000 meters \\ Cheatgrass: 150 meters (Historic)
}

An important distinction is whether a parameter has inherent predictive value or if it is acting as a surrogate for another factor; for example is northern aspect really the significant factor or is it really an indication of moisture level. The Nature Conservancy suggests other indicators for annual brome may be coarse, potassium rich soils, rainfall between 6 - 22 inches, and fall rains for germination (Carpenter \& Murray, 2005). Another consideration is if there are any regional variations in predictive indicators. To allow for such variations, the web-enabled annual predictive brome model will have the parameters exposed for modification.

In another publication Bradley and Mustard used remote sensing to locate the present extent of cheatgrass (Bradley \& Mustard, 2004). Peterson has also done work that used remote sensing to identify cheatgrass areas, and mapped a considerable part of Nevada (Peterson, 2003). Peterson published the GIS data as grid files on the Nevada Natural Heritage website (Nevada Natural Heritage Program, 2005). Both of these important cheatgrass extent resources are used as an input into the annual brome predictive model. It is essential to note that to expand the web-enabled annual brome predictive model 
beyond areas where current cheatgrass is already mapped would require a replication of this type of analysis in those areas.

\subsection{Wildfire}

Wildfires in the western United States have become more frequent and intense in recent years, posing threats to life, property, rangelands, forestlands, and wildlife habitats. Wildfires are, however, also a natural part of the ecosystem. The natural cycle of destruction and renewal creates a unique habitat for flora and fauna. In the early twentieth century, in response to particularly tragic fire seasons, the federal government agencies, such as the United States Forest Service, engaged in a policy of total fire suppression in an attempt to protect life and property. To a large extent, their efforts have been successful; however, it has resulted in some unintended consequences. The build-up of fuels due to past fire suppression has led to more extreme wildfires that cause even more damage and are harder to control. The loss of the natural fire cycle has disrupted the ecosystem, causing harm to the plants and animals that depend on it. More extreme fires cause more damage and burn deeper into the forest floor, which also impairs natural regeneration processes and opens the door to exotic and invasive species.

As a result of the new understanding of fire as a natural part of the ecosystem, wildfires are now managed differently. The prescription for every fire is no longer total suppression and some fires are allowed to burn in certain situations. Moreover, fire management techniques, such as fuel reduction by tree removal, prescribed burns, and removal of vegetation in key areas known as wildfire fuel breaks are now employed to manage the impact of fires.

There are a number of methods for installing fuel breaks, including mechanical and chemical (herbicides). The ensuing results are less intense fires with reduced threat to life and property, with better rangeland, forestland, and wildlife habitat (Schmidt, Menakis, Hardy, Hann, \& Bunnell, 2002).

\subsubsection{Wildfire Urban Interface}

The wildland urban interface (WUI) describes areas in which people have expanded development into neighboring wildlands (rangeland, forestland, and mixtures) (Price, 2005a). The mixture of homes and wildland vegetation in areas also prone to wildfire danger can be a recipe for disaster. Due to the potential for loss of life and property, there is no tolerance for wildfires, but the necessity for total wildfire suppression leads to a build up in fuel loads over time and can lead to catastrophic wildfires when they do occur. In fact, in a recent USDA report, the existence of WUI development was cited in $87 \%$ of wildfire suppression efforts and has been estimated to be directly responsible for 50 to $95 \%$ of federal wildfire costs (USDA Office of Inspector General, 2006). In effect, the presence of the WUI has continued the policy of suppression for most wildfires. As people move into the WUI, they create ground disturbances which produce an opportunity for invasive plants such as annual brome to become established. In turn, the annual brome becomes a fire threat to homes and can act as a fuse for surrounding forest fuels. Knowledge of the fire threat, and where to employ fire reduction techniques such as fire breaks, are even more important in the WUI. 
This project draws on the spatial analysis of the WUI for the entire United States done by The University of Wisconsin, at Madison, Forestry Department's Spatial Analysis for Spatial Analysis for Conservation and Sustainability (SILVIS) Laboratory (Radeloff, Hammer, Stewart, Holcomb, \& McKerefry, 2005) which was published on the Internet and will be accessed as an external web map service. The SILVIS Lab WUI data can also be viewed and downloaded from their website (University of Wisconsin, 2006). The analysis provides the ability to determine whether an individual parcel is located in the WUI, as well as national WUI statistics. For example, it is estimated that the WUI covers nine percent of the conterminous United States and that 5.1 million housing units in the state of California are in the WUI (Radeloff, Hammer, Stewart, Holcomb, \& McKerefry, 2005).

\subsubsection{Wildfire Models and Parameters}

There has been significant work done in fire modeling in general and specifically in the western United States. They include both GIS and non-GIS and one recent survey lists approximately 70 different wildfire models (MacGregor, 2004). Conference proceedings for the International Association of Wildland Fire shows there were eleven papers on modeling, risk assessment and decision support (Andrews \& Butler, 2006) and there were at least numerous presentations in recent years at the ESRI International User Conferences including some cited below.

Examples of wildfire presentation topics at the ESRI user conference include "ArcFuels: Forest Planning Tools for Managing Wildland Fuels", a combination of a number of vegetation and fire behavior models into a library of VBA macros (Ager, 2005), and "Firewise Modeling in the Wildland/Urban Interface with ArcGIS" (Price, 2005a). Another wildfire analysis example was a wildfire risk rating prepared for western Colorado that used slope, aspect and vegetation assessments in ArcGIS using Spatial Analyst Raster Calculator and map algebra (Christiansen, 2005, 2006). Price has also written two ArcUser articles (Price, 2003) (Price, 2005b) on wildfire modeling and conducted three workshops in using ArcGIS wildfire analysis at the Firewise Conference in Denver, Colorado. Price uses Spatial Analyst and 3D Analyst, and he incorporates the National Fire Protection Association 1144 Standard for Protection of Life and Property from Wildfire assessment criteria into his fire model.

The 1144 Standard (NFPA, 2002) is an excellent example of a homeowner scale landscape checklist for rating fire safety that includes criteria for emergency access, vegetation, topography, building materials, water availability, and utilities, and it would be a good tool to further analyze areas identified as wildfire risk in a GIS analysis. The 1144 Standard checklist is copyrighted, and not freely reproducible; however the Firewise communities website has similar checklists and will be available as an external link from the project website to allow the end users a more fine-grained analysis of their properties (Firewise, 2007). An example of a questionnaire based approach has been initiated in Berkeley California where the added step of hyper linking the reports to a web map allows for access to the results over the Internet (Center for Fire Research University of California Berkeley, 2007).

A good example of GIS wildfire risk modeling was done by the Marin County California Fire Department. They assessed vegetation in relation to fuel load, considered steeper 
slope to be more hazardous, used past fire history as a factor, and looked at weather conditions such as inversions that protect areas at lower elevations, and wind. They ranked areas based on their monetary value (loss), and also considered non-monetary values such as wildlife habitat. They use the analysis results to formulate plans to reduce risk such as education plans, fuel reduction efforts and fuel break installations (Amdahl, 2001).

ArcGIS Model Builder affords the ability to convert the geoprocessing processes, such as those performed in Marin County and western Colorado (above) into a model by dragging each individual data source and tool onto the Model Builder canvas and connecting the processes together in the same sequence as if they were done manually (Pratt, 2000). Advantages of using Model Builder are that it easy to make changes and rerun the model. The Model Builder interface creates a schematic diagram of the process that can be shared with others. ArcGIS Model Builder was used in this project to perform geoprocessing analysis and is documented later in the methodology section.

\subsubsection{Websites, Data}

There are numerous websites, web portals, and web mapping sites associated with wildfires and wildfire modeling. The USDA Forest Service Fire Effects Information System (FEIS) is a web database portal about fire effects on plants and animals maintained by the Rocky Mountain Research Station Fire Sciences Laboratory in Missoula, Montana. The website contains extensive background on over 900 plants including Cheatgrass (USDA Forest Service, 2006a), vegetation types, and 10 research project summaries (USDA Forest Service, 2006b).

The Fire Research and Management Exchange System, or FRAMES, is a web portal database of wildfire related information. It has an exhaustive list of subject areas such as data, document, software, fire model, mapping fuels, fire history, fire ecology, fire effects, climate, and fuels among others, and is supported by the National Biological Information Infrastructure (NBII) program, which is a division of the US Geological Survey (FRAMES, 2006).

Fire.org is a repository of public domain software for the wildland fire community to be used for wildfire planning, behavior, fuel, weather, and effects. The web portal is maintained by the Systems for Environmental Management, a Montana nonprofit research and educational corporation. Software downloads and documentation for many fire modeling software applications are also available, including BehavePlus, FARSITE, FireFamilyPlus, Fire Behavior SDK, fireLib, FIREMON, FlamMap, FOFEM, NEXUS, and NIFTT (Fire.org, 2006).

A source of nationwide coarse-scaled spatial data for wildfire management is available on compact disk that is appropriate for regional analysis, but is not appropriate scale for this project (Schmidt, Menakis, Hardy, Hann, \& Bunnell, 2002).

While most wildfire web mapping sites are generally used to map fires in progress for current emergency fire and safety concerns, there are some that map a broad range of vegetation and fire susceptibility conditions, such as the LANDFIRE Prototype Project, a three year, six million dollar project funded by the United States Department of Agriculture Forest Service, and the United States Department of Interior. Although the 
project is ongoing, the stated goal of the prototype that ended in April 2005 was to "develop the methods, tools, and protocols for producing consistent and comprehensive digital maps of current vegetation composition and structure, wildland fuels, historical fire regimes, and fire regime condition class (FRCC) to be applied across the entire United States at a 30-meter spatial resolution...for developing predictive landscape models” to support fire and land managers fire management decisions (Rollins \& Frame, 2006).

Landfire does include fine fuels such as annual brome to some extent, but it has not fully addressed their importance (Reeves, Kost, \& Ryan, 2005). Models include parameters for historical vegetation, current vegetation, landscape fire succession, weather, satellite data, canopy fuel, fire fuel effects, fire fuel behavior, and include real-time behavior models FARSITE, FlamMap and NEXUS. Products include databases, computer models, biophysical gradient maps, vegetation maps, wildfuel maps, and fire regime maps. Data are available via download and directly viewable in an Internet-based mapping tool. To date, it is not clear if the prototype project has successfully produced accurate results; however, Landfire National is an ongoing effort, building on the results of the prototype project: www.landfire.gov (Rollins \& Frame, 2006). Landfire data is also available on DVD.

There is a real need to coordinate all the fire modeling activities so that work is not duplicated and so that individual efforts can leverage work already being done by others. The Landfire Project has done that to some degree. This project utilizes the wildfire work and data available as a web map service from the Landfire website, in conjunction with WUI data also accessed as an external web service, and combines them with locally produced annual brome data to provide information to support fuel break location decisions.

\subsection{Web-enabled GIS}

Web mapping runs the gamut from simple display of scanned hard copy maps to 3D real world simulators. Other functions include address finders, trip planners, real estate locators, utility and infrastructure management, emergency response, and scientific research (Harder, 1998). Geospatial portals gather GIS for download, or serve as clearinghouses to find data. Portals can also serve GIS data directly and are becoming more popular as the volume of GIS data grows (Tang \& Selwood, 2005). The ubiquity of web mapping tools for location and directions like Mapquest (MapQuest, 2006) are a testament to the maturing of web mapping. However, such examples are very simple, often with limited data and utility.

More specialized web mapping tools, however, suffer from poor design, slow response, and the need for high bandwidth. Even with fast connection speeds, some sites serving a lot of data are often sluggish. Google Earth (Google, 2006), a free worldwide Internet mapping tool, while used mostly for finding locations, directions, and as a search engine, does have the desired ability to serve high resolution data quickly and has achieved wide acceptance and popularity.

The prevailing paradigm in GIS has necessarily been data-centric. Data acquisition, configuration, and storage are estimated to constitute as much as $80 \%$ of the time and 
cost for most GIS projects. Advancements in computer hardware, GIS software, networking, and Internet technologies, coupled with greater Internet bandwidths, have made it technically possible to deliver GIS data and functions over the Internet as web services. The synergy afforded by web services as a part of a distributed componentbased architecture will multiply many times over the individual inputs. In a GIS web services environment, geospatial data and GIS functions such as geocoding and geoprocessing are available over the Internet, and can be accessed as individual components as they are needed, but collectively they comprise a whole GIS.

The new paradigm is an open, distributed framework of distributed GIS services, as opposed to a closed, centralized GIS. A GIS analyst would search for functional components that could be married together to form solutions, in contrast to looking for data to download. Advantages can include less data to gather, download or process, lower cost to the end user for data storage, hardware and software licensing with less expertise required, and a simple web browser interface. The new paradigm is data and functionality as a service instead of data as a download (Peng \& Tsou, 2003). Public and private natural resources agencies and advocates often engage in GIS analysis and offer the results for download or as static results on a web map. Creation of interactive, modular, GIS data and functionality that could be joined together in a new mash-up to help solve new problems could become a new way to provide outreach services to clients and the public.

The new Internet GIS paradigm is not without need for new requirements, such as open interoperable standards, protocols for platform independent access, and increased reliable security. The Transmission Control Protocol and Internet Protocol (TCP/IP) are the backbone methods for Internet connectivity, which provides a standard way for computers to communicate over the web. The XML-based Simple Object Access Protocol (SOAP) is another important one. The Web Services Description Language (WSDL) defines what is available from a web service and how to obtain it. Universal Description Discovery and Integration (UDDI) is a standard way to register and discover web services, and serves as a metadata server (Peng \& Tsou, 2003).

Representational State Transfer (REST) is an alternative to SOAP XML-based communication that uses standard web uniform resource locator (URL) hypertext transfer protocol (HTTP) communication. There are many other organizations that provide standards for Web GIS such as the Open Geospatial Consortium (OGC), the International Standards Organization (ISO), American National Standards Institute (ANSI), the European Petroleum Survey Group (EPSG), the Institute of Electrical and Electronics Engineers (IEEE), the Federal Geographic Data Committee (FDGC), and the World Wide Web Consortium (W3C). There is even a XML-based Geography Markup Language (GML) from the OGC that allows geographic data to be communicated directly over the web (Peng \& Tsou, 2003). This project uses ArcGIS Server 9.2 and relies primarily on TCP/IP, WSDL, and SOAP, although ArcGIS is striving to be OGC compliant, as well.

Commercial GIS Internet software includes GeoMedia from Intergraph, MapXtreme from MapInfo, MapGuide from Autodesk (Peng \& Tsou, 2003) as well as open source MapServer developed at the University of Minnesota (University of Minnesota, 2007). The current status of web mapping has been to display data for the end user to view and 
download for analysis performed with installed GIS software. With the new release of ESRI ArcGIS Server 9.2 used in this project, server based remote geoprocessing analysis and editing are now feasible (ESRI, 2006).

This project strives to achieve a mash-up of external web map and geocoding services along with a locally served geoprocessing service into a single web application viewable in a web browser, but as we shall see this has some limitations. The current project includes display of dynamic layers, geocode locaters, plus real time server-based geoprocessing analysis, a relatively new phenomenon to web mapping (Longley, Goodchild, Maguire, \& Rhind, 2005). The project allows the client to access needed spatial data as a web service without an additional upfront capital cost, which also greatly reduces the need and cost to gather, transform, house, maintain and update data. Data obtained includes background layers such as roads, hydrography and imagery, as well as more specific key weed and fire model parameter data and other fire data as an external web service. The user interface operates through a thin client web browser which reduces cost of software licensing, and requires less hardware, less expertise, and less maintenance. 



\section{Design}

The project design specification first examined what the system must do to solve the client's problem by breaking the solution into individual tasks using Use Case analysis. The functional requirements described how the system answered the questions, including consideration of data input, data output and analysis methods. An important data consideration was the scale, resolution, and accuracy of the input data and its effect on the desired and appropriate scale for use of the output. The architecture shows how the data, hardware, software and network fit together and is followed by discussion of the software and database design. The user interface describes and illustrates how the client will interact with the system.

\subsection{System Description}

The overall purpose of the system was to find locations for potential annual brome wildfire fuel breaks. In order to answer the larger question it was helpful to break down the problem into the following six successive questions.

1. Where is my property (address, parcel, or area of interest)?

2. Where is annual brome likely to occur?

3. Where is wildfire danger likely to occur?

4. Which areas are in the Wildfire Urban Interface (WUI)?

5. Where are potential good locations for firebreaks for annual brome wildfire danger?

6. How do I install a firebreak?

\subsection{Use Case}

The following Use Case tables help illuminate the functional requirements of the system by describing the process in more detail, identifying the actor, trigger, inputs, outputs, preconditions, post-conditions, and assumptions. The system Use Case description helps to understand how the elements of each activity operate and interact, and to identify the system functional requirements and scope of the project (see Tables 3-1 - 3-6). 
Table 3-1. Use Case: Locate Area of Interest

\begin{tabular}{|l|l|}
\hline Description: & End user delineates area of interest for analysis. \\
\hline Actor: & End user (landowner, land manager, planner, insurer). \\
\hline Trigger: & End user accesses Internet Web Mapping Analysis Website. \\
\hline Major Inputs: & Address, Place Name, pan, zoom, drag a rectangle to zoom. \\
\hline Major Outputs: & Area of interest area. \\
\hline Normal Process: & $\begin{array}{l}\text { Browse to area of interest using map navigation tools. } \\
\text { Use view extent and user defined polygon to define area of } \\
\text { interest. }\end{array}$ \\
\hline Alternative Process: & $\begin{array}{l}\text { Input address, geocode address, zooms to address at predefined } \\
\text { zoom. } \\
\text { Input place name, zooms to parcel at predefined zoom. }\end{array}$ \\
\hline Preconditions: & $\begin{array}{l}\text { End user has relatively new computer, up to date web browser } \\
\text { and relatively high speed Internet connection. }\end{array}$ \\
\hline Post-conditions: & $\begin{array}{l}\text { Area of interest is located to be used to define extent for GIS } \\
\text { analysis. }\end{array}$ \\
\hline Assumptions: & $\begin{array}{l}\text { End user understands annual brome wildfire threat and is looking } \\
\text { for a solution. } \\
\text { Limit area of analysis size to predetermined maximum to prevent } \\
\text { long process times. }\end{array}$ \\
\hline
\end{tabular}

Table 3-2. Use Case: Predict Annual Brome Areas

\begin{tabular}{|c|c|}
\hline Description: & Annual brome areas predicted. \\
\hline Actor: & End user (landowner, land manager, planner, insurer). \\
\hline Trigger: & End user accesses Internet Web Mapping Analysis Website. \\
\hline Major Inputs: & $\begin{array}{l}\text { Accept default annual brome predictive model values. } \\
\text { Or input override values. }\end{array}$ \\
\hline Major Outputs: & Annual brome prediction area. \\
\hline Normal Process: & $\begin{array}{l}\text { Model annual brome area with default parameters used based on } \\
\text { assumptions, however ability to input over ride for aspect, } \\
\text { elevation, and buffer values for roads, farmland, power lines and } \\
\text { historic cheatgrass. }\end{array}$ \\
\hline Alternative Process: & $\begin{array}{l}\text { Over ride default input values for aspect, elevation, and buffer } \\
\text { values for roads, farmland, power lines and historic cheatgrass. }\end{array}$ \\
\hline Preconditions: & Area of Interest located for GIS analysis. \\
\hline Post-conditions: & $\begin{array}{l}\text { Area of predicted annual brome located and displayed. } \\
\text { Or used internally in wildfire fuel break model without display. }\end{array}$ \\
\hline Assumptions: & $\begin{array}{l}\text { Parameter model values for aspect, elevation and buffer values for } \\
\text { roads, farmland, power lines and historic cheatgrass are } \\
\text { predictive. }\end{array}$ \\
\hline
\end{tabular}


Table 3-3. Use Case: Wildfire Danger Areas

\begin{tabular}{|l|l|}
\hline Description: & Wildfire danger areas identified \\
\hline Actor: & End user (landowner, land manager, planner, insurer). \\
\hline Trigger: & End user accesses Internet Web Mapping Analysis Website. \\
\hline Major Inputs: & $\begin{array}{l}\text { Accept default wildfire model. } \\
\text { Or choose alternative wildfire model. }\end{array}$ \\
\hline Major Outputs: & Wildfire danger area. \\
\hline Normal Process: & Use external wildfire danger model results. \\
\hline Alternative Process: & Use alternative wildfire danger model results. \\
\hline Preconditions: & Area of Interest located for GIS analysis. \\
\hline Post-conditions: & Area of predicted wildfire danger located and displayed. \\
\hline Assumptions: & Use external model results for wildfire danger prediction area. \\
\hline
\end{tabular}

Table 3-4. Use Case: Wildland Urban Interface Areas

Description: $\quad$ Wildland Urban Interface (WUI) Areas Located.

Actor: $\quad$ End user (landowner, land manager, planner, insurer).

Trigger: $\quad$ End user accesses Internet Web Mapping Analysis Website.

Major Inputs: $\quad$ None required.

Major Outputs: WUI areas.

Normal Process: $\quad$ Use external WUI model results.

Alternative Process:

Preconditions: $\quad$ Area of Interest located for GIS analysis.

Post-conditions: $\quad$ Area of predicted WUI located and displayed.

Assumptions: $\quad$ Use external model results for WUI prediction area. 
Table 3-5. Use Case: Potential Annual Brome Wildfire Fuel Break Areas

\begin{tabular}{|c|c|}
\hline Description: & Areas for potential annual brome wildfire breaks located. \\
\hline Actor: & End user (landowner, land manager, planner, insurer). \\
\hline Trigger: & End user accesses Internet Web Mapping Analysis Website. \\
\hline Major Inputs: & Annual brome model output, Landfire Data and WUI data. \\
\hline Major Outputs: & Potential annual brome firebreak areas located. \\
\hline Normal Process: & $\begin{array}{l}\text { Visually assess annual brome Model output along with Landfire } \\
\text { Data and WUI data. }\end{array}$ \\
\hline Alternative Process: & $\begin{array}{l}\text { Download WUI and Landfire data. } \\
\text { Wildfire fuel breaks areas are modeled using weighted overlay } \\
\text {.parameters: } \\
\text { - Area of interest location. } \\
\text { - Predicted annual brome location. } \\
\text { - Predicted wildfire location. } \\
\text { - WUI locations. }\end{array}$ \\
\hline Preconditions: & $\begin{array}{l}\text { Area of Interest located for GIS analysis. } \\
\text { Area of predicted annual brome located. } \\
\text { Area of predicted wildfire danger located. } \\
\text { Area of WUI located. }\end{array}$ \\
\hline Post-conditions: & Areas for potential annual brome wildfire fuel break located. \\
\hline Assumptions: & $\begin{array}{l}\text { Assumptions of precondition Use Cases. } \\
\text { Correct weights for weighted overlay. }\end{array}$ \\
\hline
\end{tabular}

Table 3-6. Use Case: Wildfire Fuel Break Installation Information Alternatives

\begin{tabular}{|c|c|}
\hline Description: & $\begin{array}{l}\text { Wildfire Break Installation Information Alternatives Provided, } \\
\text { e.g. size, location, mechanical, or herbicide control. }\end{array}$ \\
\hline Actor: & End user (landowner, land manager, planner, insurer). \\
\hline Trigger: & End user accesses Internet Web Mapping Analysis Website. \\
\hline Major Inputs: & $\begin{array}{l}\text { None required. } \\
\text { Or user categorize, e.g. homeowner, ranch, public land. }\end{array}$ \\
\hline Major Outputs: & Firebreak installation information alternatives \\
\hline Normal Process: & $\begin{array}{l}\text { Provide information on wildfire fuel break installation . } \\
\text { Or provide information by category, e.g. homeowner, ranch, } \\
\text { public land. }\end{array}$ \\
\hline Alternative Process: & $\begin{array}{l}\text { Provide links to external websites with information on wildfire } \\
\text { fuel break installation. }\end{array}$ \\
\hline Preconditions: & $\begin{array}{l}\text { Area of Interest located for GIS analysis. } \\
\text { Annual brome wildfire fuel breaks needed. }\end{array}$ \\
\hline Post-conditions: & $\begin{array}{l}\text { Information on wildfire fuel break installation provided to end } \\
\text { user. }\end{array}$ \\
\hline Assumptions: & Assumptions of precondition Use Cases. \\
\hline
\end{tabular}




\subsection{Functional Requirements}

To answer the questions elicited by the Use Case analysis, the project analysis employed GIS data, a number of GIS services and functions including locator services, an annual brome predictive model, a wildfire threat predictive model, and a Wildland Urban Interface model. The individual model results combine to produce the potential annual brome fuel break location solution. Below is a description of the process, the input data, the output data and the methods employed to answer each question.

"Where is my property, or area of interest?"

- Use street address or place geocode locator services, and map zoom and pan navigation tools to find an area of interest.

- Use view extent and, graphic delineation tool to define area of interest for analysis.

- The area of interest is used as input to subsequent model processes to clip analysis layers or select subset of features.

"Where is annual brome likely to occur?"

- Use annual brome suitability model with predictive input parameters (Table 3-7) (Bradley \& Mustard, 2006).

- The area of interest clips the input layers and the user may use the default parameters or can modify the parameters. The results of the prediction of the presence of annual brome are combined with other factors to determine the threat of wildfire and possible location of a cheatgrass fuel break.

- A secondary use of the annual brome predictive layer could be by others interested in combating this non-native invasive plant on rangelands and in wildlife habitat areas.

Table 3-7. Annual Brome Model Parameters

\begin{tabular}{l|l} 
Aspect: & W \& NW \\
Elevation: & $1400-1700$ meters \\
Roads: & 700 meters \\
Hyrologic Channels & Present \\
Cultivation (farming): & 3000 meters \\
Power lines: & 1000 meters \\
Cheatgrass (Historic): & 150 meters
\end{tabular}

"Which areas are in the Wildfire Urban Interface (WUI)?"

- Use the WUI external web map service to identify areas that have urban population densities in proximity to high vegetation density.

- The WUI results are combined with other factors to determine the threat of wildfire and possible location of a cheatgrass fuel break. 
"Where is Wildfire danger likely to occur?"

- Use wildfire external web map service.

- The wildfire danger results are combined with the WUI and annual brome results to determine need and location of fire breaks.

"Where are potential good locations for firebreaks for annual brome wildfire danger?"

- Use the intersection of the annual brome, WUI, and wildfire danger model outputs to locate the potential fuel break locations.

- An alternative to the simple intersection could be a weighted overlay assigning relative values to each factor.

"How do I install a firebreak?"

- Use links to alternatives for installation of fuel firebreaks, both mechanical and herbicidal.

\subsection{System Architecture}

The architecture is a commercial off-the-shelf (COTS) ArcGIS 9.2 Server system in which the client makes requests for map data and services over the Internet (see Figure 31).

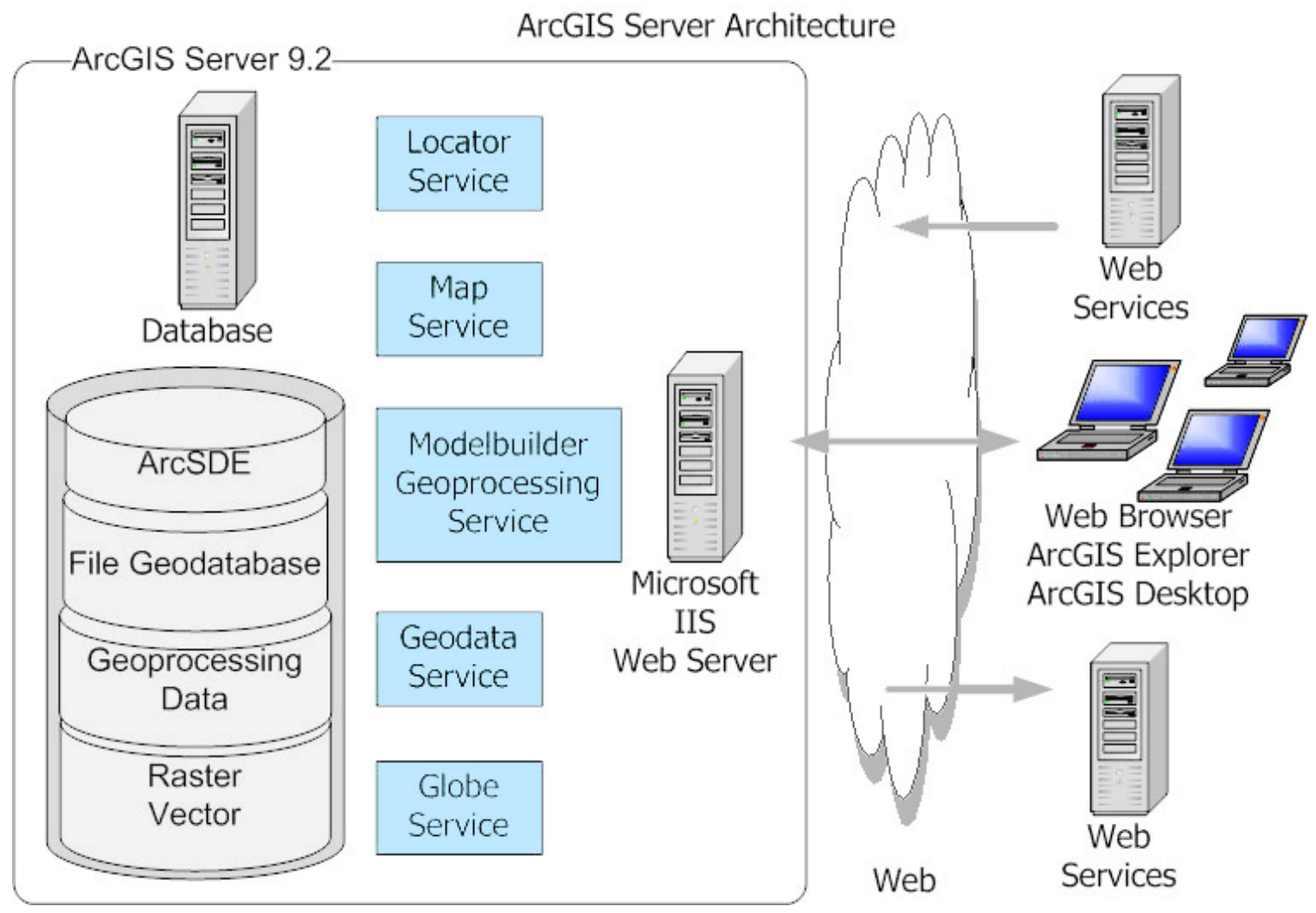

Figure 3-1. System Architecture

The server provides maps and other GIS functions. The annual brome input data is provided from a local server as a geodata service and web map service while the 
remaining map data for location and backdrop are accessed from external web map services. The geocode functions for find address or place are accessed from external geocode services. The annual brome model function is provided from the local server as an ArcGIS Model Builder geoprocessing service while the WUI model output and wildfire data are accessed as external web map services. In addition to the common web browser interface, the maps and services are also available as a web service to be used by other installed software applications such as ArcGIS Explorer and ArcMap. ArcGIS Explorer, a free downloadable GIS software client, can also interact with 3D globe map services; an external 3D globe data background globe service is provided to make use of that opportunity.

\subsection{Hardware}

The hardware consists of client computers, a web server, a GIS geodatabase server, and a GIS application server. The clients make requests for maps, geocode and geoprocessing services and the web server receives the client web requests. The web server in turn makes map, geocode, and geoprocessing requests to the GIS server. The web map data and functions generated by the GIS server are included with the reply to the client computer. During the prototype development all the server components are housed on the same computer, but at the time of deployment they may be on different machines depending on the preference of the client.

Hardware sizing was an important consideration to assure the website performs in a timely fashion. It was recommended by ESRI that ArcGIS Server software be installed on a server that has as a minimum two CPU's (or a dual core) and two Gigabyte of RAM per $\mathrm{CPU}$. The second CPU added some reliability and redundancy, but it was also essential for a geoprocessing website because one geoprocessing function can totally consume the cycles of a single CPU until the job is finished, which could last from several seconds to several minutes. The ESRI capacity planning analysis tool (received directly from Dave Peters of ESRI, designer and instructor of the Instructor Led Course, System Architecture Design, March 2007) was used to size the server hardware based on expected demand. For example, a dual core $3000 \mathrm{MHz}$ processor with $4 \mathrm{~GB}$ ram could serve approximately 33 concurrent users assuming six displays per minute per client of a $100 \mathrm{~KB}$ image (Peters, 2007). Like an electric utility, the server must be sized for peak demand to avoid slow performance.

\subsection{Network}

The client connection can be from anywhere on the Internet while all of the hardware server components could be on different machines on a local area network (LAN); however all the server components were on one machine during development for the prototype. The configuration at deployment will depend on the preferences of the client. One important caveat is that while connections from external web map services can be viewed from anywhere on the Internet, any geographic data that will be used for geoprocessing (or editing) functions over a network must be on the same LAN.

Bandwidth sizing is an important consideration to assure the website performs in a timely fashion. For example, for the hardware configuration of a dual core $3000 \mathrm{MHz}$ processor with 4 GB ram could serve approximately 33 concurrent described above, the ESRI 
capacity planning analysis recommended a network capacity of up to 3 Megabit per second (Mbps). The computation of needed bandwidth was not simply the peak demand; there must also be as much as 50\% additional capacity buffer because at higher percentages of usage congestion would slow performance. This translates into the need for approximately a T2 connection (6 Megabit per second). Bandwidth sizing was important for both the server and the client connections (Peters, 2007).

\subsection{Software}

The client computers only require web browser software to use and interact with the standard 2D map products. Clients could also install the free ArcGIS Explorer software in order to view 3D map data. The ArcGIS Server output is also available as a web map service to clients with ArcGIS desktop installed.

The prototype used Microsoft Internet Information Server (IIS) web server software and the GIS server used ArcGIS 9.2 server. The prototype used Microsoft SQL Server Express database software that comes with ArcGIS Server and includes embedded ArcSDE functionality. A file geodatabase, new with ArcGIS 9.2, could also have been used, but would be somewhat slower. A fully deployed server application could use Workgroup for up to 12 concurrent users, but for greater scalability the full ArcGIS Enterprise SDE would be required (Peters, 2007).

\subsection{Database}

The database provides the method to store, retrieve, and manipulate the data necessary to provide the website GIS, map, functions, and analysis. The website uses externally maintained data as a web service for base map layers, the geocode location functions, and the wildfire data. The data input for the annual brome habitat geoprocessing model is obtained as a map service from a SQL Server Express database housed on the local server. The fuel break analysis uses both the external web map services and the local server database web services to provide alternative firebreak recommendations.

To find the area of interest, the find address and find place tasks use external geocode services. The area of interest delineates the extent of the analysis of the annual brome geoprocessing model. The model output is written to a unique scratch geodatabase for each job in the ArcGIS Server output directory on the local server. After a specified period of time, the output directory contents are automatically deleted. The potential locations for fuel breaks are the intersection of the annual brome, wildfire, and WUI areas.

The annual brome model input data are stored in a local database, and provided as a web service. The annual brome geoprocessing output data are managed by ArcGIS server. The remaining location information and wildfire data are accessed as external web services (see Figure 3-2). 


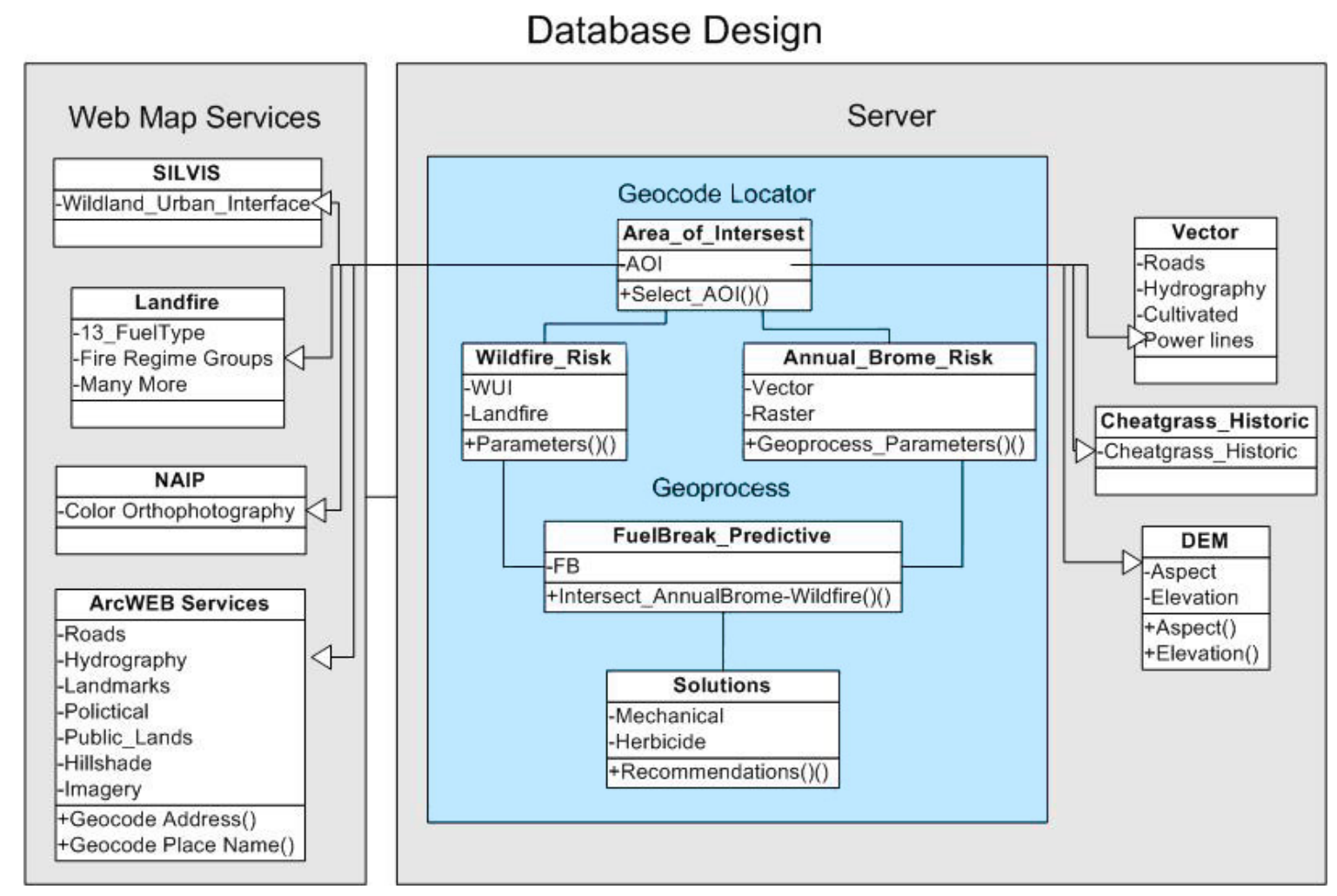

Figure 3-2. Database Schema

\subsubsection{Annual Brome}

The annual brome database stores the input data for the geoprocessing model. The intent of the website project annual brome geoprocessing model was to recreate on the web the analysis published by Bradley and Mustard (2006), so it was important to use the same source data sources as they did. First the Bradley and Mustard study site area was recreated in a web environment and then data for a wider area was obtained to extend the analysis to new areas.

The input data includes vector data: roads, power lines, cultivated (farmland), hydrologic channel, and raster data: historic cheatgrass, aspect, elevation (see Figure 3-3). The geodata are stored locally on the server in a SQL Server Express geodatabase and published as both a geodata service and a web map service. The aspect and elevation are derived from a digital elevation model (DEM). External web map data services cannot be used in a geoprocessing model service which makes it necessary to store the model input data locally even though they are available as external web map services. 


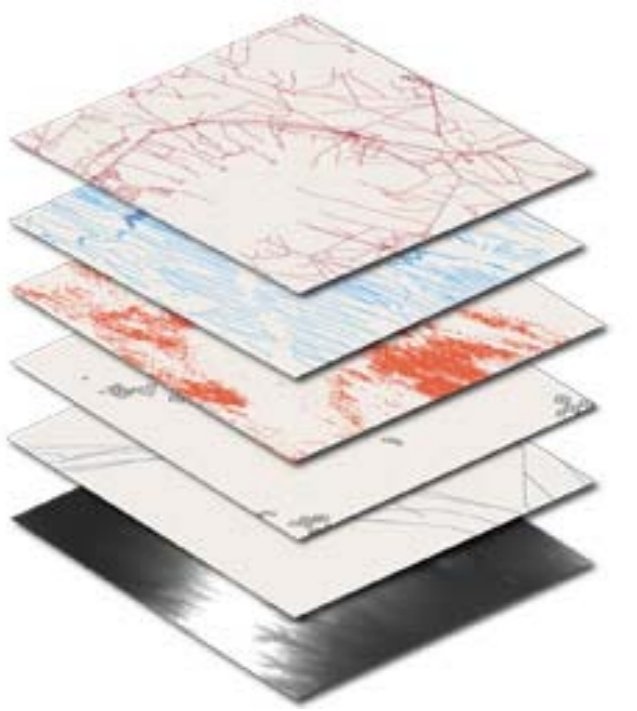

Roads

Streams

Cheatgrass

Cultivated

Powerlines

Elevation (DEM)

Aspect (Derived from DEM)

Figure 3-3. Annual Brome Input Parameter Data

The metadata is important for this project because the source information is helpful to expand the extent of the study area and establishes the appropriate scale for use (see Table 3-8). The original source for the vector road and hydrographic data is the United States Census Bureau national TIGER Line data, which is available from many sources but was downloaded for this project from ESRI. In the future, the Census Bureau plans to offer WebTIGER as a web feature service in GML format and also as a web map service (U.S. Census Bureau, 2006). Power line vector data is not commonly available and was obtained for the western U.S. from the USGS Sagemap. The Sagemap project is a collection of spatial data that was collected to research sage grouse and shrubsteppe systems (USGS, 2003). Aspect and elevation was derived from the USGS national elevation dataset digital elevation model (NED DEM). The raster national elevation dataset for the 1 arc second 30 meter data is made up of the "best available" elevation datasets which are derived from a variety of sources and with national coverage (available at different resolutions in some areas). The USGS DEM data is available from a number of sources and was downloaded from the USGS Seamless Data Distribution System website. Raster cultivation (farmland), cheatgrass (historic) as well as urban/salt flat mask layer for the prototype study site area was received directly from Bradley (personal communication, May 15, 2007). To extend the project to much of the rest of Nevada, cultivation, urban, and cheatgrass raster data was downloaded from the Nevada Natural Heritage Program (NvNHP). 


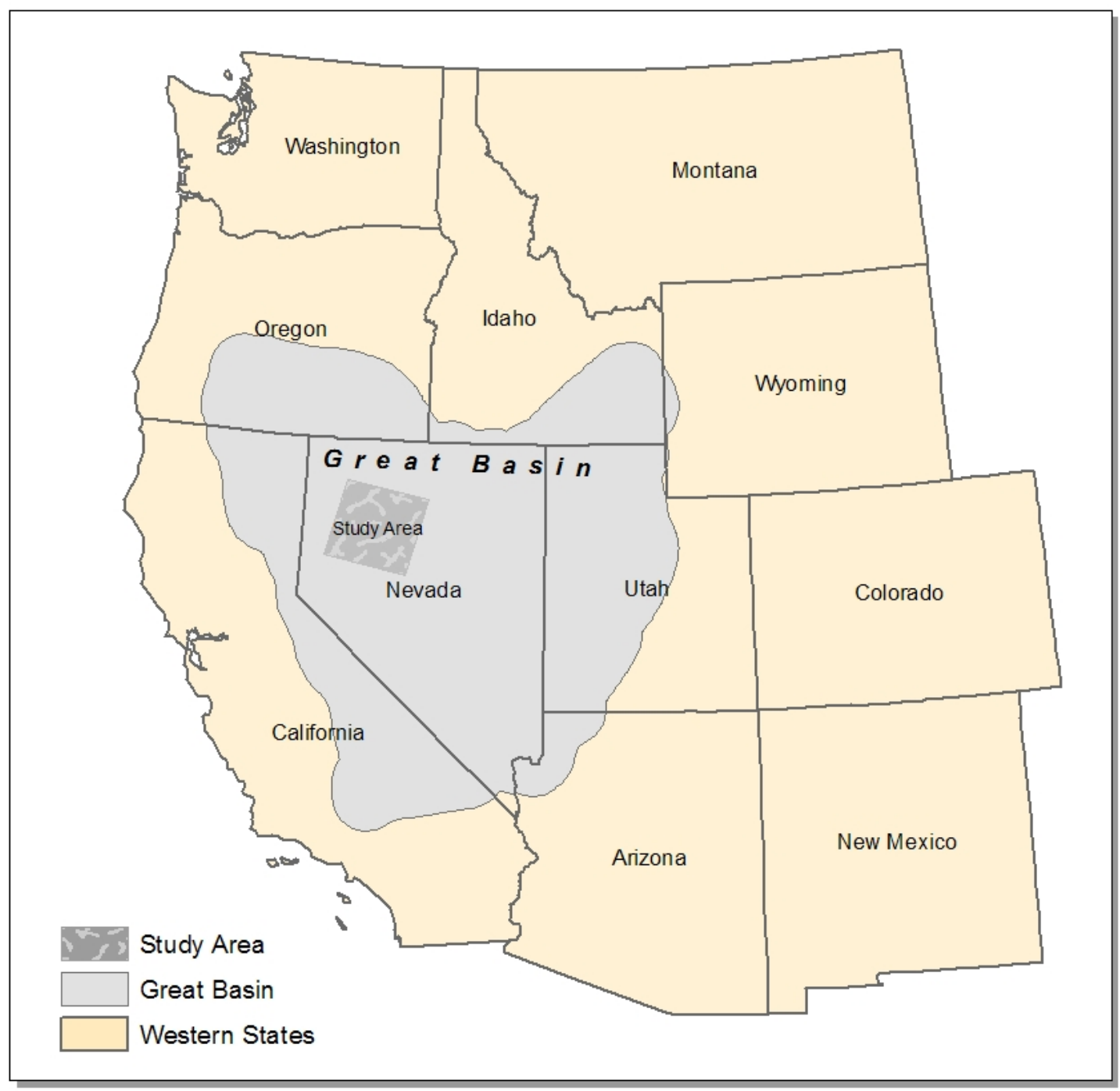

Figure 3-4. Locator Map for the Study Area and the Great Basin

Introduced accidentally from Europe and Asia over a hundred years ago, it has opportunistically gained a foothold in physically disturbed areas (Neese, 2000). The annual brome Wildfire website was prototyped in Nevada and there is a desire by the client to expand to the Intermountain West. A limitation for expansion is that all the input data for annual brome geoprocessing model must be stored in a local database and available as a local web service. Roads, hydro, power lines, and the digital elevation model (DEM) used for elevation and to derive aspect are all easily available, although it would require some time to acquire the DEMs and significant storage space for such a wide extent. Urban and cultivation data is also easily available from landuse landcover data; however, historic cheatgrass may be hard to obtain and may require undertaking a remote sensing NDVI analysis which would be a considerable constraint to expansion of the project study area 


\subsubsection{Wildland Urban Interface (per University of Wisconsin SILVIS Lab)}

The wildland urban interface (WUI) is defined as an area in which people have expanded development into wildlands (rangeland, forestland, and mixtures), a practice which fragments habitat, increases introduction of invasive plants, and subjects them to increased wildfire danger. The SILVIS Lab Forest Ecology and Management University of Wisconsin, Madison did a spatial analysis of the WUI and published the results on the Internet through their Internet mapping website (see Figure 3-5) as well as a Web Map Service (University of Wisconsin, 2006). This project will use the WUI as an indicator of wildfire risk.

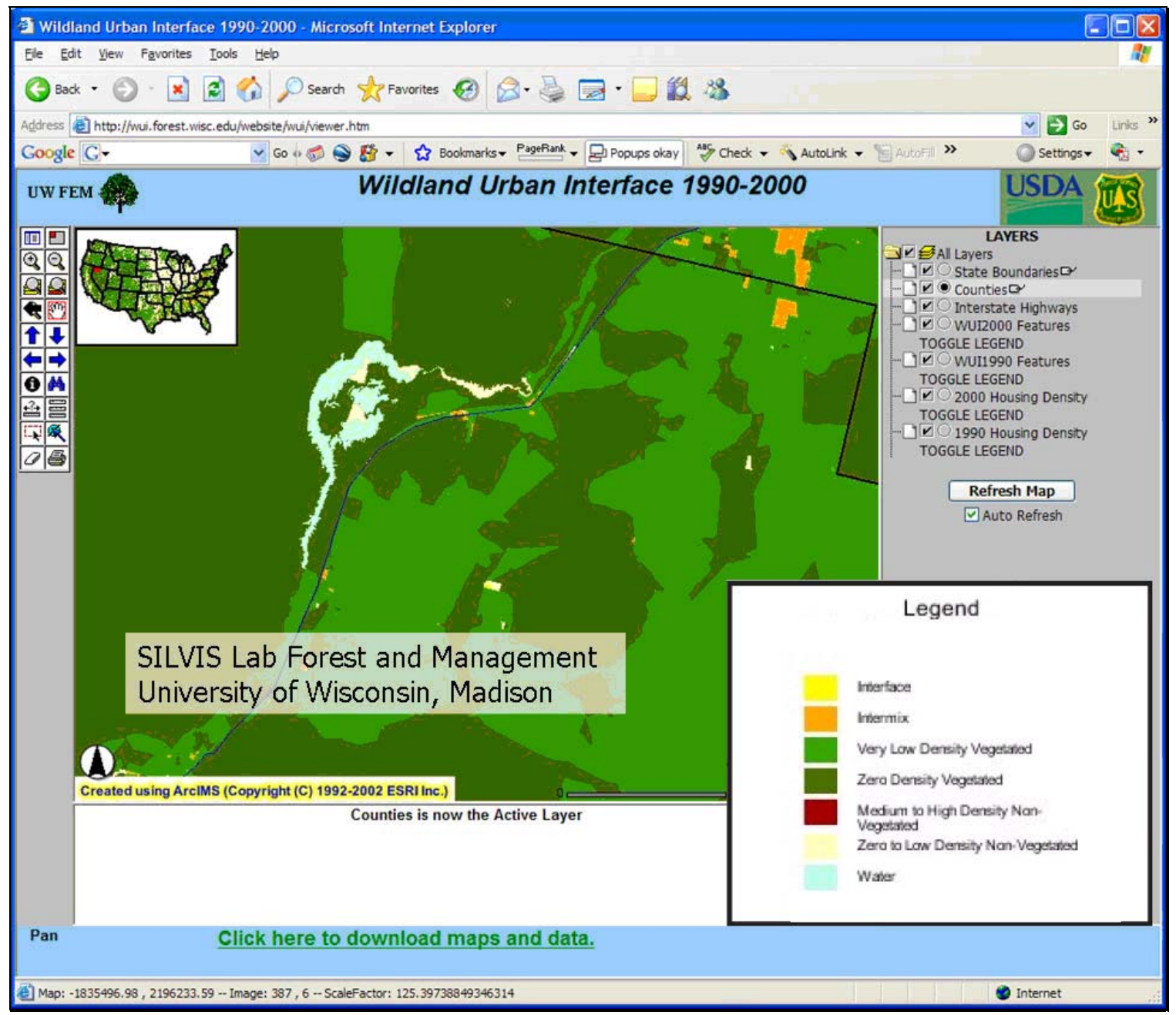

Figure 3-5. The University of Wisconsin SILVIS Lab WUI Web Map

The SILVIS Lab WUI definition uses a formula with a combination of population density and vegetation density. For a population density of a minimum 1 house per 40 acres within a census block, and vegetation cover greater than $50 \%$ within a census block, it is categorized as the intermix area; if it also has greater than $75 \%$ vegetation within 2.4 kilometers (the distance a firebrand can travel and spot a new fire) it is categorized as an interface area. Other analysis categories include Non-WUI vegetated and non-vegetated or agricultural. Census housing data (2000) is used to determine population density and USGS National Land Cover Dataset (NLCD) derived from 30 meter satellite imagery 
(1992/93) to assess vegetation (Radeloff, Hammer, Stewart, Holcomb, \& McKerefry, 2005). The Census spatial data and the USGS NLCD is the same scale as the annual brome model data and can be used together for analysis. Limitations of this data are that it is static and it does not change over time and census data generalizes population data over census areas.

\subsubsection{Wildfire (per USDA Forest Service Landfire)}

The project uses wildfire data from the Landfire (Landscape Fire and Resource Management Planning Tools Project) created by the United States Department of Agriculture Forest Service and the United States Department of Interior, completed in April, 2005. The goal was to "develop the methods, tools, and protocols for producing consistent and comprehensive digital maps of current vegetation composition and structure, wildland fuels, historical fire regimes, and fire regime condition class (FRCC) to be applied across the entire United States as a 30-meter spatial resolution...for developing predictive landscape models” to support fire and land managers fire management decisions (Rollins \& Frame, 2006).

Landfire does include fine fuels such as annual brome to some extent (Reeves, Kost, \& Ryan, 2005). Models include parameters for historical vegetation, current vegetation, landscape fire succession, weather, satellite data, canopy fuel, fire fuel effects, fire fuel behavior, and included real-time behavior models FARSITE, FlamMap and NEXUS. Products included databases, computer models, biophysical gradient maps, vegetation maps, wildfuel maps, and fire regime maps.

Data are available via download and directly viewable in an Internet-based mapping tool. To date, it is not clear if the prototype project has successfully produced accurate results; however Landfire National is an ongoing effort, building on the results of the prototype project: www.landfire.gov (Rollins \& Frame, 2006). This project has access to the full range of Landfire datasets as map layers in the web map. 
One example of Landfire data is the 13 Anderson (1982) Fire Behavior Fuel Models (Fire Behavior based on vegetation) (see Figure 3-6). Descriptions of fuel properties (amount, distribution, and continuity of live and dead vegetation/wood) based upon four groups (grass, shrub, timber, and slash) and categorized into 13 models to help users estimate fire behavior, including rate of fire spread and fire intensity. The ratings range from low to high, with the FBFM1-FBFM3 grass, FBFM4-FBFM7 shrub, FBFM8-FBFM10 timber and FBFM11-FBFM13 slash. Esh (2006) used this model as the sole indicator for the fire susceptibility model; however, she used a local vegetation dataset and adapted it to the model with assistance of local expertise. This project uses the Anderson model as an indicator of wildfire risk.

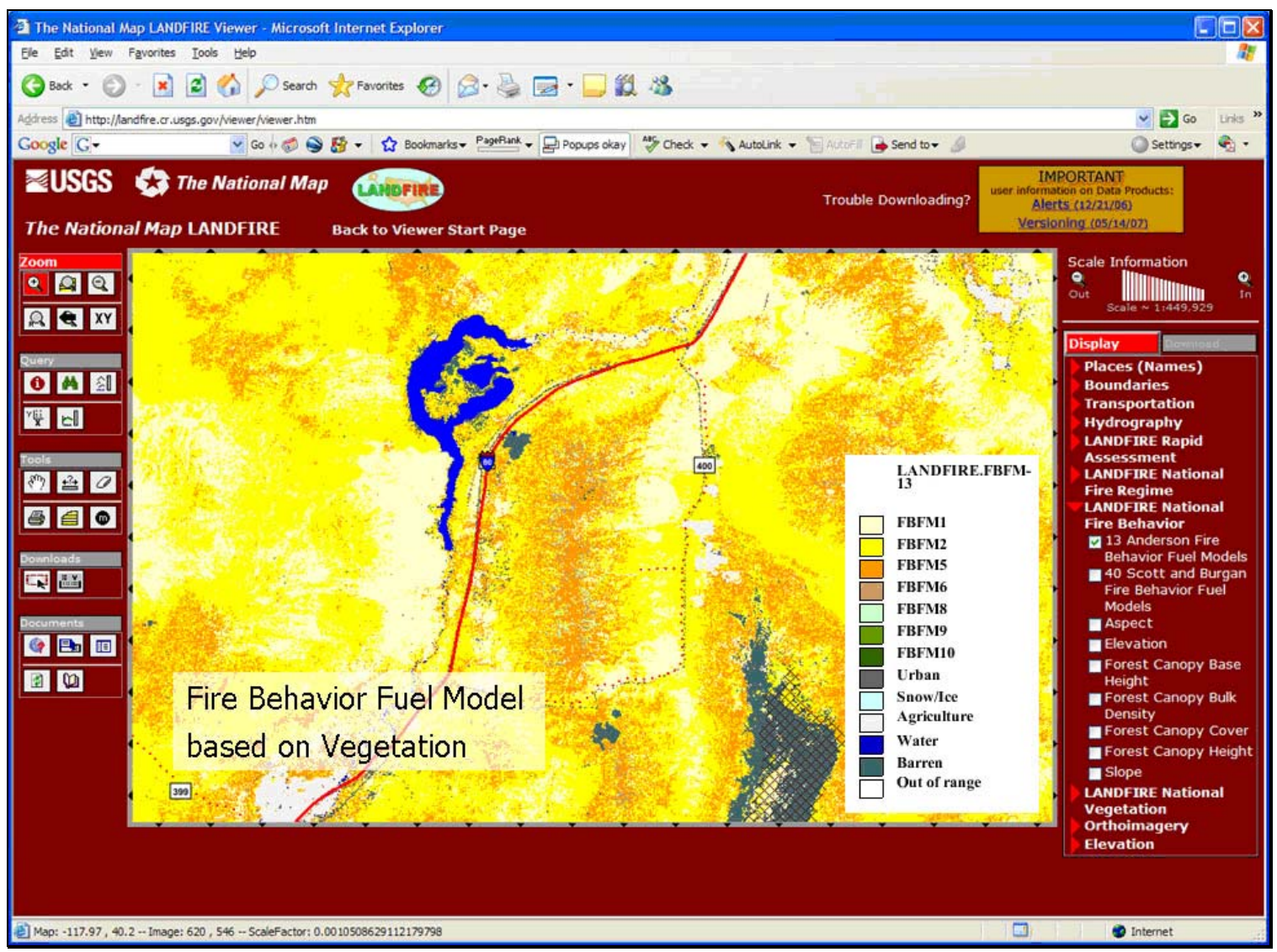

Figure 3-6. Landfire 13 Anderson Fire Behavior Fuel Models Web Map 
Another example is the Fire Regime Groups which shows fire frequency and severity using a vegetation and disturbance dynamics model (see Figure 3-7). This project uses the Fire Regime Group as an indicator of wildfire risk.

- Fire Regime I (0 to 35 year frequency, low to mixed severity)

- Fire Regime II (0 to 35 year frequency, replacement severity)

- $\quad$ Fire Regime III (35 to 200 year frequency, low to mixed severity)

- Fire Regime IV (35 to 200 year frequency, replacement severity)

- Fire Regime V (200+ year frequency, any severity)

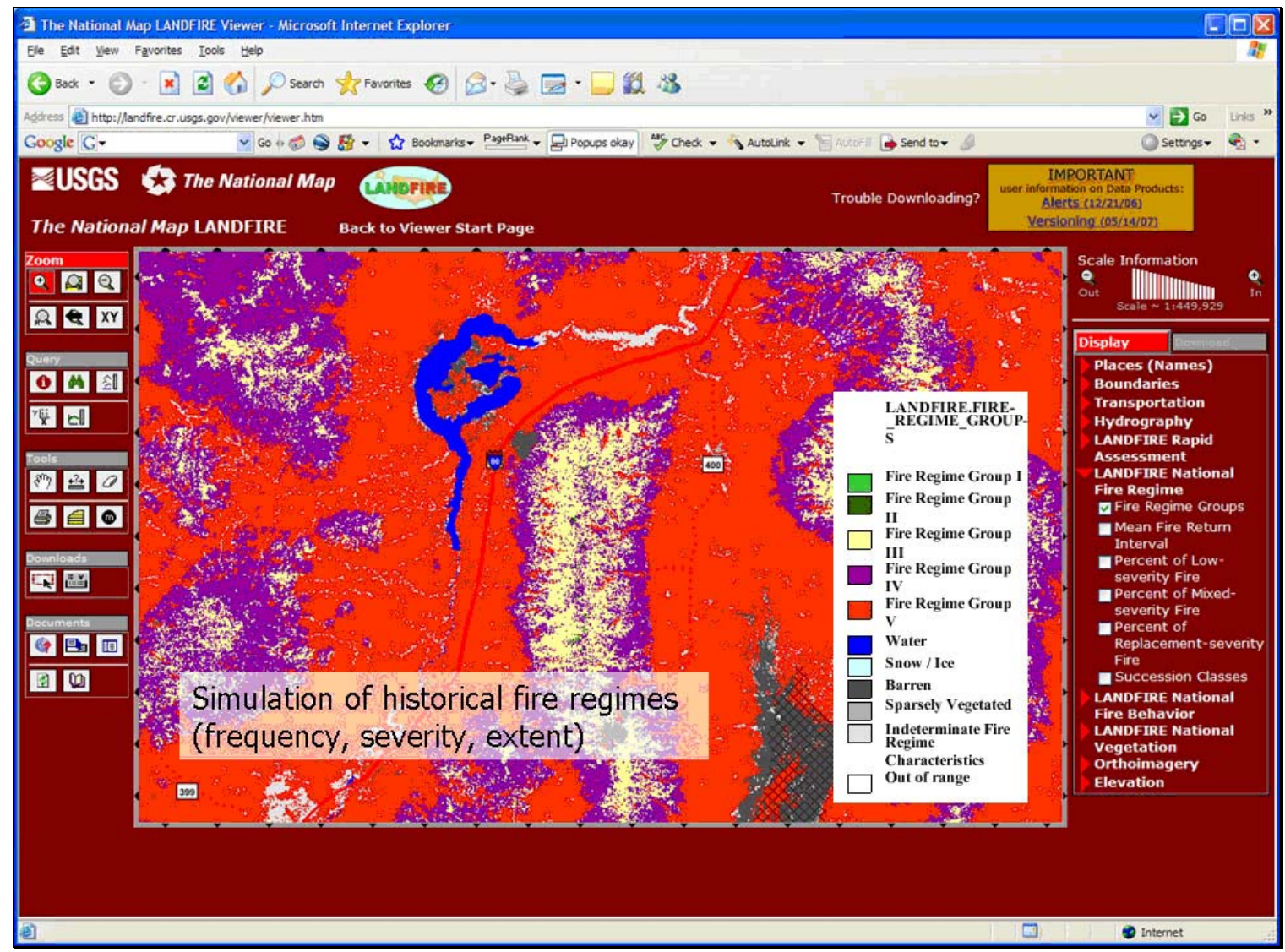

Figure 3-7. Landfire Fire Regime Groups Web Map

Full description of Landfire data products:

http://www.landfire.gov/downloadfile.php?file=LF_Data_Product_Descrip.pdf

\subsubsection{Geographic Coordinate System and Map Projection}

The choice of the geographic coordinate system and map projection system was important for accurate analysis and for proper cartographic representation. Geographic coordinate systems are a spherical representation of places on the earth and map projections are a method for transforming them onto a planar surface. Any geographic coordinate or map projection system unavoidably introduces some combination of distortion in shape, and size, and the proper choice depends on the needs of the project. For geographic datasets to align properly, they must all be in the same geographic 
coordinate system and map projection. Data assembled from disparate sources can be reprojected into a common one, or software may do the same thing by re-projecting "on the fly” without altering the base data.

This project had the added element of obtaining data from external web services which were already in a particular geographic coordinate system and projection. Both the WUI and Landfire data are national in scope; however, the WUI uses North American Datum 1983 and USA Contiguous Albers Equal Area Projection Conic projection with the central meridian in the center of the United States, and the Landfire data uses unprojected World Geographic System 1984 (WGS84). The ArcWeb service data used in this project for a base map were geographic coordinate system WGS84 (un-projected).

The UTM projection is for regional data and because of the smaller spatial extent it can be projected with more accuracy and less overall distortion. Nevada's eastern and western borders are coincident with the eastern and western boundaries of UTM zone $11 \mathrm{~N}$, so the project study site and expansion into the rest of Nevada are well suited to this choice. This project which is focused on Nevada uses WGS84 UTM11 North for locally stored data and uses the ability of ArcGIS Server to project the other web map services "on the fly". It was determined that the lowest layer map service in the web application determines the overall server map projection.

Alternatives for a wider area of the western United States would be Lambert Conic Conformal or Albers Conic Equal Area, but with the central meridian near the center of the region.

\subsection{Web Services - Application}

In ArcGIS Server 9.2 terminology, data and functionality are authored or acquired and then published as a web service. Those web services are then used by applications such as a web map application and are viewed through a web browser, or, alternatively, can be viewed through ArcGIS Explorer or ArcMap. The web service and corresponding application features are shown in Table 3-9.

Table 3-9. Author/Publish Web Services - Application Use

\begin{tabular}{|l|l|}
\hline $\begin{array}{l}\text { Author or Acquire /Publish Web Services } \\
\text { Web Map Services }\end{array}$ & $\begin{array}{l}\text { Application Use (Browser, ArcGIS) } \\
\text { (Data layers) }\end{array}$ \\
\hline Geocode Services & Growser, ArcGIS Explorer, Others) \\
\hline Model Builder Geoprocessing Models & Geoprocessing Tasks (User Interaction) \\
\hline
\end{tabular}

Connections to external web services are made by use of the external web server URL through ArcCatalog or ArcMap (see Figure 3-8). The URL's for the WUI, Landfire, ArcWeb Service Geocoding and base map services are shown in Table 3-10. 


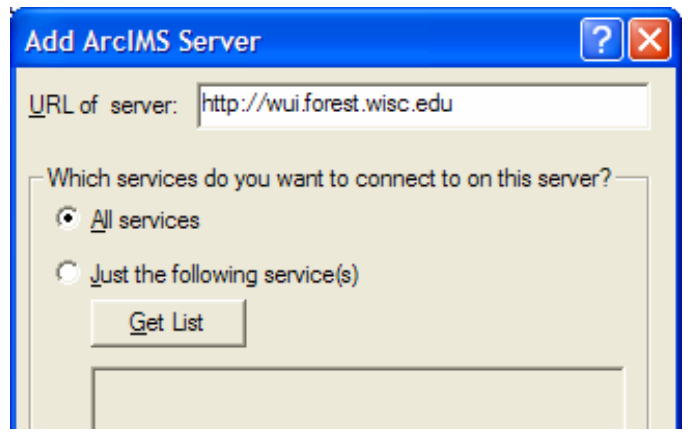

Figure 3-8. Add External Web Service

Table 3-10. External Web Service Uniform Resource Locators (URLs)

Model Data:

Landfire: http://landfire.cr.usgs.gov

The SILVIS Lab at the University of Wisconsin, Madison WUI:

http://wui.forest.wisc.edu/website/wui/index.htm

Background Data:

National Agriculture Imagery Program (NAIP): http://gdw.apfo.usda.gov

ArcWeb Services: http://www.esri.com/software/arcwebservices/index.html

ArcGIS Online: http://arcgisonline.esri.com/

USGS: http://gisdata.usgs.net

\subsection{Performance and Security}

As mentioned earlier, performance is contingent on proper sizing of hardware (processors, memory), network capacity, and choice and configuration of software. Other simple factors used to improve performance are use just the map layers that are necessary to do the job, layer scale dependency, simple web optimized symbolization, and smaller maps. Asynchronous JavaScript and XML (AJAX) provides the ability to refresh only a portion of the web page which requires less data to be transferred, is quicker, and gives a better user experience. Caching is pre-rendering maps at predefined scales which make them faster because the maps are retrieved as static files rather than being generated dynamically. A limitation is the cached image is static and individual layers cannot be turned off and on. This project used few map layers, simple symbols, AJAX and external web map services. Caching would be a consideration for future iterations of the project which cover a larger geographic extent.

The primary means of security in a web environment is the use of a firewall and use of software to screen for computer viruses and other malicious software. There are many configurations possible for a firewall, but the key function is to limit and control interaction between a LAN or individual computer and the Internet to avoid malicious access. Other means of higher security are to use password protection so that only authorized access is possible, and the use of encryption over a secure network that uses hypertext transfer protocol over an encrypted secure socket layer (https). General network 
design, administration and security are often handled by the use of specialized staff or service providers. The project prototype relied on other experts for these services.

\subsection{Web Map Application User Interface}

The primary user interface is the web mapping page accessible by a standard web browser with no special software or plug-in required (see Figure 3-9).

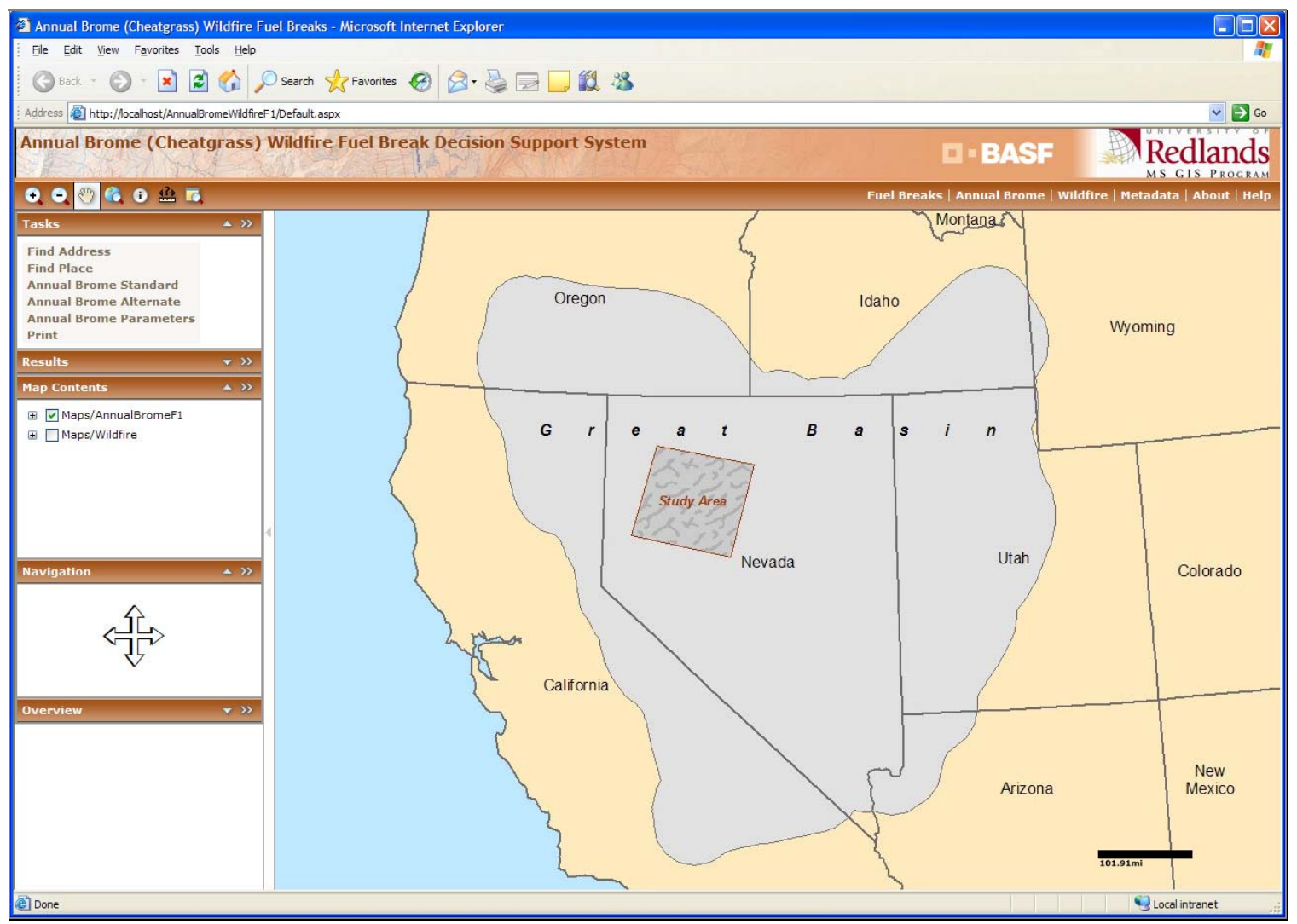

Figure 3-9. Website User Interface 
In the standard web browser interface, a column on the left of the page contains tools for panning, zooming, identifying, measuring as well as a magnification window (see Figure 3-10).

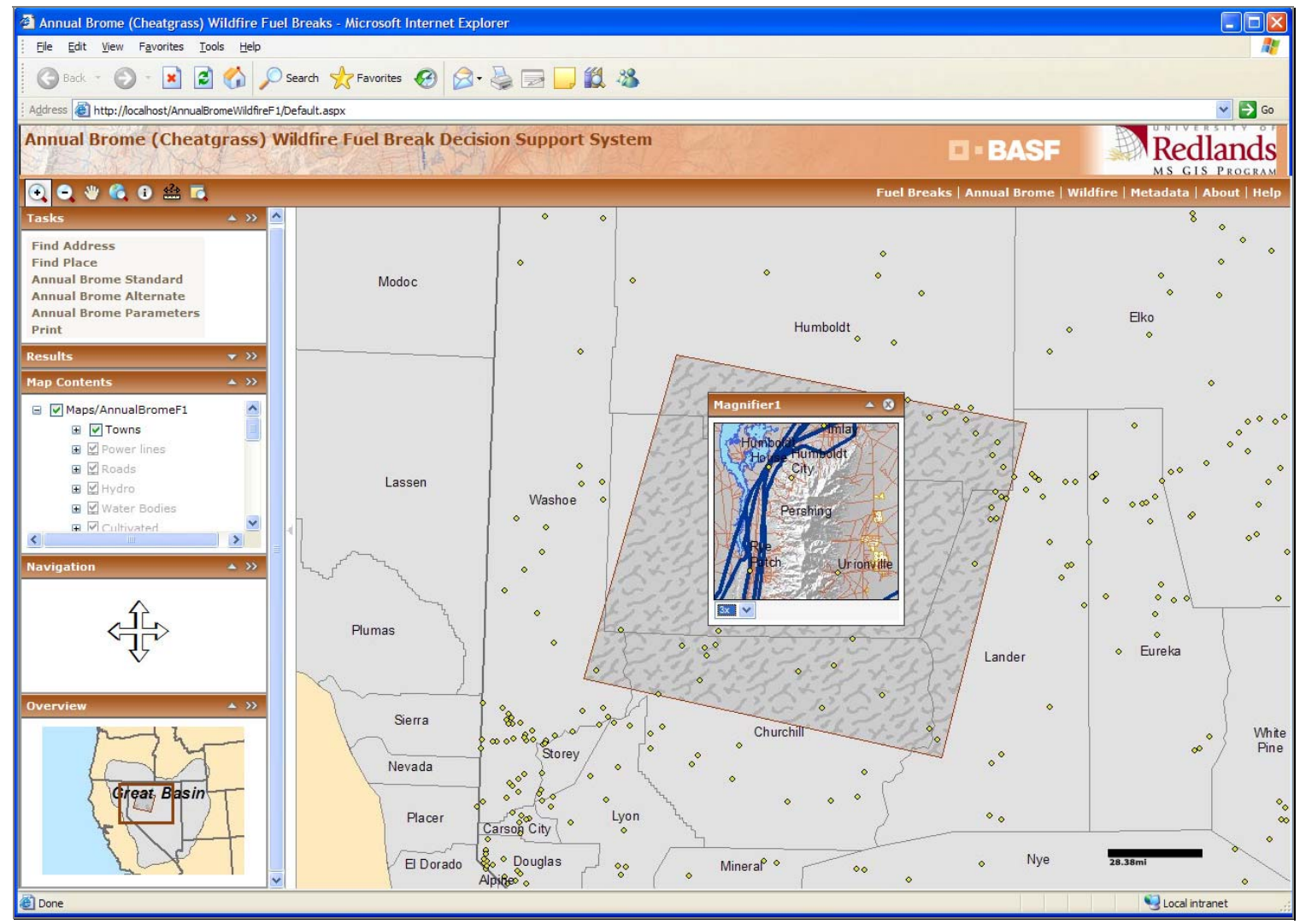

Figure 3-10. Website User Interface Magnifier Window 
There is also a tasks panel, another panel to display geocoding and geoprocessing task results, a table of contents, navigation tools, and an overview map. The table of contents includes a legend and check boxes to toggle layers on and off (see Figure 3-11).

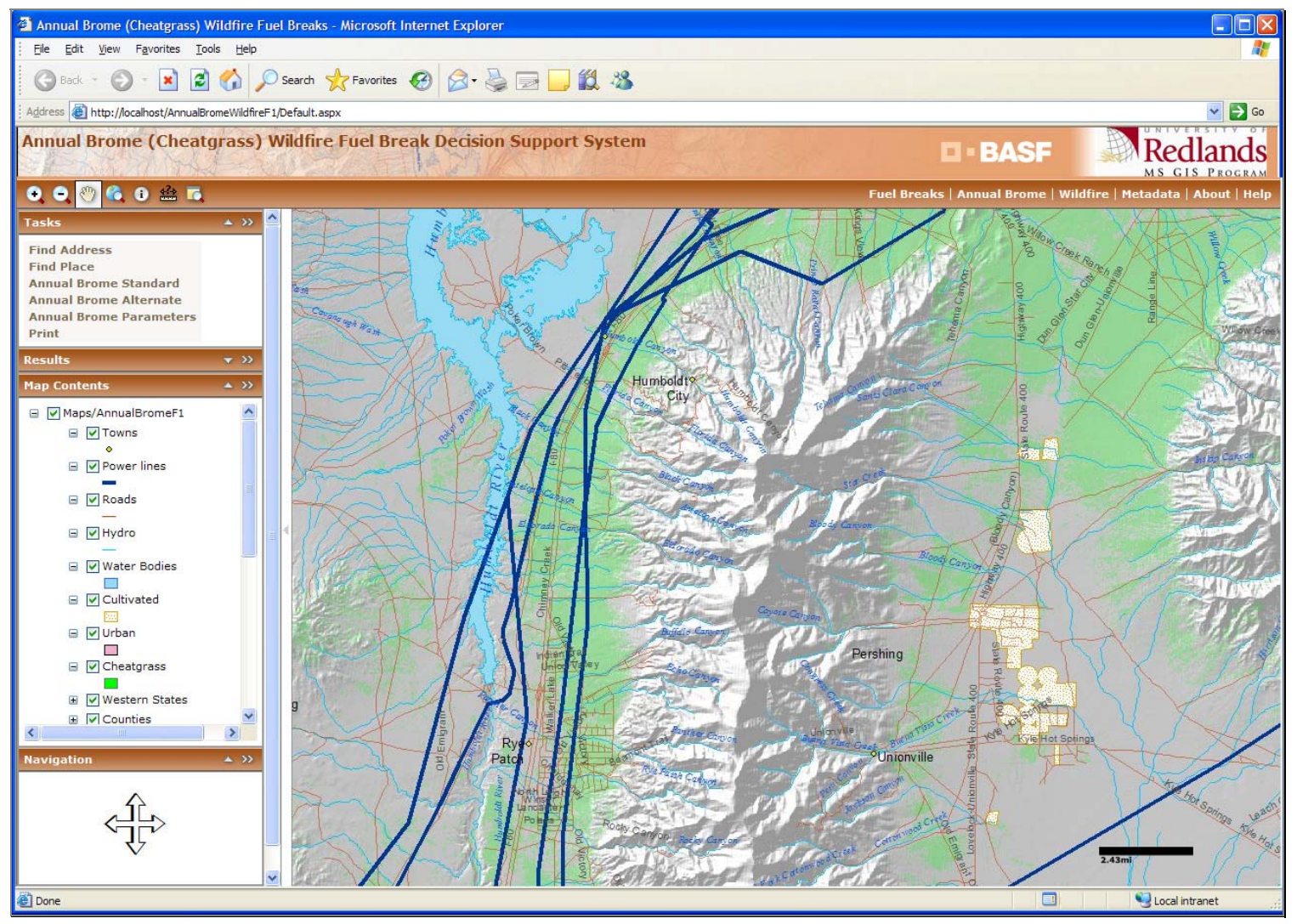

Figure 3-11. Website Model Input Layers, Overview

The majority of the web page is the map area which is to the right of the task bars. Links on the right side of the header give access general information about the intended purpose of the web map analysis, metadata, information on external web map services, and website user manual help. There is a qualifying statement which informs the end user that the analysis is meant to be a decision support tool and any decisions should also rely on local wildfire experts and on-the-ground analysis. 
In addition to the model input data other background layers are available from external web maps services. For example Figure 3-12 shows orthophotography from National Agriculture Imagery Program (NAIP) that is available for much of the United States for free from the USDA (USDA, 2007)

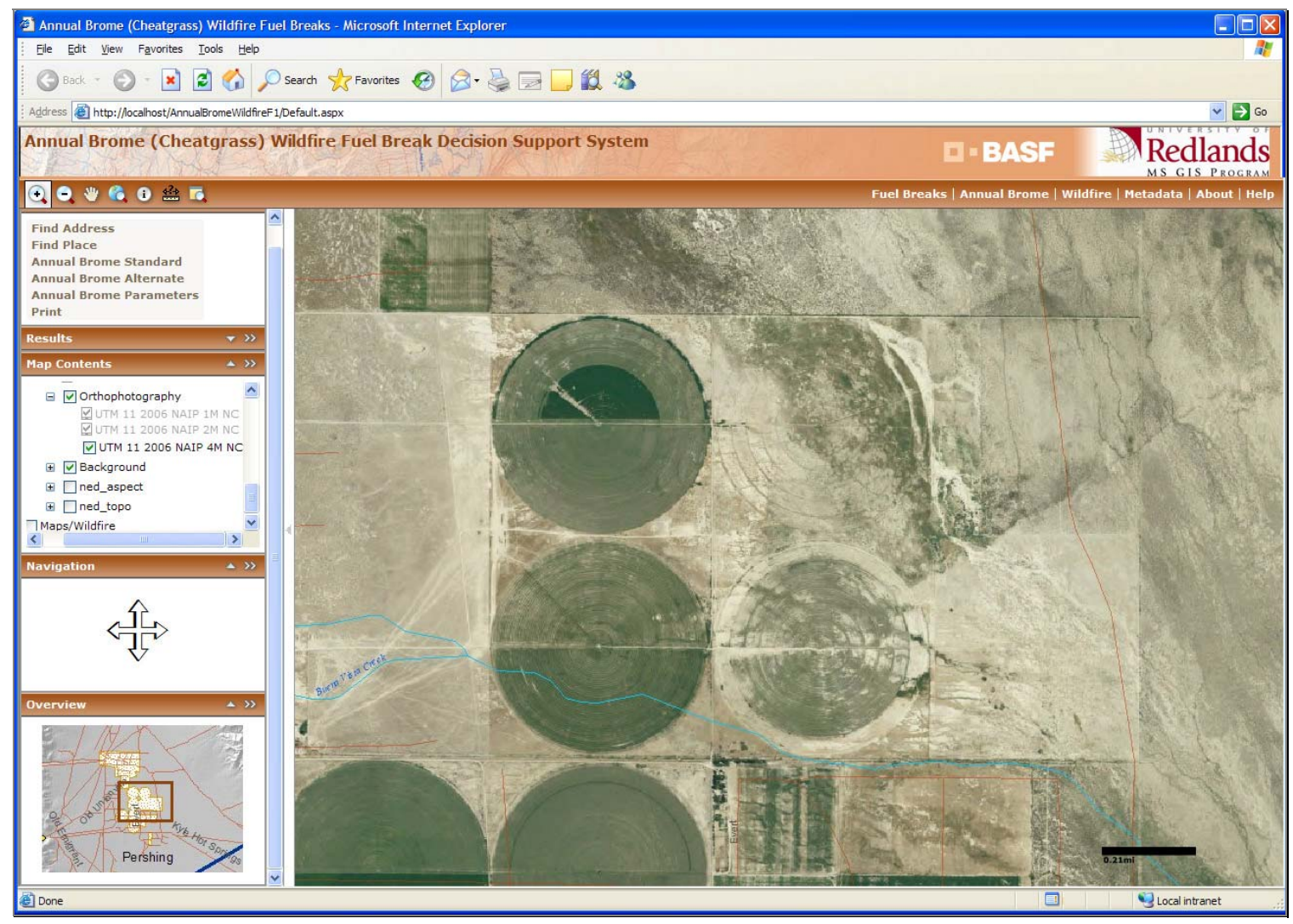

Figure 3-12. National Agriculture Imagery Program (NAIP) Map

There is also a version of the project accessible by ArcGIS Explorer, free downloadable software from ESRI, which features expanded functionality including 3D capability. The output is also available as a web service that can be accessed through the standard ArcGIS desktop user interface.

When the user starts the web application, the data necessary for the project analysis is loaded and the user is able to turn data layers on and off. There are geocode locator and navigation tools to find the area of interest by address, place name, or by using panning and zooming map navigation tools. The area of interest is delineated by screen extent, and by the user drawing a graphic polygon. The annual brome geoprocessing model allows the user to run the model with default values or to enter their own parameter values. In addition to the screen view, the output is available in print layout form.

The website also includes links to non-GIS information about alternatives for fuel break installation such as mechanical or herbicides. 


\section{Methodology}

The web map application allows the user to find an area of interest, use the annual brome geoprocessing model to assess annual brome risk, and use web map services to assess wildfire and wildland urban interface risk. The user assesses the combined risk to determine areas in need of annual brome wildfire fuel breaks.

\subsection{Project Risks}

The project risk areas were fire and weed domain knowledge, technological scope, and client participation. The project relied on research in the domain areas of weed and fire science to provide the accurate predictive parameters. The technological risks were to use new software technology to web-enable the model and perform the geoprocessing on the server. Performance was dependant on proper sizing of hardware and correct configuration of the software. The other major risk was that the end user would be knowledgeable enough about technology, weeds, and wildfire to be able to make use of the tools and results.

\subsection{Geocode}

Geocoding converts an address or place name to a set of coordinates and locates it on earth or a map (Longley, Goodchild, Maguire, \& Rhind, 2005). A geocode tool can be created to use a local dataset or, alternatively, geocode functionality can be obtained as a web service. In the latter case addresses and place names could be located even if none of the addresses or place names data were stored locally. This project will obtained address and place name geocode functionality as an external web service from ESRI ArcWeb Services, a commercial subscription system. ArcWeb services include a number of GIS data services such as data layers, and web mapping tools in addition to geocoding. The subscription is prepaid and charges against the account are made based on number of times the service is accessed. This project took advantage of a free ArcWeb account for students.

The geocode service is added as a task when building the web application from within the web application development framework either from ArcGIS Server manager or Visual Studio (See Appendix A).

\subsection{Web Map}

The web map contains base data layers such as roads, hydrography, political boundaries and landmarks to enable the end user to find an area of interest. Additional layers such as orthophotography and USGS topographic maps can be useful, but a balance must be maintained between the amount of data displayed and the speed of the web application. The web map also contains layers that are used as input in the geoprocessing analysis which are discussed in the next section. The base map location layers could be assembled and stored in a local server database, or obtained as an external web service. There are many choices for external web map services including free ones such as ArcGIS Online, free government services such as United States Geological Survey (USGS), and Farm Service Agency (FSA), and commercial outlets such as ArcWeb services. This project will obtained base map layers as an external web map service from ArcWeb services. 
The map service is added as a layer when building the web application from within the web application development framework either from ArcGIS Server manager or Visual Studio (see Appendix A).

\subsection{Annual Brome}

Bradley and Mustard (2006) found that, “...Cheatgrass was 10\% more likely to be found in elevation ranges from 1400 to $1700 \mathrm{~m} . . ., 6 \%$ more likely on west and northwest facing slopes, and $3 \%$ more likely within hydrographic channels....cheatgrass was $20 \%$ more likely to be found within $3 \mathrm{~km}$ of cultivation, $13 \%$ more likely to be found within $700 \mathrm{~m}$ of a road, and $15 \%$ more likely to be found within $1 \mathrm{~km}$ of a power line. Finally ... cheatgrass was $26 \%$ more likely to be present within $150 \mathrm{~m}$ of areas occupied by cheatgrass in 1973."

The risk parameters are geoprocessed in real time to produce a risk map on the website from a geoprocessing service created from a Model Builder model. The end user chooses the Annual Brome task, uses the polygon tool to delineate the area of interest and enters parameter values or accepts the defaults and then submits the task. The task runs asynchronously, so the user can perform other tasks while the model runs. The user receives feedback on the progress of the task and is notified when the task is completed. The completed task is added to the task results where the user can turn the layer on.

The geoprocessing model built in Model Builder uses the ArcGIS Spatial Analyst tools, Euclidean Distance, Reclassify, Aspect, Extract by Attribute and the Weighted Overlay. The Weighted Overlay tool assesses the relative risk of the annual brome factors. The area of interest spatial extent of the geoprocessing model is delineated by use of an interactive feature set polygon used as a model environmental variable. The Extract by Attribute tool is used to identify raster input factors. The Euclidean distance tool is used to determine distances and the Reclassify tool is used to set the distance parameter values for input factors to the Weighted Overlay tool. The Aspect tool is used to derive aspect values from the Digital Elevation Model and the Reclassify tool is used to set the aspect parameter values. The Reclassify tool is also used to set the elevation parameter values. Each process is discussed in more detail in the sections below.

\subsubsection{Weighted Overlay}

All the inputs are combined in a weighted overlay and each factor is assigned a relative percent value as determined by Bradley and Mustard's research outlined above; however in the weighted overlay tool the percent influence must add up to 100 , so the values are scaled so their total equals 100 . Areas within the parameters are given a value of 9 and everything else is given a value of 1 (see Table 4-1). 
Table 4-1 Annual Brome Weighted Overlay

\begin{tabular}{|l|l|r|r|r|}
\hline \multicolumn{1}{|c|}{ Layer } & \multicolumn{1}{c|}{ Parameter } & Value & Influence & \multicolumn{1}{c|}{ Standardize } \\
\hline Aspect & W \& NW & 9 & $6 \%$ & $6 \%$ \\
\hline Elevation & $1400-1700$ meter & 9 & $10 \%$ & $11 \%$ \\
\hline Hydro & $(60$ meter) & 9 & $3 \%$ & $3 \%$ \\
\hline Roads & 700 meter & 9 & $13 \%$ & $14 \%$ \\
\hline Cultivation & 3000 meter & 9 & $20 \%$ & $22 \%$ \\
\hline Power lines & 1000 meter & 9 & $15 \%$ & $16 \%$ \\
\hline Cheatgrass (Historic) & 150 meter & 9 & $26 \%$ & $28 \%$ \\
\hline Total & & & $\mathbf{9 3} \%$ & $\mathbf{1 0 0 \%}$ \\
\hline
\end{tabular}

Figure 4-1 shows the weighted overlay portion of the annual brome risk geoprocessing Model Builder model.

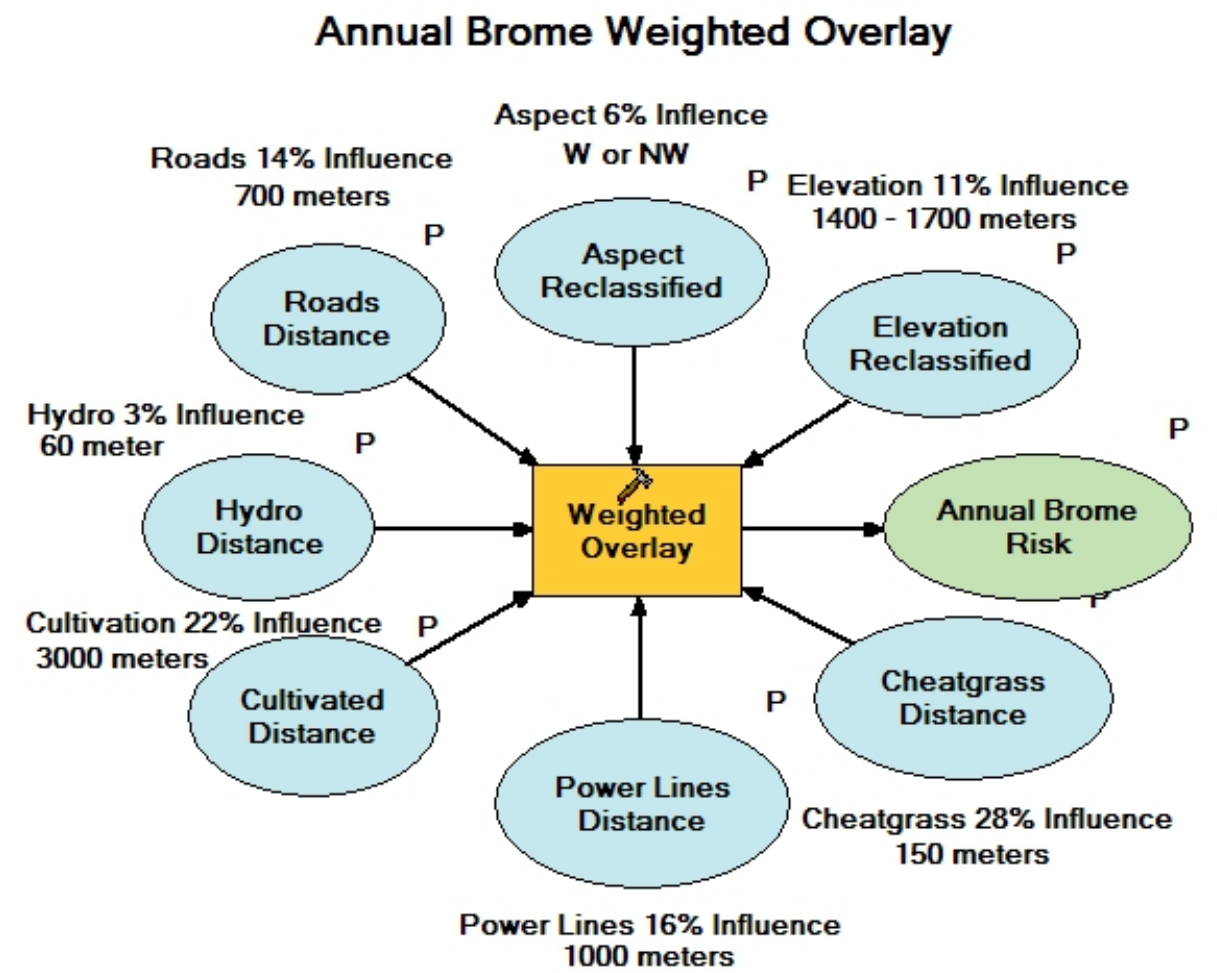

Figure 4-1. Annual Brome Weighted Overlay Model

The inputs to the weighted overlay tool are elevation, aspect and Euclidean distance, so the creation of the aspect data derived from the DEM and Euclidean distance data are preconditions to the weighted overlay. The reclassify tool can be used to set the distance, aspect and elevation parameters before they are input into the weighted overlay to allow the end user to set the parameter values. Euclidean distance and reclassify are discussed in more detail in section 4.4 .3 and the reclassify parameter values are discussed in section 4.4.4. 


\subsubsection{Spatial Extent}

In Model Builder a feature set polygon variable was created in the model, set to be equal to the extent, and made a model parameter. When the user runs the model they are prompted to create a polygon to delineate the area of interest which limits the geoprocessing to that extent. Figure 4-2 demonstrates the use of feature set as a variable parameter to represent extent. Note the input factors shown in Figure 4-3 are now encapsulated in the Weighted Overlay Table input.

\section{Annual Brome Weighted Overlay - Extent}

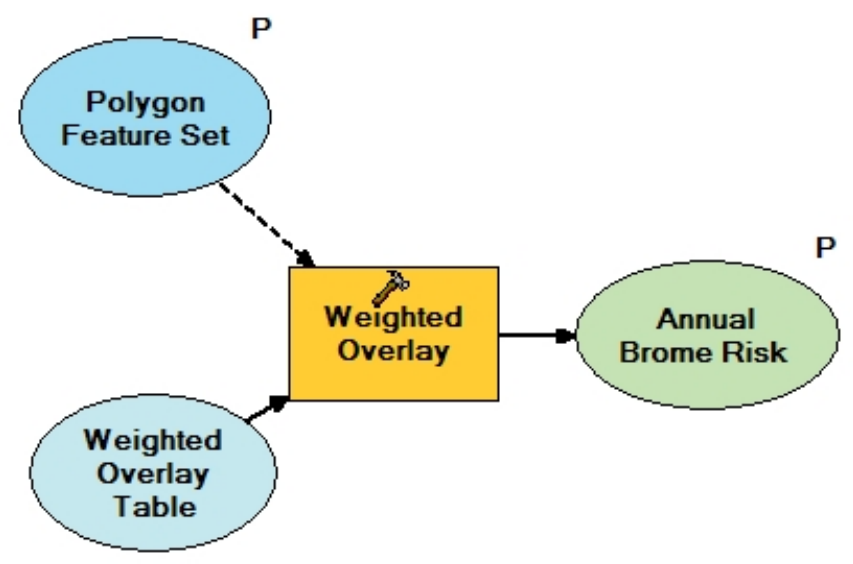

Figure 4-2. Annual Brome Model Delineate Area of Interest

\subsubsection{Euclidean Distance and Reclassify}

The Euclidean Distance tool determines distances from historic cheatgrass, hydrography, cultivation, road, and power line inputs. Figure 4-3 shows an example of the Euclidean Distance tool with streams as input. Output direction is a standard output of Euclidean Distance, but it is not used in this model. The distances are then reclassified to parameter distance values with the Reclassify tool. Note, in this example, the reclassification table has been made a parameter and the value is exposed to modification by the end user.

\section{Euclidean Distance and Reclassify $P$}

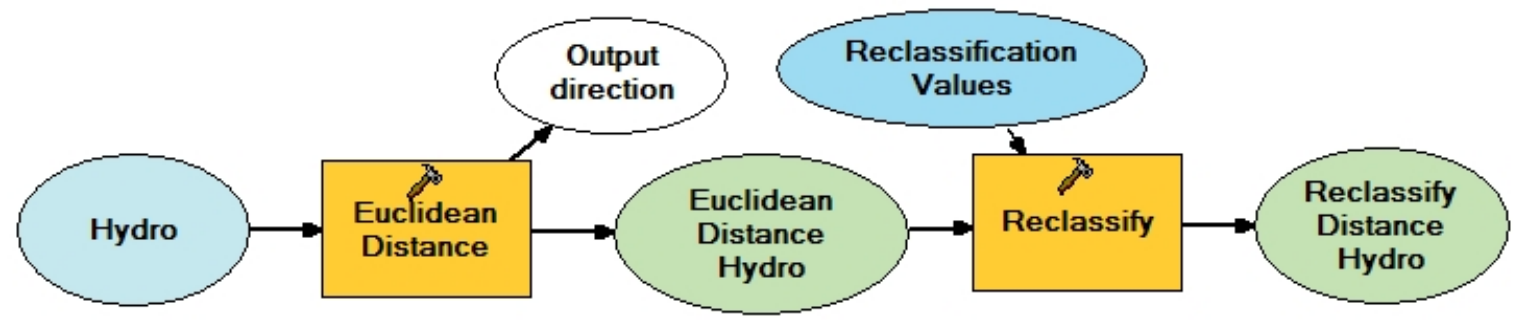

Figure 4-3. Euclidean Distance Reclassify Model

The elevation and aspect are also reclassified to parameter values aspect west and northwest, elevation 1400 - 1700 meters with the Reclassify tool. The model is 
geoprocessed "on the fly" on the website and the reclassify parameters are exposed to the end user to adjust for local conditions. The reclass could be done directly in the Weighted Overlay tool, but the additional Reclassify step allows the end user to be able to change the reclass parameter values. The distance, aspect, or elevation parameters could have their values exposed to the end user for adjustment depending on their needs.

For raster input into the Euclidean Distance tool, a selection must first be made to represent the geographic phenomena in question. Because raster data is continuous, simply finding the Euclidean Distance of a raster dataset will generate distances from the extent of the dataset. For example, the historic cheatgrass raster for the study area has coverage for the entire area with cell values of one where cheatgrass is present and zero where it is not. So the historic cheatgrass raster must first be extracted by attribute value of one to represent historic cheatgrass before it is input into the Euclidean Distance tool (see Figure 4-4).

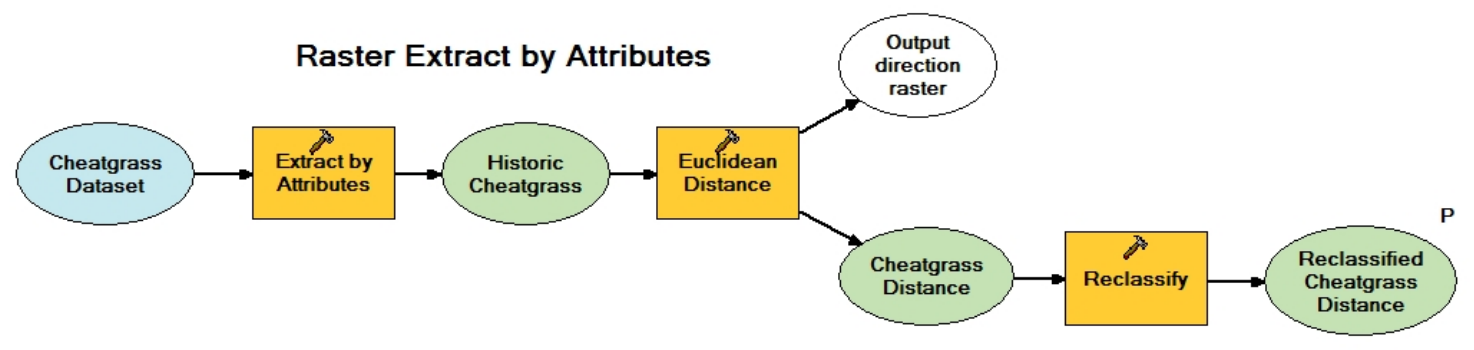

Figure 4-4. Raster Extract by Attributes

\subsubsection{Reclassify Parameter Values}

As outlined above, the parameters for distance, elevation, and aspect are categorized as either inside or outside specific ranges of values, creating abrupt boundaries at the specific values, rather than graduated changes which would be expected in nature. The weighted overlay allows for changing values gradually for aspect, elevation and distance which may more closely resemble change in nature.

For example, in the model the distance from power lines is valued 9 for $0-1000$ meters and 1 for all distances greater than 1000 meters (see Standard Schema Table 4 -2). An alternative would be to have a gradual tapering from 9 to 1 over a range of distances. Bradley and Mustard's data show the decrease in percent influence over distance and these values can be reclassified by rescaling the percent influence values 0 to 15 into integers from 1 - 9 (see Alternative Schema Table 4-2). Figure 4-5 shows a graphic representation of the standard and alternate reclassification schemas for power lines. Similar alternate reclassification schemas could be made for cheatgrass, cultivation, roads, elevation, aspect and hydro input factors (see Tables 4-3 -4-8). 
Table 4-2. Power line Reclassification

\begin{tabular}{|r|c|c|c|c|}
\hline $\begin{array}{c}\text { Distance From } \\
\text { (meters) }\end{array}$ & $\begin{array}{c}\text { Distance To } \\
\text { (meters) }\end{array}$ & $\begin{array}{c}\text { Percent } \\
\text { Influence* }\end{array}$ & $\begin{array}{c}\text { Standard } \\
\text { Schema }\end{array}$ & $\begin{array}{c}\text { Alternative Graduated } \\
\text { Schema** }\end{array}$ \\
\hline 0 & 780 & 15 & 9 & 9 \\
\hline 780 & 1080 & 13 & 9 & 8 \\
\hline 1080 & 1500 & 11 & 1 & 7 \\
\hline 1500 & 1950 & 9 & 1 & 5 \\
\hline 1950 & 2400 & 6 & 1 & 4 \\
\hline 2400 & 3000 & 3 & 1 & 2 \\
\hline 3000 & $>3000$ & 0 & 1 & 1 \\
\hline
\end{tabular}

*Bradley and Mustard (2006)

${ }^{*}$ Calculated by rescaling Percent Influence values 0 - 15 into integers 1 - 9

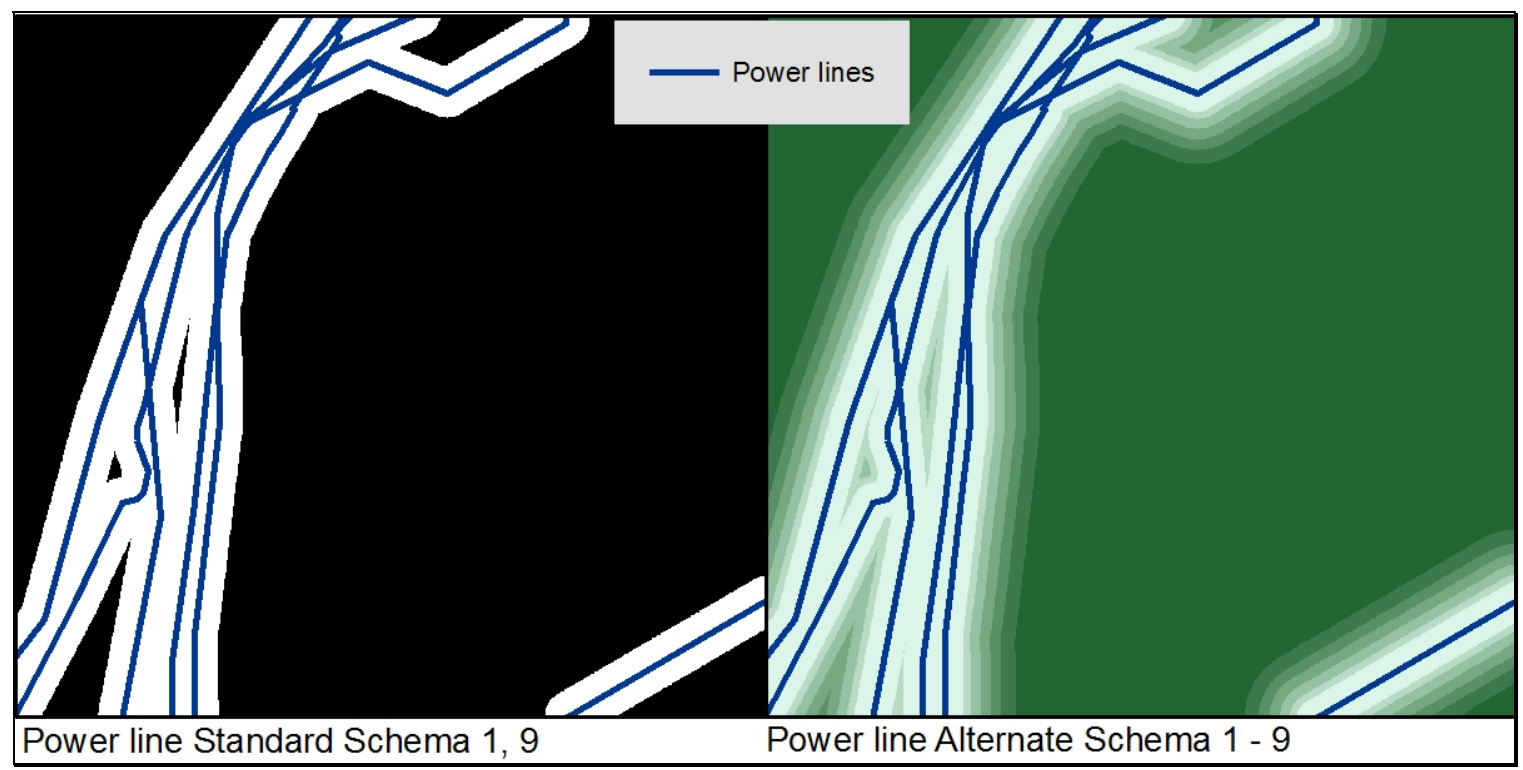

Figure 4-5. Power line Reclassifications

Table 4-3. Cheatgrass Distance Reclassification

\begin{tabular}{|r|r|c|c|c|}
\hline \multicolumn{1}{|c|}{$\begin{array}{c}\text { Distance From } \\
\text { (meters) }\end{array}$} & $\begin{array}{c}\text { Distance To } \\
\text { (meters) }\end{array}$ & $\begin{array}{c}\text { Percent } \\
\text { Influence* }\end{array}$ & $\begin{array}{c}\text { Standard } \\
\text { Schema }\end{array}$ & $\begin{array}{c}\text { Alternative Graduated } \\
\text { Schema** }\end{array}$ \\
\hline 0 & 30 & 26 & 9 & 9 \\
\hline 30 & 60 & 16 & 9 & 6 \\
\hline 60 & 90 & 9 & 9 & 3 \\
\hline 90 & 120 & 4 & 9 & 1 \\
\hline 120 & 150 & 1 & 9 & 1 \\
\hline 150 & $>150$ & 0 & 1 & 1 \\
\hline
\end{tabular}

*Bradley and Mustard (2006)

${ }^{\star *}$ Calculated by rescaling Percent Influence values 0 - 26 into integers 1 - 9 
Table 4-4. Cultivation Distance Reclassification

\begin{tabular}{|r|c|c|c|c|}
\hline $\begin{array}{c}\text { Distance From } \\
\text { (meters) }\end{array}$ & $\begin{array}{c}\text { Distance To } \\
\text { (meters) }\end{array}$ & $\begin{array}{c}\text { Percent } \\
\text { Influence* }\end{array}$ & $\begin{array}{c}\text { Standard } \\
\text { Schema }\end{array}$ & $\begin{array}{c}\text { Alternative Graduated } \\
\text { Schema }\end{array}$ \\
\hline 0 & 3300 & 20 & 9 & 9 \\
\hline 3300 & 4200 & 17 & 1 & 8 \\
\hline 4200 & 5400 & 12 & 1 & 5 \\
\hline 5400 & 6600 & 6 & 1 & 3 \\
\hline 6600 & 7800 & 3 & 1 & 1 \\
\hline 7800 & $>7800$ & 0 & 1 & 1 \\
\hline
\end{tabular}

*Bradley and Mustard (2006)

${ }^{\star *}$ Calculated by rescaling Percent Influence values 0 - 20 into integers 1 - 9

Table 4-5. Roads Distance Reclassification

\begin{tabular}{|r|r|c|c|c|}
\hline $\begin{array}{c}\text { Distance From } \\
\text { (meters) }\end{array}$ & \multicolumn{1}{c|}{$\begin{array}{c}\text { Distance To } \\
\text { (meters) }\end{array}$} & $\begin{array}{c}\text { Percent } \\
\text { Influence* }\end{array}$ & $\begin{array}{c}\text { Standard } \\
\text { Schema }\end{array}$ & $\begin{array}{c}\text { Alternative Graduated } \\
\text { Schema** }\end{array}$ \\
\hline 0 & 60 & 13 & 9 & 9 \\
\hline 60 & 120 & 12 & 9 & 8 \\
\hline 120 & 180 & 11 & 9 & 8 \\
\hline 180 & 240 & 9 & 9 & 6 \\
\hline 240 & 300 & 8 & 9 & 4 \\
\hline 300 & 360 & 6 & 9 & 3 \\
\hline 360 & 420 & 5 & 9 & 3 \\
\hline 420 & 480 & 4 & 9 & 2 \\
\hline 540 & 540 & 3 & 9 & 1 \\
\hline 600 & 600 & 2 & 9 & 1 \\
\hline 660 & 660 & 1 & 9 & 1 \\
\hline 720 & 720 & 0 & 1 & 1 \\
\hline
\end{tabular}

*Bradley and Mustard (2006)

${ }^{\star *}$ Calculated by rescaling Percent Influence values 0 - 13 into integers 1 - 9

Table 4-6. Hydro Distance Reclassification

\begin{tabular}{|r|r|c|c|c|}
\hline $\begin{array}{c}\text { Distance From } \\
\text { (meters) }\end{array}$ & $\begin{array}{c}\text { Distance To } \\
\text { (meters) }\end{array}$ & $\begin{array}{c}\text { Percent } \\
\text { Influence* }\end{array}$ & $\begin{array}{c}\text { Standard } \\
\text { Schema }\end{array}$ & $\begin{array}{c}\text { Alternative Graduated } \\
\text { Schema** }\end{array}$ \\
\hline 0 & 60 & 3 & 9 & 9 \\
\hline 60 & 120 & 2 & 1 & 6 \\
\hline 120 & 180 & 1 & 1 & 3 \\
\hline 180 & $>180$ & 0 & 1 & 1 \\
\hline
\end{tabular}

*Bradley and Mustard (2006)

**Calculated by rescaling Percent Influence values 0 - 3 into integers 1 - 9 
Table 4-7. Elevation Reclassification

\begin{tabular}{|c|c|c|c|c|}
\hline $\begin{array}{l}\text { Elevation From } \\
\text { (meters) }\end{array}$ & $\begin{array}{l}\text { Elevation To } \\
\text { (meters) }\end{array}$ & $\begin{array}{c}\text { Percent } \\
\text { Influence* }\end{array}$ & $\begin{array}{l}\text { Standard } \\
\text { Schema }\end{array}$ & $\begin{array}{c}\text { Alternative Graduated } \\
\text { Schema** }\end{array}$ \\
\hline 0 & 1120 & 1 & 1 & 1 \\
\hline 1120 & 1310 & 6 & 1 & 5 \\
\hline 1310 & 1330 & 10 & 1 & 9 \\
\hline 1330 & 1350 & 8 & 1 & 7 \\
\hline 1350 & 1370 & 10 & 1 & 9 \\
\hline 1370 & 1390 & 10 & 1 & 9 \\
\hline 1390 & 1410 & 7 & 9 & 6 \\
\hline 1410 & 1430 & 4 & 9 & 4 \\
\hline 1430 & 1450 & 10 & 9 & 9 \\
\hline 1450 & 1470 & 10 & 9 & 9 \\
\hline 1470 & 1490 & 10 & 9 & 9 \\
\hline 1490 & 1520 & 10 & 9 & 9 \\
\hline 1520 & 1550 & 10 & 9 & 9 \\
\hline 1550 & 1580 & 5 & 9 & 5 \\
\hline 1580 & 1600 & 8 & 9 & 7 \\
\hline 1600 & 1630 & 7 & 9 & 6 \\
\hline 1630 & 1670 & 2 & 9 & 2 \\
\hline 1670 & 1710 & 1 & 9 & 1 \\
\hline 1710 & 1760 & 1 & 1 & 1 \\
\hline 1760 & 2800 & 1 & 1 & 1 \\
\hline 2800 & $>2800$ & 0 & 1 & 1 \\
\hline
\end{tabular}

*Bradley and Mustard (2006)

${ }^{\star *}$ Calculated by rescaling Percent Influence values 0 - 10 into integers 1 - 9

Table 4-8. Aspect Reclassification

\begin{tabular}{|r|c|c|c|}
\hline \multicolumn{1}{|c|}{ Aspect } & Percent Influence & $\begin{array}{c}\text { Standard } \\
\text { Schema }\end{array}$ & $\begin{array}{c}\text { Alternative Graduated } \\
\text { Schema** }\end{array}$ \\
\hline Flat & 1 & 1 & 1 \\
\hline North & 1 & 1 & 1 \\
\hline Northeast & 1 & 1 & 1 \\
\hline East & 1 & 1 & 1 \\
\hline Southeast & 1 & 1 & 1 \\
\hline South & 1 & 1 & 1 \\
\hline Southwest & 1 & 1 & 1 \\
\hline West & 6 & 9 & 9 \\
\hline
\end{tabular}

*Bradley and Mustard (2006)

${ }^{\star *}$ Calculated by rescaling Percent Influence values 0 - 7 into integers 1 - 9 
Furthermore the website exposes the parameters to the end user so changes like these can be made. However, an important question is, what progression of parameter values best represents reality. Choices should be based on sound scientific theories and/or evidence collected on the ground.

\subsubsection{Annual Brome Habitat Model}

Figure 4-6 shows the full annual brome habitat risk model with inputs, the feature set delineate area of interest polygon, the Extract by Attribute tool, the Euclidean distance tool, the Reclassify tool and the Weighted Overlay tool.

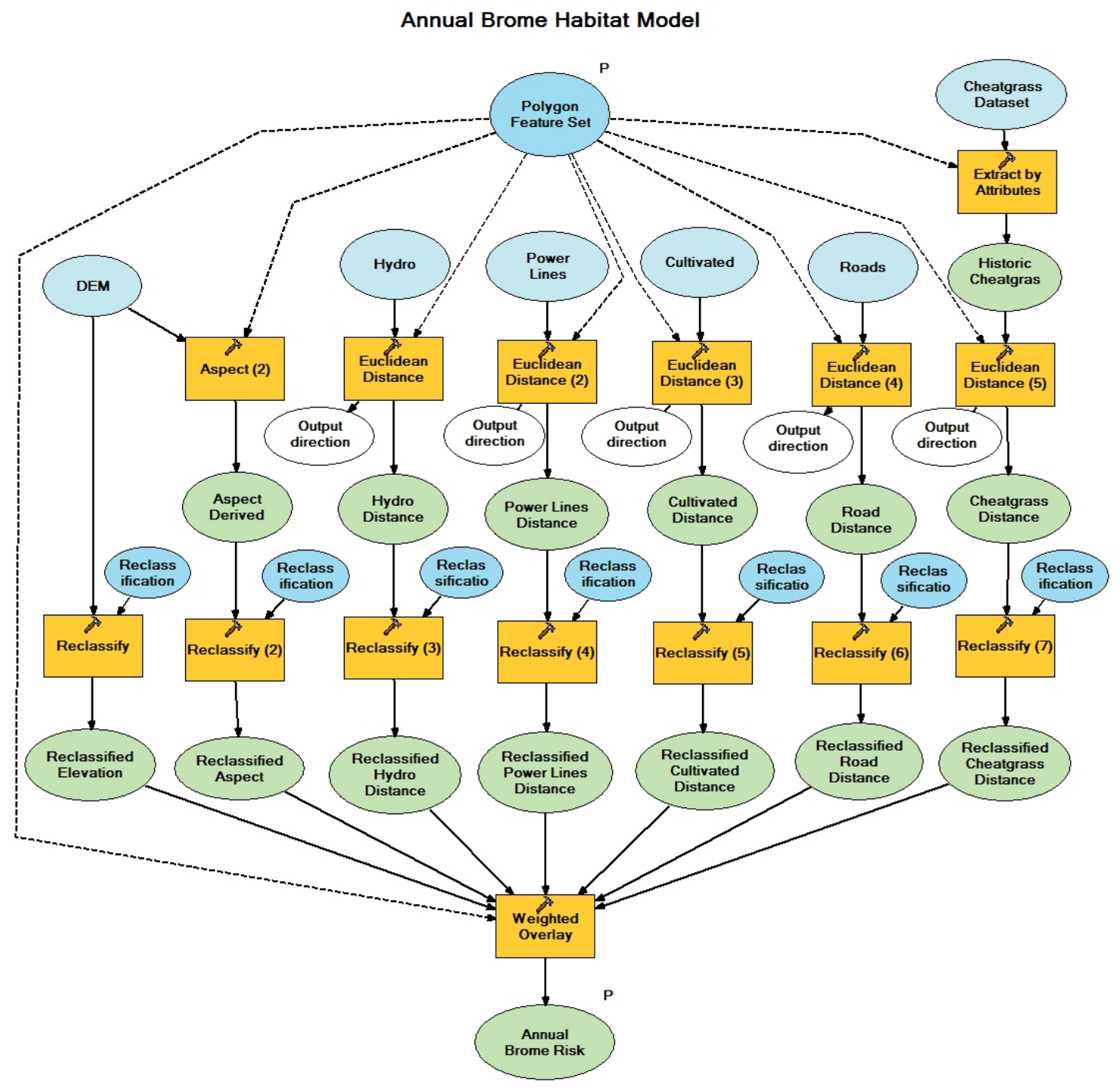

Figure 4-6. Annual Brome Habitat Risk Model

The full model above is expected to be run on parcel size data, and only takes a few minutes to run. By contrast, it takes about 10 minutes to run for the whole prototype study area, which is a little smaller than a Landsat scene. If the expectation is that such large areas are going to be regularly analyzed, then an alternative to reduce processing 
time would be to preprocess the Euclidean distance data for all the inputs and store the output in a local database. The disadvantage to this approach is that as inputs are updated, the Euclidean distance data would need to be updated, and it could require considerable data storage.

It is important to note that there are caveats to the use of a Model Builder model as a geoprocessing service. There are fewer data types supported as parameters (10 versus 80 ) than in regular ArcGIS desktop. ArcGIS Server Object Container (ArcSOC) must have permissions to the model directory. It is better to use relative or UNC directory paths and use the variable \%Scratchworkspace\% for the scratch workspace environment to make it easier to move service from development environment to deployment. Output must be configured to the correct server directory. Output from one model is not automatically available to another model, as in ArcGIS desktop, because each output is written to a unique job directory on the server. This is necessary because several users may be using the website concurrently and this prevents overwriting the other users' output. Access to previous model output must be done programmatically. If these limitations are not respected the model can still be published, but it will not perform correctly on ArcGIS Server.

The process to create a web-enabled geoprocessing task is to create the geoprocessing model, publish it on ArcGIS Server as a web service and use the task in a website application. The model is created in ArcGIS Model Builder or with a script. The model can be added to a map MXD table of contents as a tool layer where the output is symbolized as it will appear in the web application. The model is published from ArcGIS Server Manager, or ArcCatalog, as a geoprocessing service, as a stand alone toolbox, or as a tool layer in a map MXD. In this project, the geoprocessing model was created in Model Builder, and published from ArcCatalog as a tool layer in a map MXD that also included the model input data.

Once published, the geoprocessing service is available as a service from ArcGIS Server that can be added as a task to a web application from within the web application development framework either from ArcGIS Server Manager or Visual Studio (see Appendix A).

\subsubsection{Modify Parameter Values}

The annual brome model, as shown in Figure 4-5, provides a static set of parameters. To modify the parameters, the website developer could update the model and republish the geoprocessing service. This would be a good way to update default parameters based on new research results. The parameter values can also be exposed for modification by the end user, which allows the client to input their local expert knowledge into the process. Many input and environmental variables can be made into user determined parameters; however, ArcGIS Server supports only 10 parameter data types versus 80 in ArcGIS (see Table 4-9). One example of the use of a variable parameter we have already seen is the use of a feature set polygon to set the spatial extent environmental variable. 
Table 4-9. ArcGIS Server Supported Parameter Data Types

Feature Set

Record Set

Raster

String

File

Double

Long

Date

Boolean

Linear Unit

The reclassify values discussed in section 4.4 .4 can be made into variables accessible to the client. For example, if it was determined for a particular area that different elevation, aspect, or distance to historic cheatgrass, cultivation, power lines, or hydrologic channels should be used, then those values could be changed by the user at the website. In Model Builder, all that is necessary to change the reclassification values for distance to power lines, for instance, is to make the reclassification values a variable parameter. When the Model Builder model is run the distance reclassification values are accessible through a dialog box. However, in ArcGIS Server many variable parameters, including reclass, cannot be published and made available through a geoprocessing service. So it is necessary to choose another tool that has a variable parameter that can still be accessed when it becomes a geoprocessing service.

The workaround, in this case, is to use Reclass by Table in place of the Reclassify tool, and make the input remap table a variable parameter. The remap table does not work in ArcGIS Server either; however, it can be converted to a Record Set data type that is compatible with ArcGIS Server. The Record Set variable must be set to the schema of another dataset. The Reclassify tool reclassification table has the needed schema and can be saved as an INFO table to use as the Record Set schema. A DBF table can also be used to set the schema. Figure 4.7 shows the use of Reclass by Table and Record Set variable parameter to set the distance ranges and reclassification values for power lines Euclidean distance. 


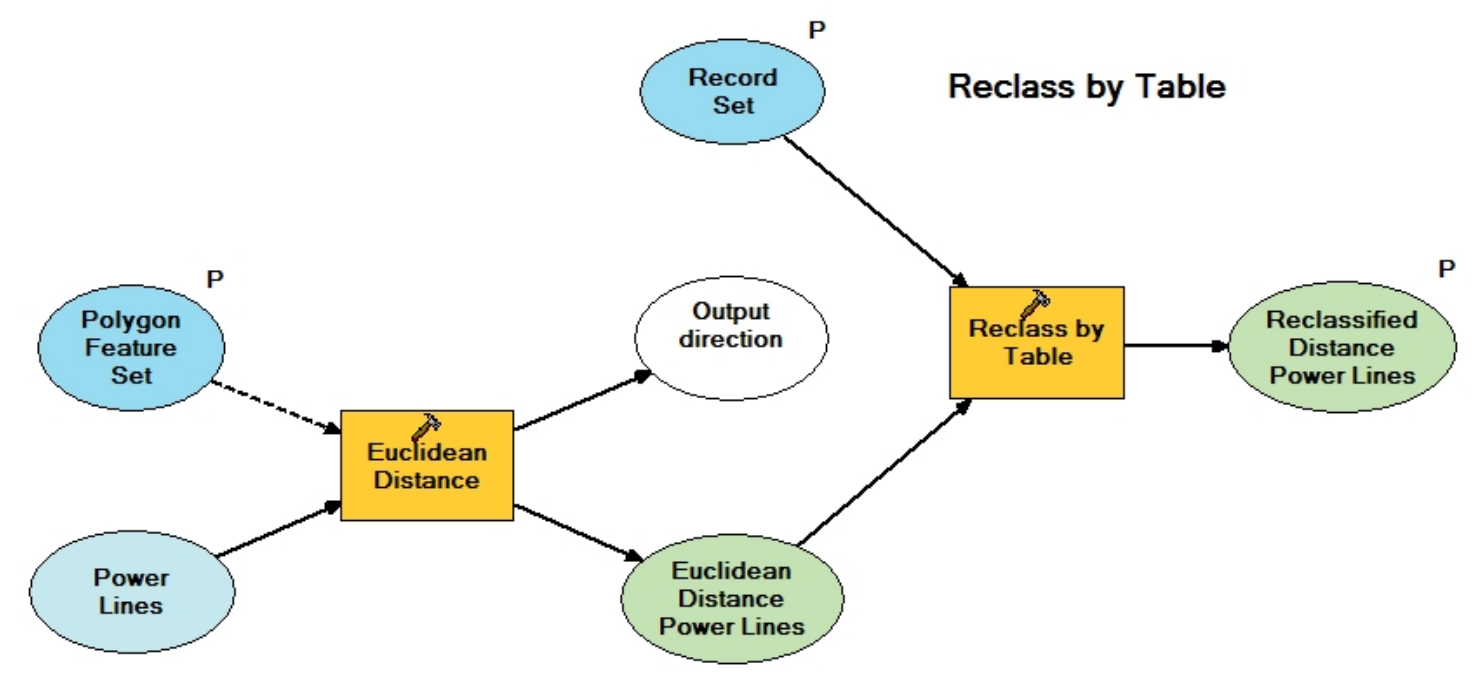

Figure 4-7. Reclass by Table

\subsection{Wildland Urban Interface}

The wildland urban interface (WUI) is defined as an area in which people have expanded development into wildlands (rangeland, forestland, and mixtures), a practice which fragments habitat, increases introduction of invasive plants, and subjects them to increased wildfire danger. The University of Wisconsin, at Madison, Forestry Department's Spatial Analysis for Spatial Analysis for Conservation and Sustainability (SILVIS) Laboratory conducted a spatial analysis of the WUI and published the results on the Internet available through their Internet mapping website as well as a Web Map Service (University of Wisconsin, 2006). This project will use the WUI as an indicator of wildfire risk.

The SILVIS Lab WUI definition uses a formula with a combination of population density and vegetation density. For a population density of a minimum 1 house per 40 acres within a census block, and vegetation cover greater than $50 \%$ within a census block, it is categorized as the intermix area; if the surrounding area within 2.4 kilometers (the distance a firebrand can travel) has greater than $75 \%$ vegetation in an area minimum size greater 5 square kilometers area (to rule out parks), it is categorized as an interface area. Other analysis categories include Non-WUI vegetated and non-vegetated or agricultural. Census housing data (2000) is used to determine population density and USGS National Land Cover Dataset derived from 30 meter satellite imagery (1992/92) to assess vegetation (Radeloff, Hammer, Stewart, Holcomb, \& McKerefry, 2005). Limitations of this data are that it is static and it does not change over time and census data generalizes population data over census areas.

Accessing The SILVIS Lab WUI analysis as a web service also makes use of the methodology and logic underlying the data for the intermix and interface areas as shown by the definitions as queries in Table 4-10. This saves the need to acquire census population and land cover data, the generation of population and vegetation densities and creation of a spatial intersection between those two areas. Another advantage is the 
results as a web service is they are already symbolized, have a legend and accompanying base layers. A disadvantage is the data cannot be used as input to a geoprocessing model.

Table 4-10. WUI Criteria

Intermix $=$ population density $>1$ house $/ 40$ acres AND vegetation density $>50 \%$ (census block)

Interface $=$ population density $>1$ house $/ 40$ acres AND vegetation density $>75 \%$ within $2.4 \mathrm{~km}\left(>5 \mathrm{~km}^{\wedge} 2\right)$

\subsubsection{WUI Web Service}

The map service is added as a layer to the MXD in ArcMap by adding a new ArcIMS connection using The SILVIS Lab WUI (see Figure 4-8). Alternatively, the web service could be added to the web application from within the web application development framework either from ArcGIS Server Manager or Visual Studio.

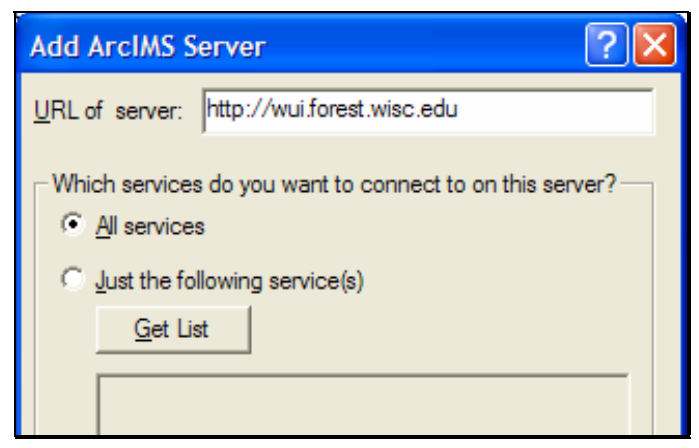

Figure 4-8. Add The SILVIS Lab WUI Web Service

\subsection{Landfire}

The goal of the LANDFIRE Project, funded by the United States Department of Agriculture Forest Service and the United States Department of Interior, is to "develop the methods, tools, and protocols for producing consistent and comprehensive digital maps of current vegetation composition and structure, wildland fuels, historical fire regimes, and fire regime condition class (FRCC) to be applied across the entire United States as a 30-meter spatial resolution...for developing predictive landscape models" to support fire and land managers fire management decisions (Rollins \& Frame, 2006).

Model parameters include historical vegetation, current vegetation, landscape fire succession, weather, satellite data, canopy fuel, fire fuel effects, fire fuel behavior, and the real-time behavior models FARSITE, FlamMap and NEXUS. Products include databases, computer models, biophysical gradient maps, vegetation maps, wildfuel maps, and fire regime maps. Data include fire behavior models, elevation, aspect, slope, fire regimes, remotely sensed, fuel and vegetation models are available via download and directly viewable in an Internet based mapping tool: www.landfire.gov. This project will use the Landfire datasets as an indicator of wildfire risk.

One example of Landfire data is the 13 Anderson (1982) Fire Behavior Fuel Models (Fire Behavior based on vegetation). Descriptions of fuel properties (amount, distribution, and continuity of live and dead vegetation/wood) based upon four groups (grass, shrub, timber, and slash) and categorized into 13 models to help users estimate fire behavior, 
including rate of fire spread and fire intensity. Esh (2006) used this model as the sole indicator for the fire susceptibility model; however she used a local vegetation dataset and adapted it to the model with assistance of local expertise.

Another example is the Fire Regime Groups which shows fire frequency and severity using vegetation and disturbance dynamics model (see Table 4-11).

Table 4-11. Fire Regime Groups

\begin{tabular}{|l|l|l|}
\hline Fire Regime Groups & Frequency (Years) & Severity \\
\hline Fire Regime I & 0 to 35 & low to mixed \\
\hline Fire Regime IV & 35 to 200 & replacement \\
\hline Fire Regime II & 0 to 35 & low to mixed \\
\hline Fire Regime III & 35 to 200 & replacement \\
\hline Fire Regime V & $200+$ & any \\
\hline
\end{tabular}

Advantages to accessing Landfire as a web service are: the data does not have to be acquired and stored locally, the data has already been symbolized, and they can be toggled on and off just as if the data layer was stored locally.

In addition to these two data sets there are approximately 25 other wildfire datasets from Landfire available as layers in the project web map. A shortcoming of the Landfire web map services is they do not currently have legends. Another disadvantage is the data cannot be used as input to a geoprocessing model. Full descriptions of Landfire data products are available from the Landfire website:

http://www.landfire.gov/downloadfile.php?file=LF_Data_Product_Descrip.pdf

\subsubsection{Wildfire Web Service}

The map service is added as a layer to the MXD in ArcMap by adding a new ArcIMS server connection using the Landfire web map service (see Figure 4-9). Alternatively the web service could be added to the web application from within the web application development framework either from ArcGIS Server manager or Visual Studio.

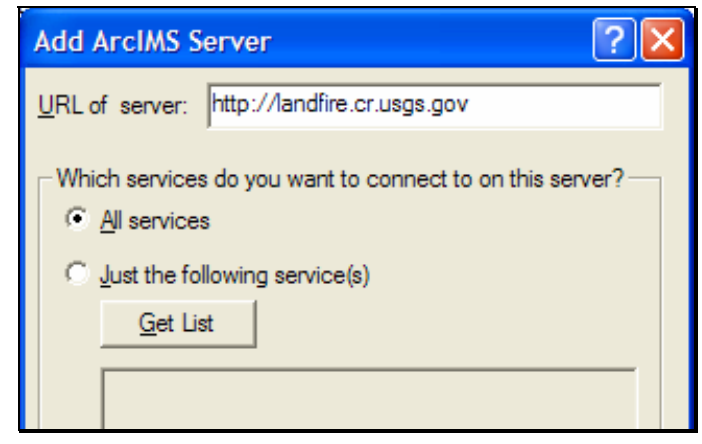

Figure 4-9. Add Landfire Web Service

\subsection{Fuel Breaks}

The potential areas for annual brome wildfire fuel breaks are the intersection of the areas that are high risk in the annual brome model, the WUI, and wildfire. The website allows the three outputs to be viewed as layers that the end user can turn off and on to make a comparison and judgment. 
Initially, a goal of the project was to also create a Fuel Break model that used the Annual Brome model, the WUI model, and the wildfire data as input and was geoprocessed as and intersection or as a weighted overlay as shown schematically in the Annual Brome Fuel Break Model (Figure 4-10). However, currently that is not possible because a geoprocessing model cannot use data from an external web service. That is because inputs to a geoprocessing model need to access the underlying geometry and attributes of the external web map services, and the WUI and Landfire web services are only available as images. In order to do a geographic intersection or weighted overlay, the WUI and wildfire data would have to be stored in a database on a local server. Methods to accomplish a geoprocessed Fuel Break Model are discussed in Chapter 7, Future Directions.

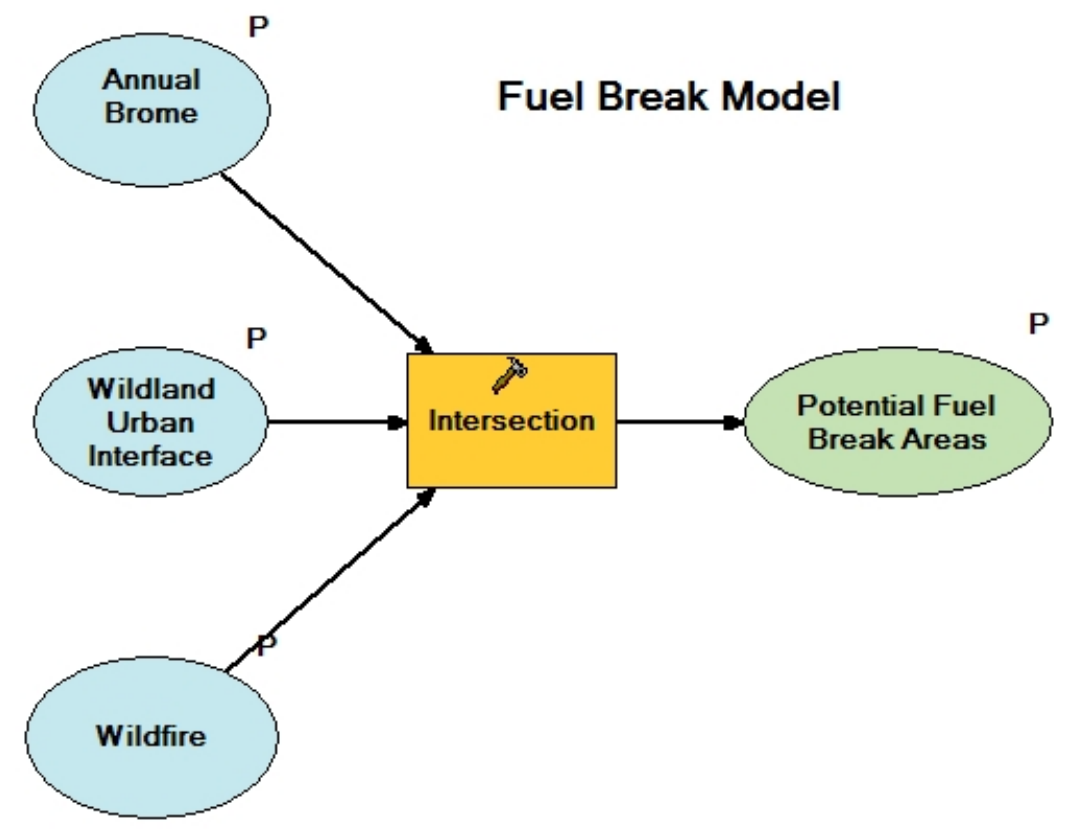

Figure 4-10 Annual Brome Wildfire Fuel Break Model

\subsection{Website Application}

A web map application was created to allow the user to find an area of interest, use the annual brome geoprocessing model to assess annual brome risk, and use web map services to access wildfire and wildland urban interface risk. Custom Web applications can be created using the ArcGIS Server Web Application Development Framework (ADF), or the ADF template can be used either from ArcGIS Server Manager or Visual Studio. This project began with the ADF template and added customizations.

Geocode tasks were added and directed to external geocoding web services. Web map resources were added from a local web map services and from external web map services. A geoprocessing task was added using a local geoprocessing service. A simple print function tool was downloaded from ArcGIS Server development blog (Baker, 2007) and installed to provide basic print functionality. The template provides zoom, pan, identify, measure, and navigate functions. External links to website help, metadata, 
annual brome information, wildfire information, WUI information, The SILVIS Lab WUI, Landfire, BASF, and information about the installation of wildfire fuel breaks. 


\section{Results}

The project website results are shown in Figures 5-1 - 5-8 and depict task results for geocoding, annual brome risk, WUI, wildfire, and print. The areas for fuel breaks are determined by comparing the annual brome, WUI and wildfire results.

\subsection{Geocode}

The geocode Find Address and Find Place tasks are accessed by clicking the hyperlink in the task panel (upper left). An interactive dialogue panel opens and the user enters location information and presses the find button (see Figure 5-1). Matches are returned to the results as a location which can be right clicked to use the zoom to or pan to context menu choices (see Figure 5-2).

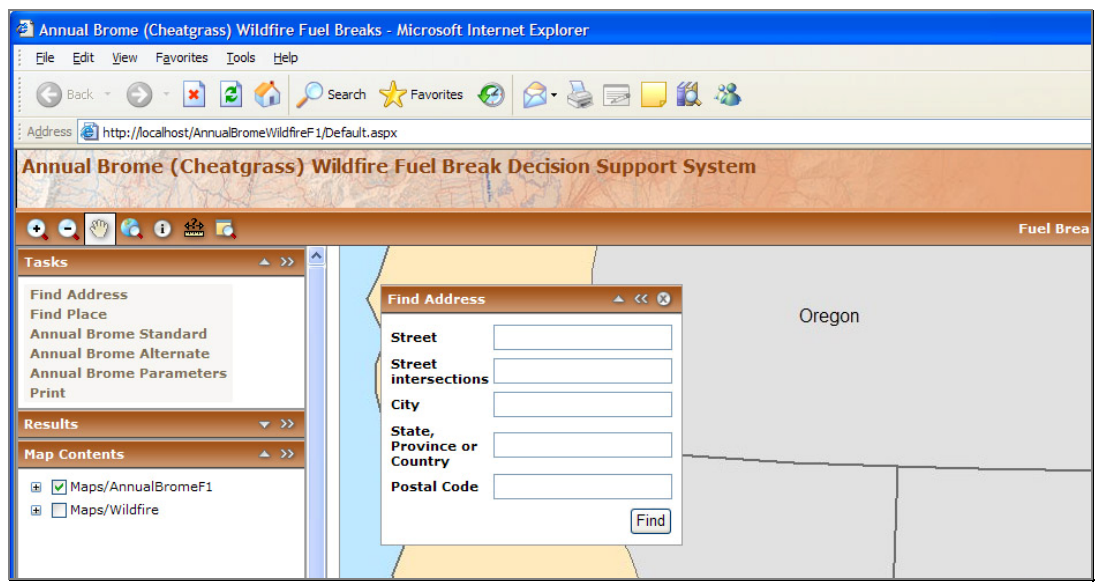

Figure 5-1. Geocode Address Website User Interface

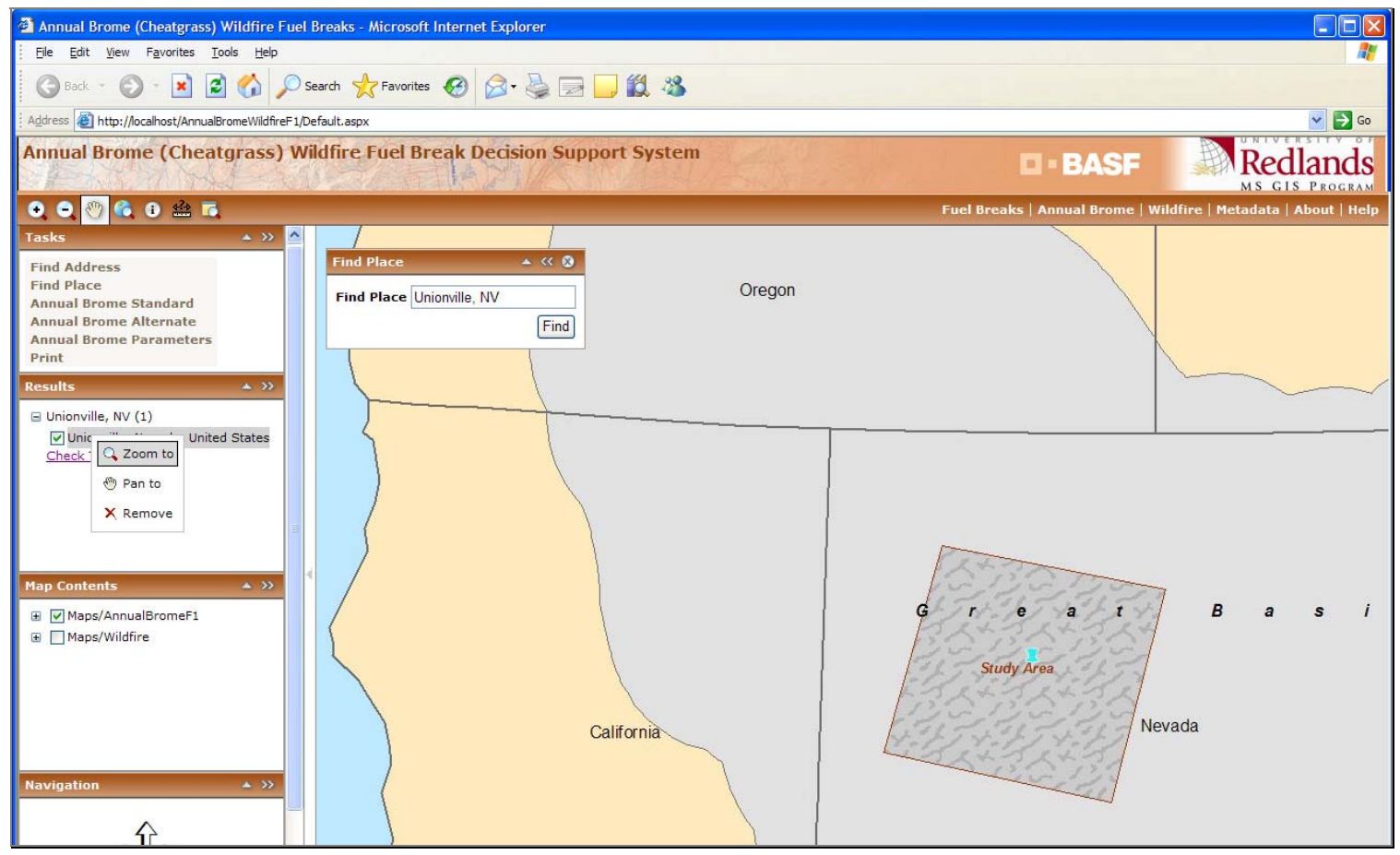

Figure 5-2. Find Place Results 


\subsection{Annual Brome}

The annual brome geoprocessing task is accessed by clicking the hyperlink in the task panel (upper left). An interactive dialogue panel opens and the user enters parameter information, delineates the area of interest and presses the submit button (see Figure 5-3).

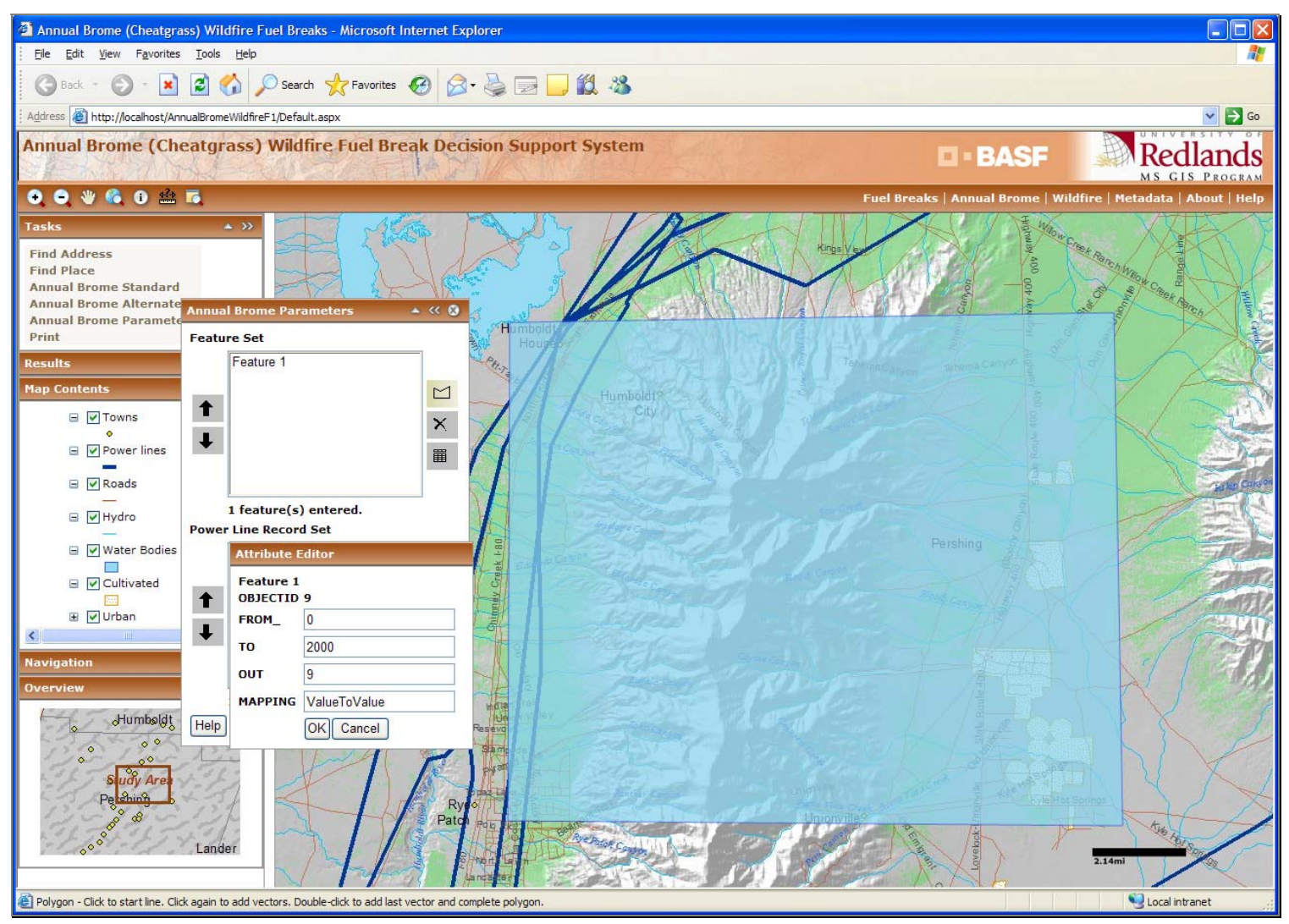

Figure 5-3. Annual Brome Model - Delineate Area of Interest, Input Parameters

The annual brome habitat risk map is returned to the results panel where the map layer can be turned on. Figure 5-4 shows the results for the model with parameters reclassified as one or nine, while Figure 5-5 shows the results for the annual brome model when the parameters are reclassified on a graduated scale from one through nine. 


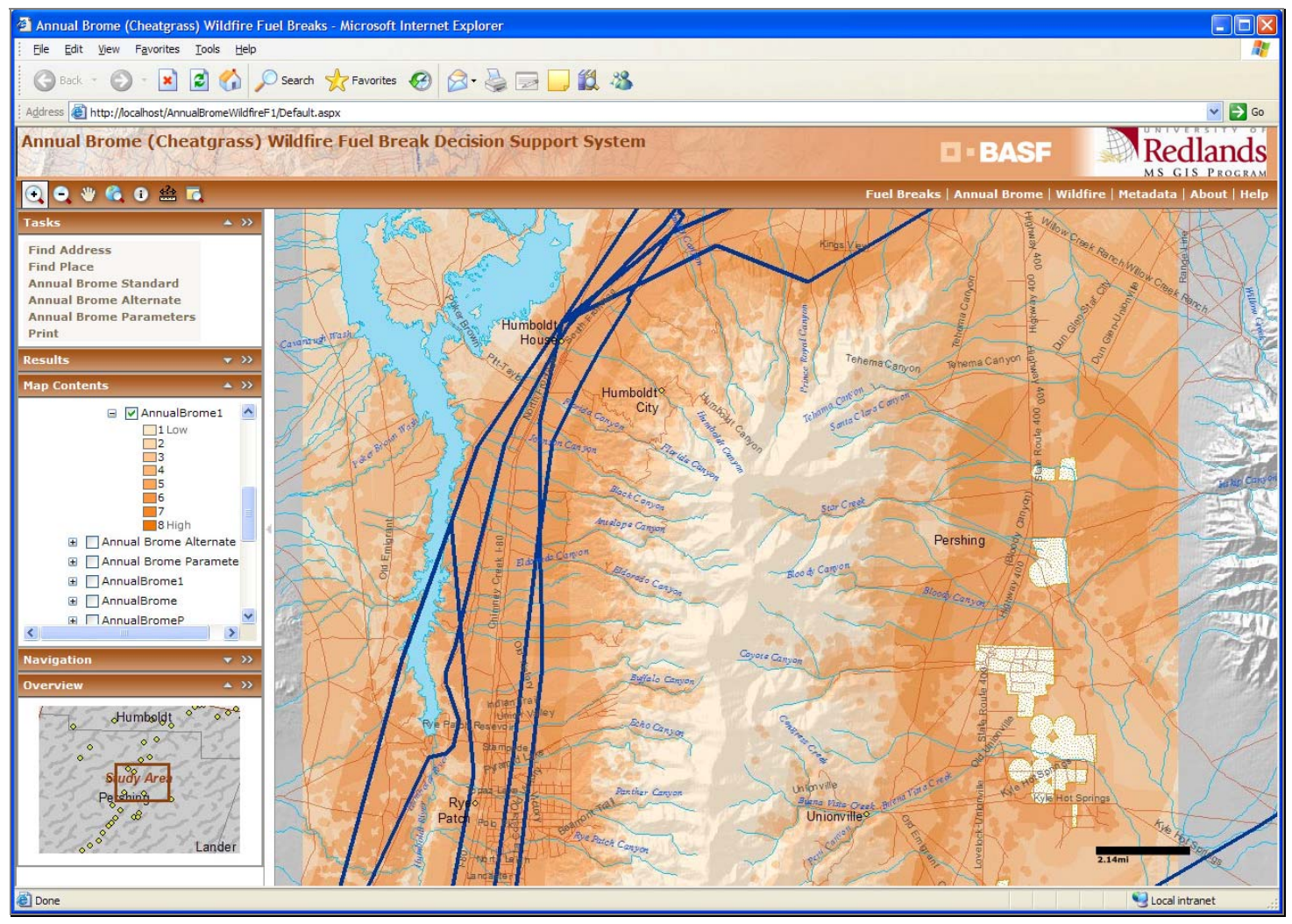

Figure 5-4. Annual Brome Risk Map Classified 1, 9

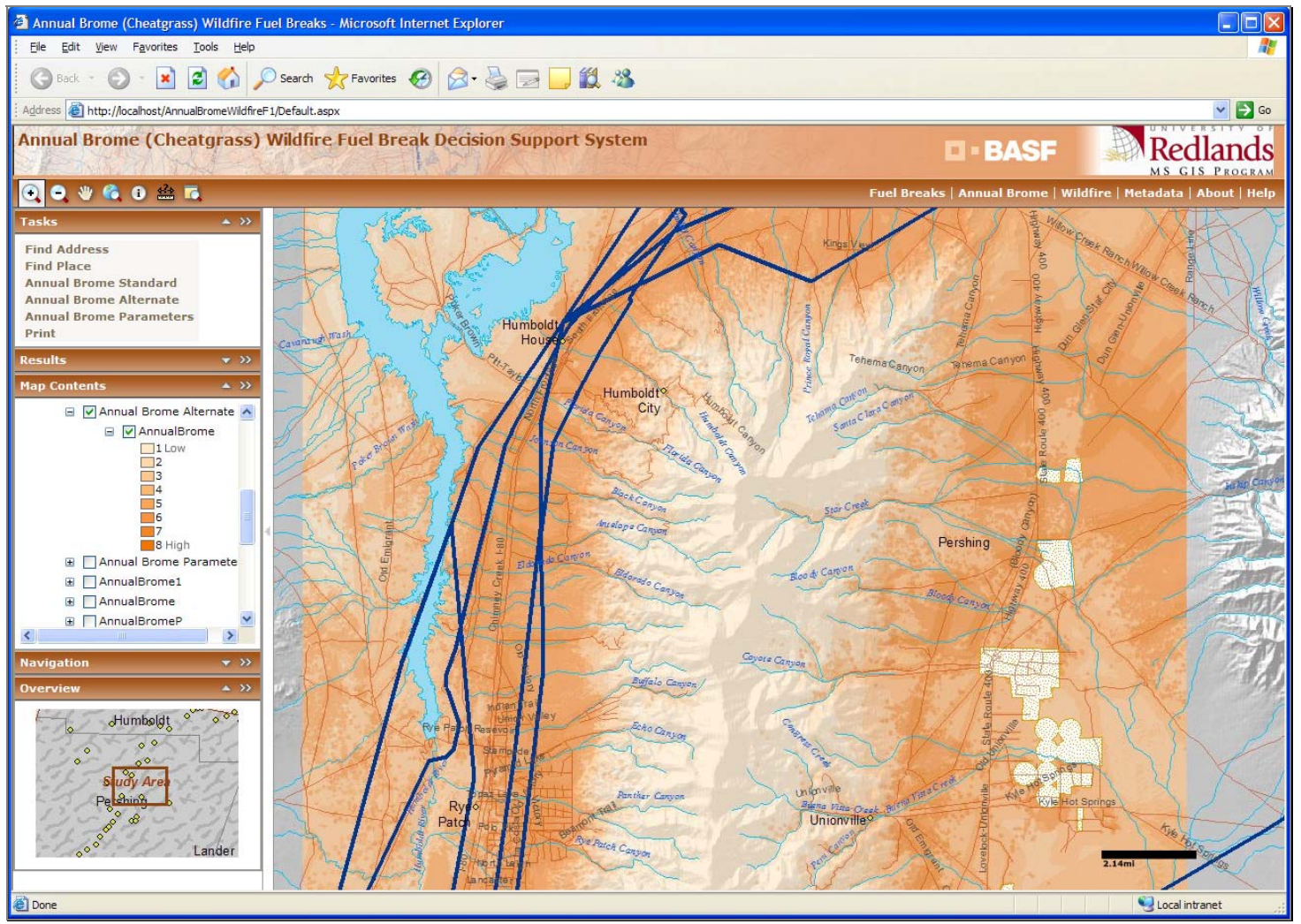

Figure 5-5. Annual Brome Risk Map Parameters Classified 1 - 9 


\subsection{Wildland Urban Interface}

The SILVIS Lab Wildland Urban Interface analysis results are available from the map contents panel as a map layer that can be turned on and off and compared with the annual brome risk results. The results show areas where there is a combination of high population density and high vegetation density, this is an indicator of wildfire risk, and they are categorized as Wildland Urban Interface or Wildland Urban Intermix. The table of contents includes a descriptive legend (see Figure 5-6).

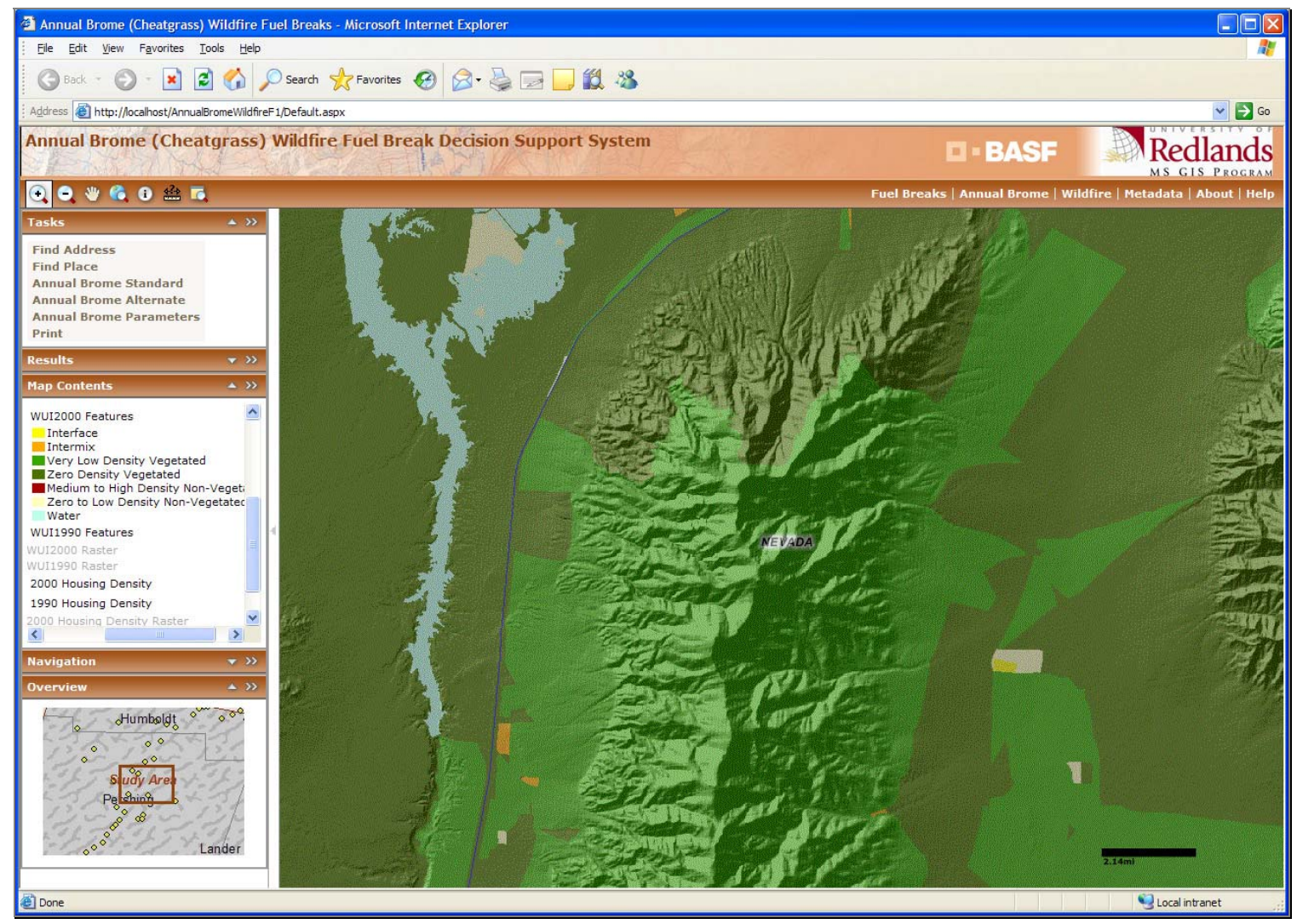

Figure 5-6. The University of Wisconsin SILVIS Lab WUI Web Map Results 


\subsection{Wildfire}

Wildfire data are available from the map contents panel as a map layer that can be turned on and off. Over 24 layers of wildfire data commonly used by wildfire experts are available and are used as indicators of wildfire risk in this project. The map layer can be turned on and off and compared with the annual brome and WUI risk results. One example is the 13 Anderson (1982) Fire Behavior Fuel Models (Fire Behavior based on vegetation). Descriptions of fuel properties (amount, distribution, and continuity of live and dead vegetation/wood) based upon four groups (grass, shrub, timber, and slash) are categorized into 13 models to help users estimate fire behavior, including rate of fire spread and fire intensity. The ratings range from low to high, with the FBFM1-FBFM3 grass, FBFM4-FBFM7 shrub, FBFM8-FBFM10 timber and FBFM11-FBFM13 slash (see Figure 5-7).

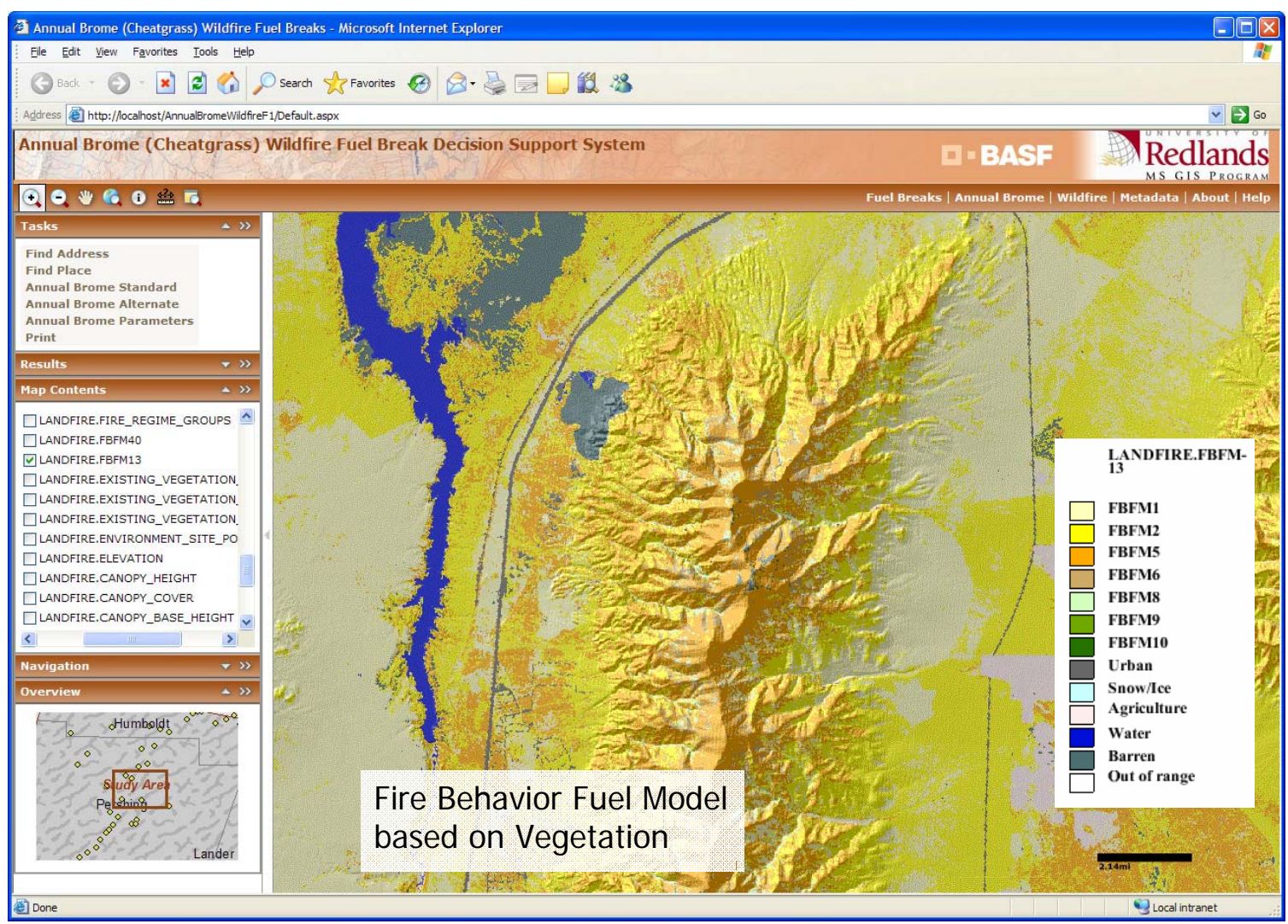

Figure 5-7. Landfire 13 Anderson Fire Behavior Fuel Models Web Service Map 
Another example is the Fire Regime Groups which shows fire frequency and severity using vegetation and disturbance dynamics model. The table of contents includes a descriptive legend, but one has been added to the web map window for illustration (see Figure 5-8).

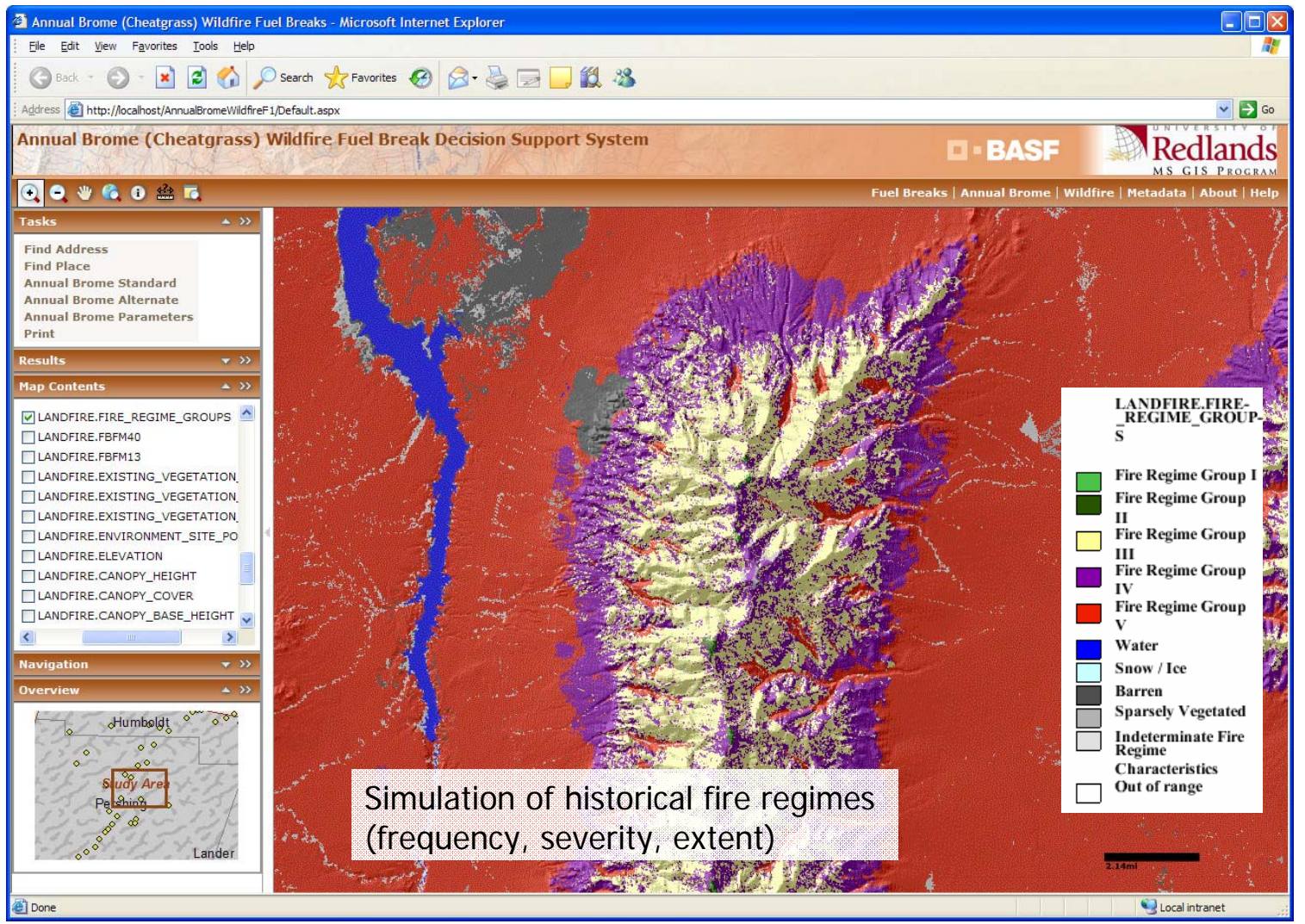

Figure 5-8. Landfire Fire Regime Group Web Service Map 


\subsection{Fuel Breaks}

The areas for fuel breaks are determined by comparing the annual brome, WUI and wildfire results (see Figure 5-9).

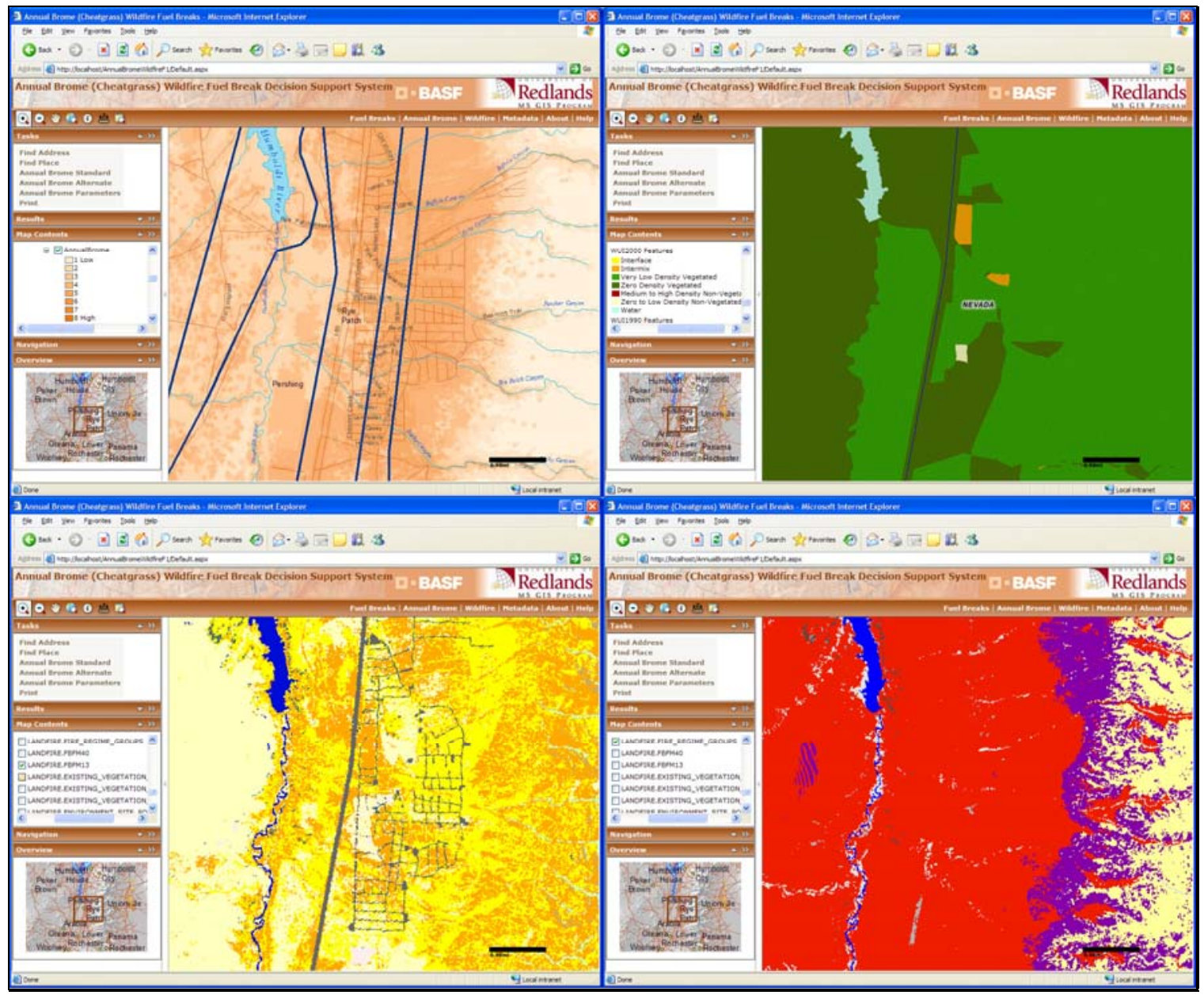

Figure 5-9. Fuel Break Decision Support Maps 


\subsection{Print}

The Print task is accessed by clicking the hyperlink in the task panel (upper left). An interactive dialogue panel opens and the user enters optional map title, size, resolution and scale information, and presses the Create Print Page button (see Figure 5-10). An example of a print preview result is shown in Figure 5-11.

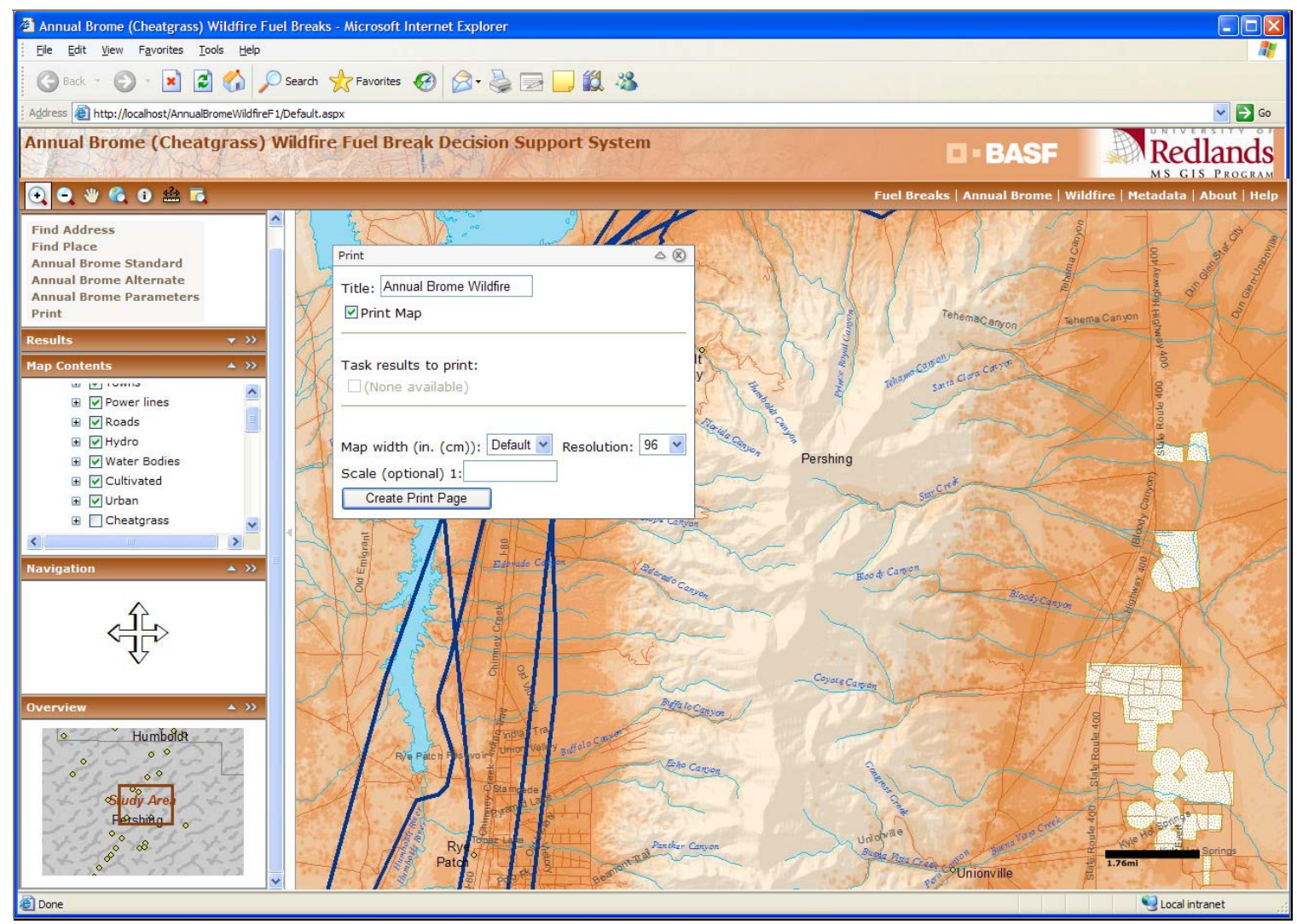

Figure 5-10. Print Task Website User Interface 


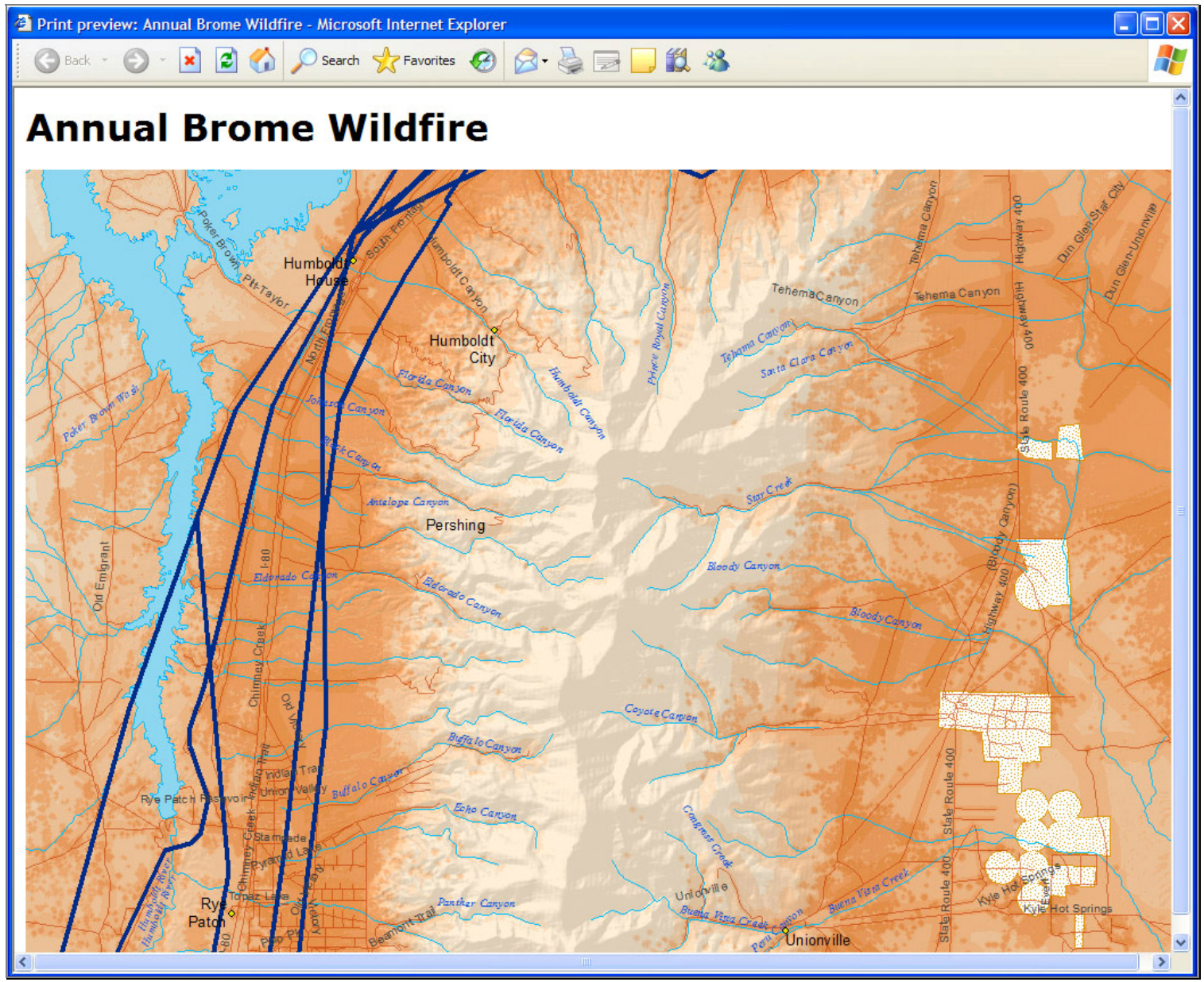

Figure 5-11. Print Preview Example 



\section{Discussion}

The project website provides a real-time, dynamic, web map, with annual brome wildfire fuel break decision support information for land owners, land managers and others. The annual brome geoprocessing model translates the latest weed science research into web geoprocessing services, and allows the end user to adjust parameters to match local conditions. The project created a mash-up of a number of external web services that both reduced development cost and time, and also avoided duplication of effort and leverages expertise in GIS, WUI, and wildfire modeling. The end user needs only a web browser and is saved the time and expense and expertise required to download and configure data, license and learn software, and maintain and update the system. An advantage of the annual brome web model is that the Model Builder model can be replaced remotely on the website and the changes are immediately available to all users. Likewise any updates to the WUI or Landfire data are immediately available on the project website.

It is not technically possible to use external web map services as input into a geoprocessing task to create a single fuel break map. However, the new annual brome habitat risk analysis output produced by the website can be compared with the WUI and wildfire map analysis provided by the external web map services. The output can be seen in the same web map and the annual brome, WUI and wildfire layers can be toggled on and off to provide information to support fuel break placement decisions by the end user for areas of concern. 



\section{Future Directions}

The first and most rewarding new addition would be to expand the website functionality to the rest of Nevada, and to neighboring states and the rest of the Great Basin. The only thing necessary to achieve this is to add the missing data for those areas to the local server geodatabase and publish it as a web map service. The vector data - roads, hydro, and power lines - have already been acquired. The raster digital elevation model (DEM) used for elevation has also been acquired, although it would require approximately 1 Gigabyte of server storage space for such a wide extent. Urban and cultivation data is easily available from a variety of landuse landcover datasets. Historic cheatgrass data is available for a significant portion of Nevada. Additional historic cheatgrass data is hard to obtain and would likely require undertaking a remote sensing NDVI analysis; this would be a considerable constraint to expanding the project to the remainder of Nevada and to the rest of the Great Basin.

As noted, the annual brome research distance, elevation and aspect parameter values create a discrete, abrupt cut-off at the specific values, rather than the more nuanced and graduated value change expected in nature. The reclass values can be adjusted to change more gradually either manually, or by choosing an appropriate algorithm that would more realistically reflect changes. Additional research may be necessary to obtain accurate values to reflect changes in transitional zones.

Perhaps the most compelling opportunity for future enhancement would be to use external WUI and wildfire web map services for input into a local geoprocessing model for fuel breaks. That is not possible in ArcGIS Server 9.2 and it is not clear if it is something that will be available in future software releases. Currently the WUI and wildfire (Landfire) data would have to be downloaded and stored locally for them to be used in a geoprocessing model. An alternative would be to programmatically download the WUI and wildfire data for the area of interest data in real time. Then the annual brome, WUI and wildfire sub-models could be combined in a fuel break model as an intersection of the high risk areas or a weighted overlay as shown in Figure 4-8.

Currently, as mentioned, the WUI datasets are only available as layers to be viewed and cannot be incorporated into a fuel break geoprocessing model unless they are downloaded. Another alternative is the input data for the WUI model to be downloaded; a local model predicting the WUI danger using population density and vegetation fuel source could then be run. Not only could the WUI data be used as input in a geoprocessing model, it could also reflect any changes in population and vegetation density when those layers are updated.

Likewise, the wildfire data from Landfire are only available as layers to be viewed and can only be incorporated into a fuel break geoprocessing model if it is stored in a local database. The Landfire data is downloadable from their website and it is also available on DVD.

Another alternative is a local model predicting wildfire danger could be built that uses downloaded slope, aspect, and vegetation (fuel source) data. Fire history and weather history data could be added to make the wildfire model more realistic and temporal data 
such as fuel moisture, rainfall, wind and weather and fuel moisture levels could be added make it more dynamic.

Technical additions that would be beneficial are expanded "print” and "export graphic" functions that would make it easier to share results off line and in other documentation. It would be possible to access the layout objects programmatically to create a more sophisticated print layout and graphic export functions, but these additions are expected as enhancements to ArcGIS Server 9.3. 


\section{Conclusion}

The project has yielded a real-time, dynamic, web mapping service, which in turn provides annual brome wildfire fuel break information to support decisions by land owners, land managers and others. The annual brome geoprocessing model determines annual brome risk based on the latest research, and the parameters can be adjusted by the end user. The project provides WUI and wildfire (Landfire) information dynamically through web map layers from external web map services to help ascertain the wildfire threat at a given location. The potential areas for annual brome wildfire fuel breaks are the areas at the intersection of high risk from the annual brome model, the WUI model, and the wildfire model. The risk layers are accessible in the same web map so the end user can easily toggle between outputs for the same geographic area to determine overall risk.

Even though it is possible to zoom to a very large scale (small extent) in the digital web map environment, the underlying analysis is still based on the 30 meter by 30 meter cell size with an accuracy of plus or minus 60 meters. It is important to remember that the scale of the input data limits the use of the output analysis to 1:100,000 or smaller scale (i.e. larger extent). The results are appropriate for use at the community planning level for rangeland and forestland at the size of approximately several hundred acres. It should also be stressed that the analysis is meant to be a decision support tool and any decisions should also rely on local wildfire experts and on-the-ground analysis. 



\section{References}

Ager, A. (2005). ARCFUELS: Forest Planning Tools for Managing Wildland Fuels. Paper presented at the Proceedings of the Twenty-Fifth Annual ESRI User Conference, San Diego, CA.

Amdahl, G. (2001). Disaster Response GIS for Public Safety. Redlands, CA: ESRI. Andrews, P., \& Butler, B. W. (2006, March 28 - 30). Fuels Management - How to Measure Success: Conference Proceedings. Paper presented at the Fuels Management - How to Measure Success: Conference Proceedings, Portland, OR.

Baker, B. (2007). ArcGIS Server Development Blog. Print Task Simple. Retrieved May 20, 2007, from http://blogs.esri.com/Dev/blogs/arcgisserver/archive/tags/Printing/default.aspx

BASF. (2006). BASF The Chemical Company. BASF Group: BASF in Brief. Retrieved October 23, 2006, from http://www.corporate.basf.com/en/investor/ueberblick/?id=5p2Eb9RP7bcp2Nq

Bradley, B., \& Mustard, J. (2004). Identifying land cover variability distinct from land cover change: Cheatgrass in the Great Basin. Remote Sensing of Environment, 94(2), 204-213.

Bradley, B., \& Mustard, J. (2006). Characterizing The Landscape Dynamics Of An Invasive Plant And Risk Of Invasion Using Remote Sensing. Ecological Applications, 16(3), 1132-1147.

Brown, M. (2006, October 18, 2006). BLM News. Preparing For Fire Season 2006., from www.nv.blm.gov/elko/pdf/NewsReleases2006/PreventionReleaseno1May2006.pd $\underline{\mathrm{f}}$

Carnachan, R. (1997). Wisconsin Soil Mapping Guide 4, 2nd Edition. Retrieved August 11, 2007, from http://www.sco.wisc.edu/pubs/guides/soils.pdf

Carpenter, A. T., \& Murray, T. A. (2005). Element Stewardship Abstract. Bromus tectorum L. (Anisantha tectorum (L.) Nevski) cheatgrass downy brome. Retrieved October 19, 2006, from http://ncweeds.ucdavis.edu/esadocs/bromtect.html

Center for Fire Research University of California Berkeley. (2007). Fire Information Engine Toolkit. Retrieved July 26, 2007, from http://firecenter.berkeley.edu/toolkit/

Christiansen, J. (2005). Calculating Wildfire Hazard Levels: Algebraic Raster Construction using Spatial Analyst. Paper presented at the ESRI 2005 International User Conference, San Diego CA.

Christiansen, J. (Cartographer). (2006). Calculating Wildfire Hazard Levels: Algebraic Raster Construction using Spatial Analyst [Location: ESRI Map Book Vol. 21 pp. 67.].

Davison, J., \& Smith, E. (2005). Cooperative Extension Bringing the University to You. A Homeowner's Guide to Cheatgrass, Fact Sheet-05-29. Retrieved July 26, 2006, from http://www.unce.unr.edu/publications/FS87/FS8745.pdf

Esh, H. (2006). The Wildland/Urban Interface: Cheatgrass, Fire Danger, and Fuel Breaks. Unpublished Major Individual Project submitted in partial satisfaction of 
the requirements for the degree of Master of Science in Geographic Information Systems., University of Redlands, Redlands, CA.

ESRI. (2006). What's Coming in ArcGIS Server 9.2. Retrieved October 25, 2006, from http://www.esri.com/software/arcgis/arcgisserver/about/whats-coming.html

Fire.org. (2006). Public Domain Software for the Wildfire Community. Retrieved October 2, 2006, from http://fire.org

Firewise. (2007). Resources for The Homeowner. Retrieved July 12, 2007, from http://firewise.org/resources/homeowner.htm

FRAMES. (2006). Fire Research and Management Exchange System. Retrieved October 3, 2006, from http://frames.nbii.gov/portal/server.pt?open=512\&objID=205\&PageID=0\&cache $\mathrm{d}=$ true \&mode $=2$

Gillham, J. H. (2001). Invasive Species Inventory and Weed Susceptibility Prediction Model for Southwestern Wyoming. University of Wyoming, Laramie.

Google. (2006). Google Earth Copyright 2006 Google. All rights reserved. Retrieved October 25, 2006, from http://earth.google.com/

Harder, C. (1998). Serving Maps on the Internet. Redlands, CA: ESRI.

Longley, P. A., Goodchild, M. F., Maguire, D. J., \& Rhind, D. W. (2005). Geographic Information Systems and Science (Second ed.). West Sussex, England: Wiley.

MacGregor, D. (2004). An Inventory of Models, Tools, and Computer Applications for Wildand Fire Management. Retrieved September 21, 2006, from http://www.firescience.gov/documents/Wildland\%20Fire\%20Models\%20Inventor y\%20Dec-2004.pdf

MapQuest. (2006). Copyright 2006 MapQuest, Inc. ("MapQuest"). All rights reserved. Retrieved October 25, 2006, from http://www.mapquest.com/

Neese, E. (2000). Plant Guide. Cheatgrass Bromus tectorum L. Retrieved June 15, 2006, from http://plants.usda.gov/plantguide/pdf/pg_brte.pdf

Nevada Natural Heritage Program. (2005). GIS at the Nevada Natural Heritage Program. Retrieved Octobler 17, 2006, from http://heritage.nv.gov/gis/gis.htm

NFPA. (2002). National Fire Protection Association. NFPA 1144 Standard for Protection of Life and Property From Wildfire., from http://www.nfpa.org/aboutthecodes/AboutTheCodes.asp?DocNum=1144

NRCS. (2007). Ohio NRCS. National Map Accuracy Standards Retrieved August 11, 2007, from http://www.oh.nrcs.usda.gov/technical/gis/natl_map_accuracy.html

Peng, Z.-R., \& Tsou, M.-H. (2003). Internet GIS. Hoboken, NJ: John Wiley \& Sons.

Peters, D. (2007). An ESRI Technical Reference Document. System Design Strategies. Retrieved March 19, 2007, from http://www.esri.com/library/whitepapers/pdfs/sysdesig.pdf

Peterson, E. (2003). Mapping Percent-Cover of the Invasive Species Bromus tectorum (Cheatgrass) over a Large Portion of Nevada from Satellite Imagery. Retrieved May 7, 2007, from http://heritage.nv.gov/reports/brtetext.pdf

Pratt, M. (2000). Modeling Fire Hazard. ArcUser, from http://www.esri.com/news/arcuser/0700/files/firemodel.pdf

Price, M. (2003). Modeling the Wildland/Urban Interface. ArcUser, April-June 2003. 
Price, M. (2005a). Firewise Modeling in the Wildland/Urban Interface with ArcGIS. Paper presented at the Twenty-Fourth Annual ESRI International User Conference, San Diego, CA.

Price, M. (2005b). Modeling Topography and Fuels at the Wildland/Urban Interface. ArcUser, January-March 2005.

Radeloff, V. C., Hammer, R. B., Stewart, J. S., Holcomb, S. S., \& McKerefry, J. F. (2005). The Wildland-Urban Interface in the United States. Ecological Applications, 15(3), 799-805.

Reeves, M. C., Kost, J. R., \& Ryan, K. C. (2005). Fuels Products of the LANDFIRE Project. Paper presented at the Fuels Managment - How to Measure Success, Portland, OR.

Rollins, M. G., \& Frame, C. K. (2006). The LANDFIRE Prototype Project: Nationally Consistent and Locally Relevant Geospatial Data for Wildfire Management. . Retrieved October 2, 2006. from www.landfire.gov.

Schmidt, K. M., Menakis, J. P., Hardy, C. C., Hann, W. J., \& Bunnell, D. L. (2002). Development of Coarse-Scale Spatial for Wildland Fire and Fuel Managment. Retrieved October 9, 2006. from http://www.fs.fed.us/rm/pubs/rmrs_gtr87.pdf.

Tang, W., \& Selwood, J. (2005). Spatial Portals Gateways to Geographic Information. Redlands, CA: ESRI.

U.S. Census Bureau. (2006, July 26, 2006). The Future of TIGER/Line. Retrieved April 7, 2007, from http://www.census.gov/geo/www/tiger/future/future_tl.html

University of Minnesota. (2007). MapServer. Welcome to Map Server. Retrieved July 12, 2007, from http://mapserver.gis.umn.edu/

University of Wisconsin. (2006). Silvis Lab Forest Ecology \& Managment. The Wildland-Urban Interface. Retrieved January 3, 2007, from http://silvis.forest.wisc.edu/projects/WUI_Main.asp

USDA. (2007). Aerial Photography Field Office (APFO). National Agriculture Imagery Program (NAIP) Retrieved August 6, 2007, from http://165.221.201.14/NAIP.html

USDA Forest Service. (2006a). Fire Effects Information Plant Species Life Form. Species: Bromus tectorum. Retrieved October 26, 2006, from http://www.fs.fed.us/database/feis/plants/graminoid/brotec/

USDA Forest Service. (2006b). Fire Effects Information System. Retrieved October 2, 2006, from http://www.fs.fed.us/database/feis/index.html

USDA Office of Inspector General. (2006). Audit Report Forest Service Large Fire Suppression Costs. Retrieved January 5, 2007. from http://www.usda.gov/oig/webdocs/08601-44-SF.pdf.

USGS. (1947). National Mapping Program Standards. United States National Map Accuracy Standards Retrieved August 11, 2007, from http://rockyweb.cr.usgs.gov/nmpstds/nmas647.html

USGS. (2003). Sagemap Overview. Retrieved May 21, 2007, from http://sagemap.wr.usgs.gov/sage_grouse.htm

Wilderness Society. (2006). Facts. 2006 Fire Season To-Date by the Numbers. Retrieved February 19, 2007, from http://www.wilderness.org/Library/Documents/upload/WildfireSeason2006_Octo ber31.pdf 


\section{Appendix A: Application Development Framework (ADF)}

Application Development Framework (ADF) Add Geocode Task:

To add a geocode task from a geocode service in Microsoft Visual Studio, choose the Geocode Resource Manager and use these steps (see Figure 9-1):

- (1) Edit Resources

- (2) Add

- (3) Definition

- (4) Choose ArcWeb Services in Geocode Resource Definition Editor, enter user name and password

- (5) Choose geocoding resource. Note that a choice can be made of preconfigured geocoding tool created at the ArcWeb Services website (as was done here) or one can be built and accessed from the local server

- (6) Then fromTask Manger choose task results container Buddy Control Collection Editor

- (7) In Buddy Control Editor Add item and choose a Task Results

- (8) Choose Geocode Resource Manager

- (9) Choose Geocode Resource 


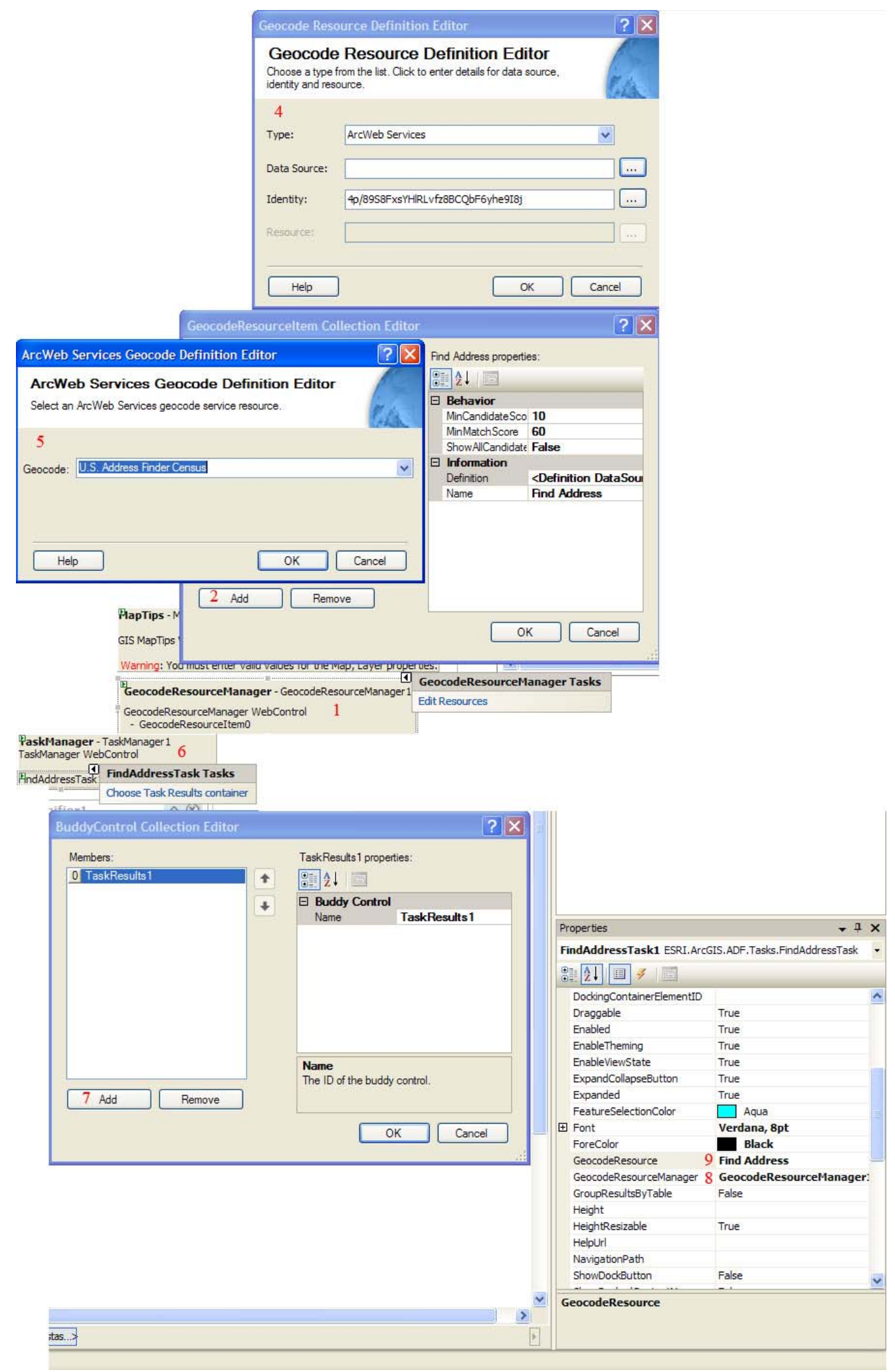

Figure Appendix A-1. Add ArcWeb Geocode Service 
Application Development Framework (ADF) Add Map Service:

The map service is added as a layer when building the web application from within the web application development framework either from ArcGIS Server manager or Visual Studio. To add a web map to a web application from a web map service in Microsoft Visual Studio, choose the Map Resource Manager and use these steps (see Figure 4-2):

- (1) Edit Resources

- (2) Add

- (3) Definition

- (4) Choose ArcWeb Services in Map Resource Definition Editor, enter user name and password

- (5) Choose map. Note a choice can be made of preconfigured maps or a map with custom layers can be created at the ArcWeb Services website (as was done here).

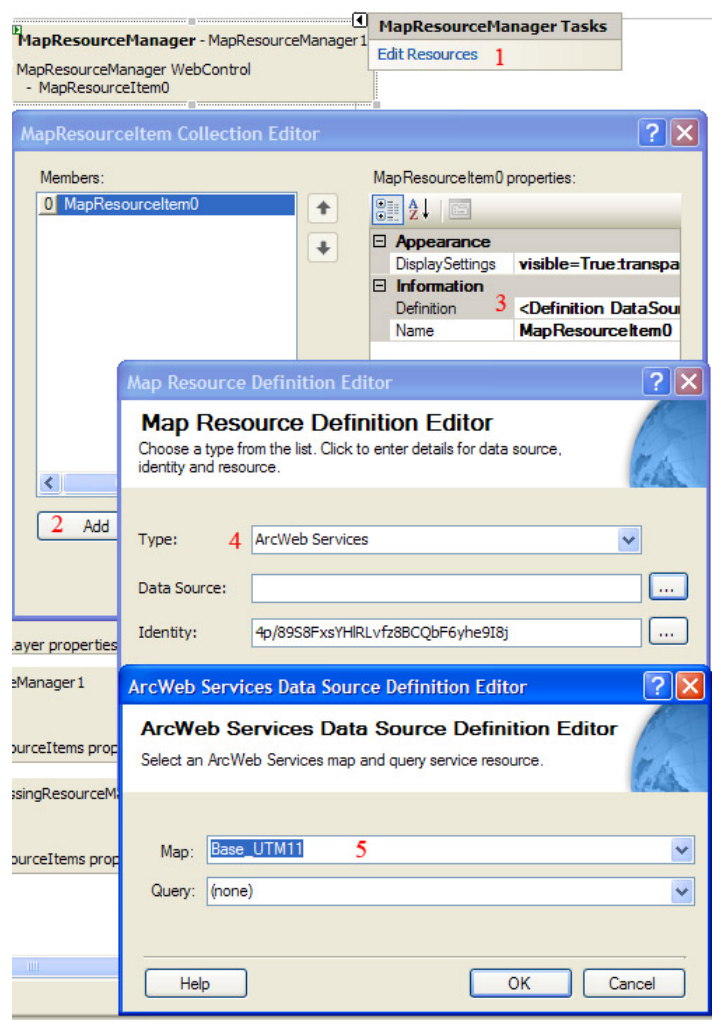

Figure Appendix A-2. Add ArcWeb Map Service

Application Development Framework (ADF) Add Geoprocessing Task:

Once published, the geoprocessing service is available as a service from ArcGIS Server that can be added as a task to a web application from within the web application development framework either from ArcGIS Server manager or Visual Studio. To add a web map to a web application from a web map service in Microsoft Visual Studio, choose the Geoprocessing Resource Manager and use these steps:

- (1)Edit Resources 
- (2) Add

- (3) Definition

- (4) Choose localhost in Geoprocessing Resource Definition Editor

- (5) Choose geoprocessing resource which is accessed from the local server

- (6) In Task Manger choose task results container

- (7) Add item from Buddy Control Collection Editor, and choose a Task Results

- (8) In properties choose Geoprocessing Resource Manager

- (9) Choose Geoprocessing Resource 